\title{
WestVirginiaUniversity
}

THE RESEARCH REPOSITORY @ WVU

Graduate Theses, Dissertations, and Problem Reports

2010

\section{Modeling of forest harvest scheduling and terrestrial carbon sequestration}

\author{
Benktesh Dash Sharma \\ West Virginia University
}

Follow this and additional works at: https://researchrepository.wvu.edu/etd

\section{Recommended Citation}

Sharma, Benktesh Dash, "Modeling of forest harvest scheduling and terrestrial carbon sequestration" (2010). Graduate Theses, Dissertations, and Problem Reports. 4656.

https://researchrepository.wvu.edu/etd/4656

This Dissertation is protected by copyright and/or related rights. It has been brought to you by the The Research Repository @ WVU with permission from the rights-holder(s). You are free to use this Dissertation in any way that is permitted by the copyright and related rights legislation that applies to your use. For other uses you must obtain permission from the rights-holder(s) directly, unless additional rights are indicated by a Creative Commons license in the record and/ or on the work itself. This Dissertation has been accepted for inclusion in WVU Graduate Theses, Dissertations, and Problem Reports collection by an authorized administrator of The Research Repository @ WVU.

For more information, please contact researchrepository@mail.wvu.edu. 


\title{
MODELING OF FOREST HARVEST SCHEDULING AND TERRESTRIAL CARBON SEQUESTRATION
}

\author{
by
}

\section{Benktesh Dash Sharma}

Dissertation Submitted to the Davis College of Agriculture, Natural Resources and Design at West Virginia University

in partial fulfillment of the requirements

for the degree of

\author{
Doctor of Philosophy \\ in \\ Forest Resources Science \\ Approved by \\ Jingxin Wang, Ph.D., Committee Chairperson \\ Joseph F. McNeel, Ph.D. \\ John R. Brooks, Ph.D. \\ Michael P. Strager, Ph.D. \\ Gary Miller, Ph.D. \\ Division of Forestry and Natural Resources \\ Morgantown, West Virginia
}

2010

Keywords: Spatio-temporal optimization, system modeling, emission reduction, land use change, afforestation, woody biomass, wood products, sustainable forest management. 


\section{Abstract \\ MODELING OF FOREST HARVEST SCHEDULING AND TERRESTRIAL CARBON SEQUESTRATION}

\section{By Benktesh Dash Sharma}

It has generally been agreed that forests sequester atmospheric carbon and thus contribute to mitigating anthropogenic emissions in a cost effective manner compared to other available carbon sequestration techniques. With increasing concerns on global greenhouse gases and emerging carbon markets, additional carbon sequestered as a result of sustainable forest management activities can be of significant benefits for forest landowners. Harvesting, an important forest management activity, plays a crucial role in determining the forest's ability in sequestrating carbon. Harvesting modifies the forest carbon sequestration potential depending on time of harvest, age of stands, species composition, and types of harvest. The allocation of forest harvest units (tracts over time and space) come under the broader domain of tactical forest harvest scheduling. A need to analyze the role of different harvesting strategies was found essential, as such analysis will help design harvest schedules for a given forest aimed at enhancing carbon sequestration.

In order to study the forest harvest strategies, a computer-based forest planning system was developed for generating and visualizing a spatio-temporal forest harvesting plan for different management objectives. The system adapted a two staged block generation approach using maximal feasible cliques to formulate spatial, temporal and related restrictions. The linear programming based solver was employed to provide the solution to the spatial problem which resides at the backend along with a relational database which stores different forest, operation and management related data. The system runs with minimal information required from the user, such as management objective selected, time frame of the planning horizon and periods, and other management restrictions as binary inputs. All the modeling processes and complexities were automated in the system using tested algorithms which are often the major challenges in planning processes. This integrated system simplifies the planning processes 
and ensures that the generated spatial plan meets the long term objectives of management. The developed system was used to optimize different harvest schedules. The generated schedules had different objective functions ranging from maximization of timber production; maximization of timber production and stand carbon stock; to maximization of only carbon stock under clearcut and selection cut methods applicable for both long and short rotations.

Altogether, 19 different harvest schedules were developed to evaluate forest carbon sequestration. Higher carbon sequestration rates can be achieved by maximizing current harvested volume and future carbon stock when stands recover from the disturbance effects of harvesting in both selection cut and clearcut methods without undermining the potential benefits from harvested timber. The recovery period option explored is a new approach in generating harvest schedules for enhanced carbon sequestration combined with achievable timber benefits. The optimized harvest scheduling was then implemented for the entire state for possible carbon enhancement options. Carbon sequestration in the four terrestrial ecosystem components including forests, agricultural lands, abandoned mine lands and harvested wood products were modeled using a system modeling approach. This model tracks carbon stock and flow in different components over time. The carbon stored in harvested forest product pools were estimated using existing, as well as potential, growth-to-removal ratios followed by decay functions applicable for different forest product types.

Several potential enhancement options in the terrestrial carbon sequestration were obtained by generating management scenarios including afforestation activities in marginal agricultural lands and abandoned mine lands. The research found that current terrestrial ecosystem components in West Virginia sequester atmospheric carbon at the rate of 4.99 million tons of carbon per year with a possibility of achieving an enhanced sequestration of 7.62 million tons of carbon per year when all the available options are implemented. The study also concluded that sustainable terrestrial ecosystem management can provide higher carbon sequestration rates at a lower cost than available alternative options. It also provides a path to utilize this green energy to substitute for fossil fuels to meet the long-term objectives of emission control in the state. 


\section{DEDICATION}

I wish to wish to dedicate this dissertation to Kuladevata Shri Lata Kafali, Late Shri Nanda Ram Sharma my grandfather, father Ram Chandra Sharma, and mother Tulasi Devi Sharma who emphasized the importance of education, nurtured me with the notion of personal sacrifices and inspired me to set high goals. I am extremely indebted to my wife Sabina and daughter Opal for their love and care during my research. I would like to dedicate to my sisters, Bhubaneshwori Sharma and Shobha Sharma, and inlaws, Keshav Prasad Sharma and Indira Devi Sharma for the pain they suffered from a leaving a close family circle for approximately five years. Finally, I would like thank my younger brother Kali Das Sharma who helped in several ways during my studies and life in the US. 


\section{ACKNOWLEDGEMENTS}

This dissertation is an outcome of a long journey at different academic institutions and guided by many individuals. I consider myself fortunate to be able to work under Dr. Jingxin Wang, who is my major professor and under whose guidance I was able to bring my learning to the current level. I am extremely indebted to him for his continuous involvement in my academic upbringing as well as in my professional endeavors to this point. I value Dr. John R. Brooks, Dr. Michael P. Strager and Dr. Gary Miller for their technical contribution and academic support during my years at West Virginia University. Similarly, Dr. Joseph F. McNeel, who also serves on my committee, deserves my utmost appreciation and gratitude for his motivation and support from the beginning. I consider these five key individuals as guiding pillars in my future career.

I would also like to thank Dr. Kathryn Piatek and Dr. Ray R. Hicks for their support during my study at WVU. I would like to thank Ishwar Dhami and Sudiksha Joshi, my colleagues from Nepal for their gratitude in several of my important life events. I would also like to thank Adebola, Suresh, Nathan, Jingang, Jhinzuo, Wenshu, Pradip, Matt, and John from Percival Hall who have been the finest colleagues and friends. Those mentioned above have directly contributed to my academic achievement and their support has been invaluable as I made a start upon my doctorate career. 


\section{TABLE OF CONTENTS}

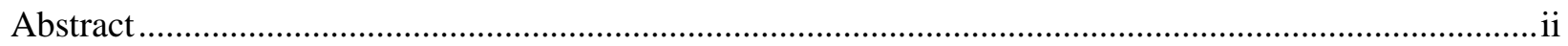

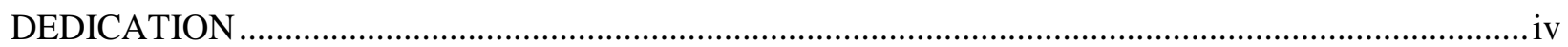

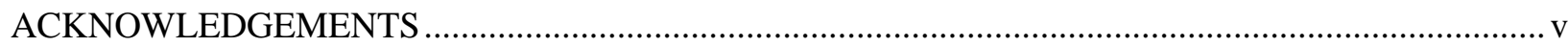

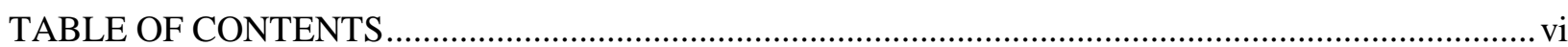

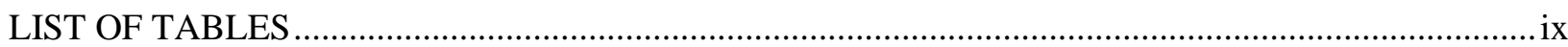

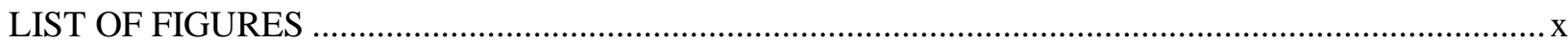

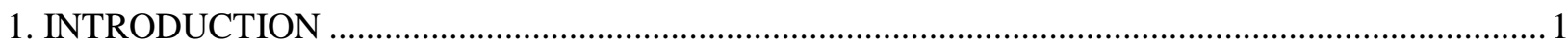

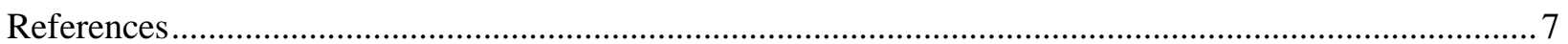

2. DEVELOPMENT OF SPATIO-TEMPORAL FOREST HARVEST PLANNING SYSTEM FOR

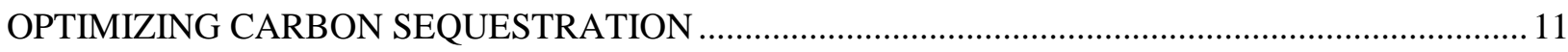

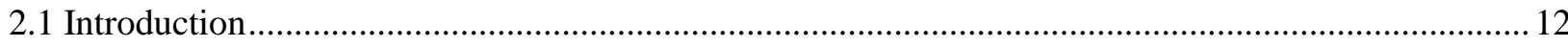

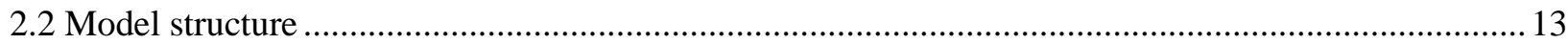

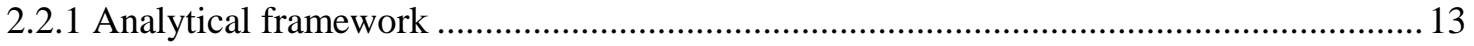

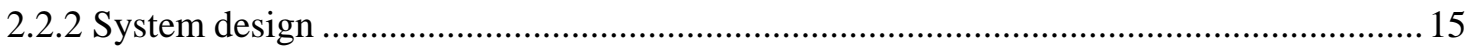

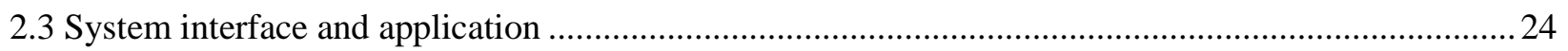

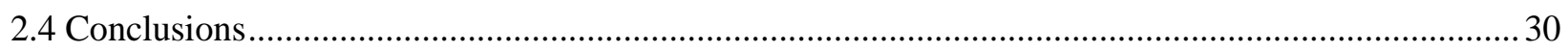

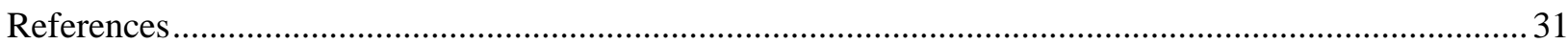

3. EVALUATING FOREST HARVEST STRATEGIES TO ENHANCE TIMBER PRODUCTION AND

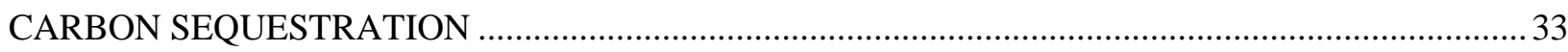

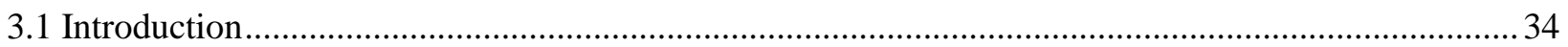

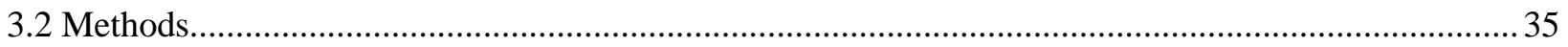

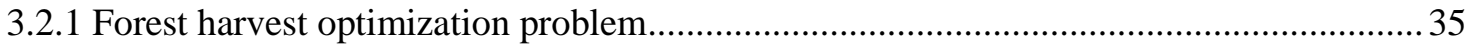

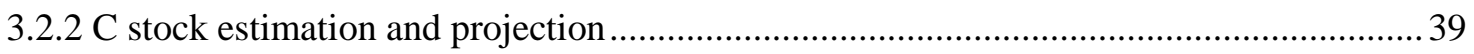

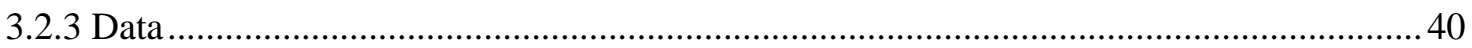

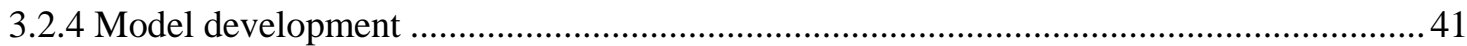

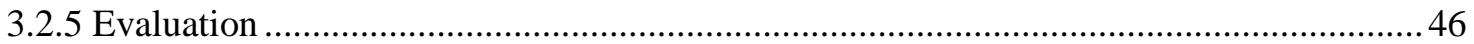

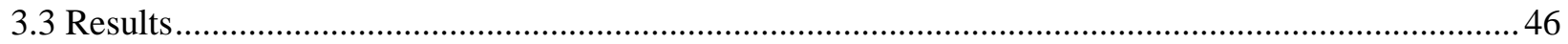

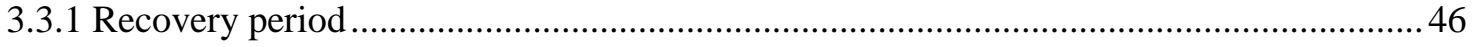

3.3.2 C sequestration under "no-harvest" situation............................................................ 47 


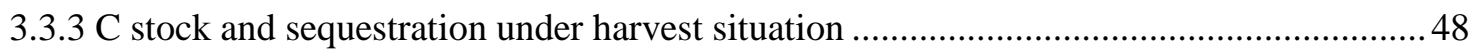

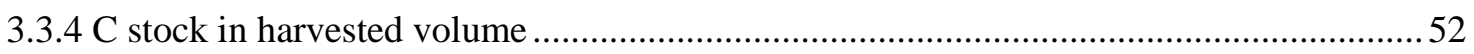

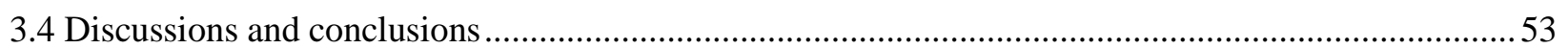

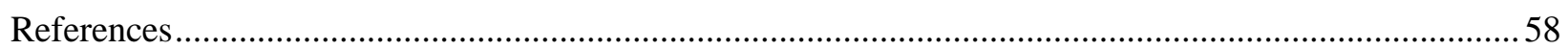

Appendix 3.1 Algorithm implemented to generate scheduling MILP model. ..........................................61

4. MODELING TERRESTRIAL CARBON SEQUESTRATION ENHANCEMENT POTENTIAL IN

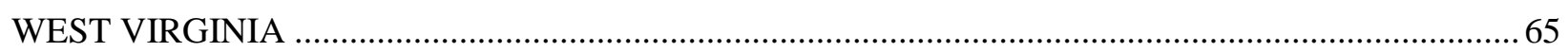

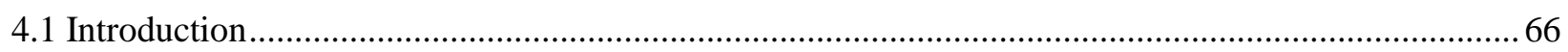

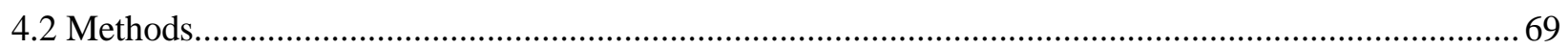

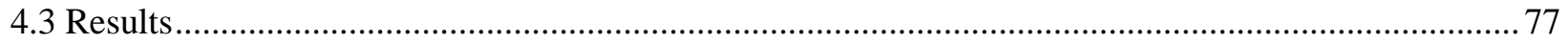

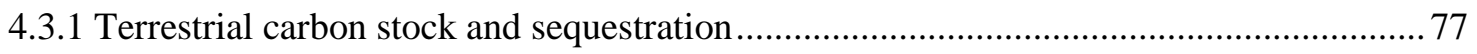

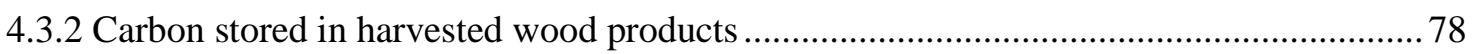

4.3.3 Carbon emission reduction through biomass utilization................................................ 82

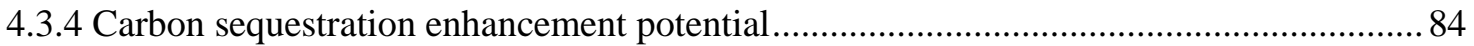

4.3.5 Alternative $C$ sequestration and terrestrial $C$ sequestration .......................................91

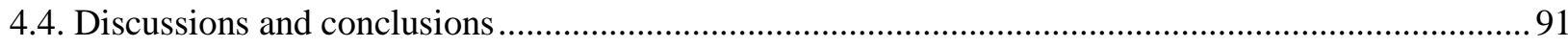

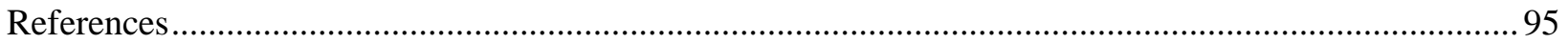

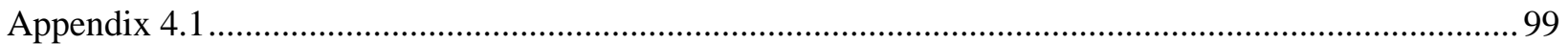

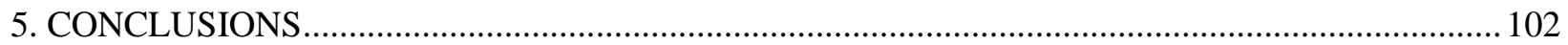

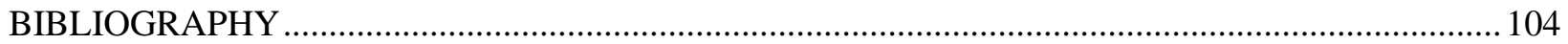

APPENDIX A: INTRODUCTION TO FOREST VEGETATION SIMULATOR (FVS) ....................... 112

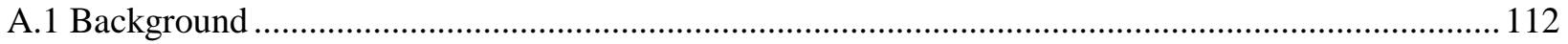

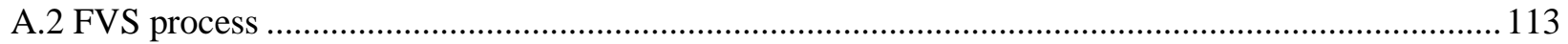

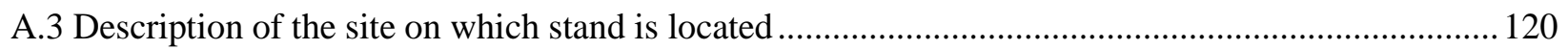

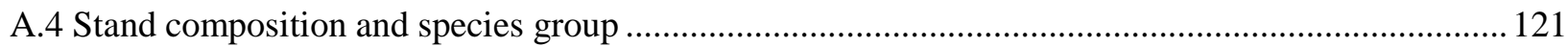

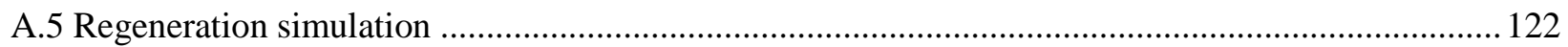

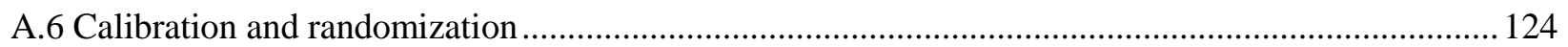

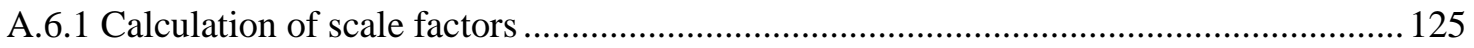

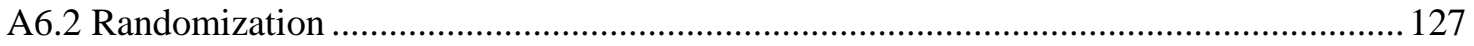

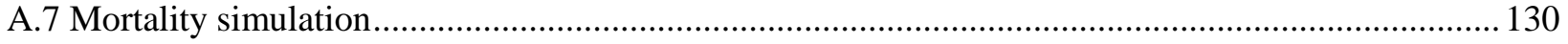

A.7.1 Determining the number of mortality trees ................................................................ 130 
A.7.2 Dispersing mortality to individual tree records

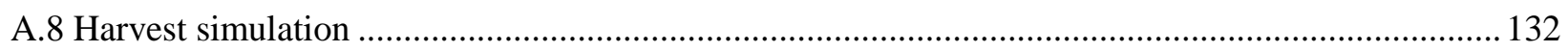

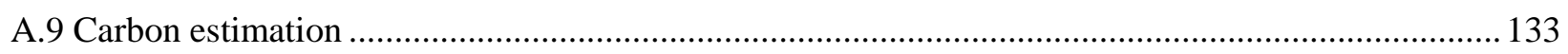

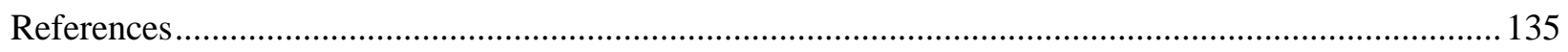

APPENDIX B: INTRODUCTION TO USING FOREST HARVEST PLANNING SYSTEM .............. 136

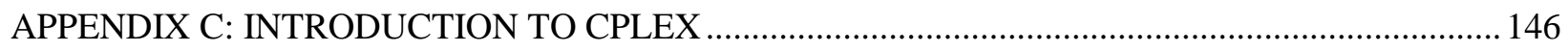

APPENDIX D: APPLICATION OF TERRESTRIAL CARBON SEQESTRATION MODEL...............152

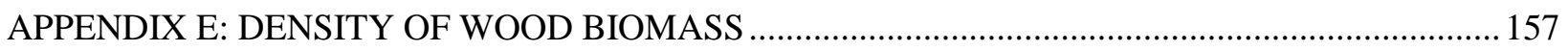

APPENDIX F: GROWTH TO REMOVAL RATIO OF FOREST GROWING STOCK (CFT/YEAR) IN

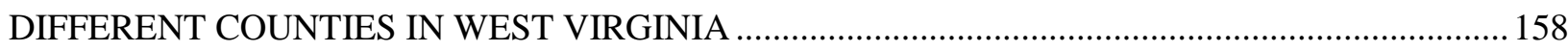

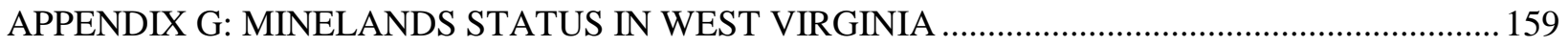




\section{LIST OF TABLES}

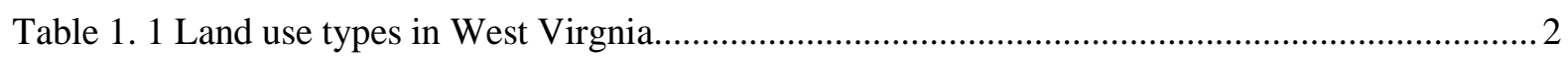

Table 1. 2 Forest harvest activities and corresponding removed volume in West Virginia................... 3

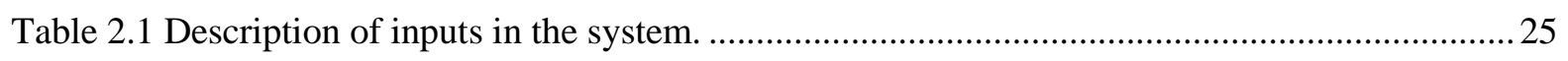

Table 2.2 Descriptions of different clear-cut harvesting strategies...............................................2 27

Table 2.3 Summary of $\mathrm{C}$ sequestration rate, standing $\mathrm{C}$ stock and harvested $\mathrm{C}$ stock.......................28

Table 3.1 Descriptive statistics for the stand inventory data used in simulation............................... 41

Table 3.2 Description of different harvesting strategies. This table should be referrenced to identify the applicable constraints and maximization objectives to interpret results in this paper. ........... 42

Table 3.3 Summary of recovery period in years in two different cutting types. ................................. 47

Table 3.4 C stock removed in merchantable volume for different models. ........................................53

Table 3.5 Summary of total $\mathrm{C}$ stock ( $\mathrm{tC} / \mathrm{ha})$ in different schedules over different years....................56

Table 4.1 Harvested wood products, use longevity and half-lives................................................. 73

Table 4.2 Definition of model parameters................................................................................. 74

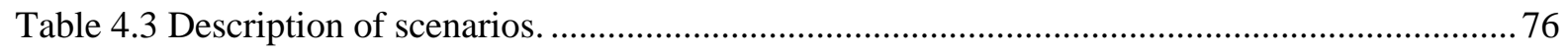

Table 4.4 Amount of carbon (million t) stored in forests in WV by major species group.................. 77

Table 4.5 Annual estimate of volume of wood products from different sources. ............................... 80

Table A.1 Stand level data in stored in database....................................................................... 115

Table A.2 Individual tree data stored in database. .................................................................. 118

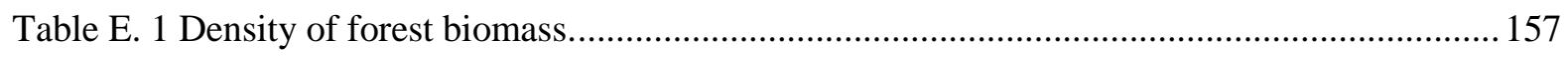

Table F. 1 Forest growth to removal ratio in West Virgnia. ........................................................ 158

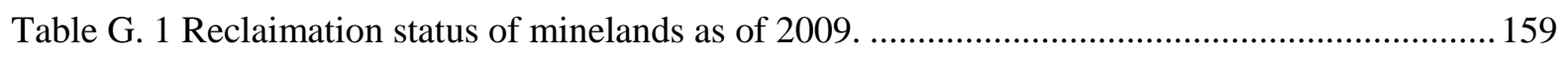

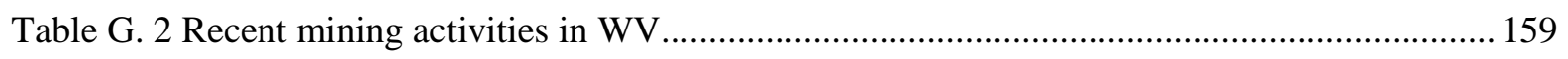




\section{LIST OF FIGURES}

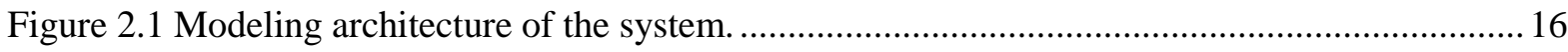

Figure 2.2 Entity-Relationship (ER) Model implemented in the system. ........................................ 17

Figure 2.3 Block relationship of forest consisting of 4 stands. ...................................................... 18

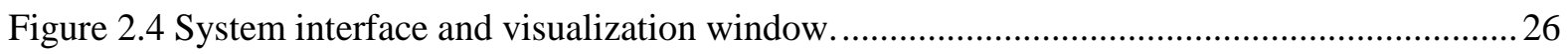

Figure 2.5 Carbon sequestration rate (tC/ha/year) (a) and long term carbon stocks (b) under different

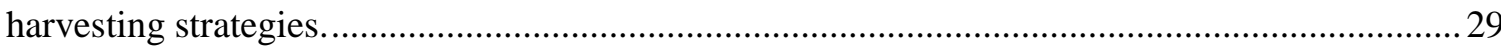

Figure 3.1 Growth characteristic illustrations of 2 pairs of stands. (a) Stand 1 and 2 show different growth characteristics after they are harvested in different time periods (b) Stand 1 and 2 show similar growth characteristics after harvesting at any time period. .............................................. 37

Figure 3.2 Stand and bock relationship under clear cut and partical cut.......................................... 43

Figure 3.3 C growth in forest for 200 years under "no harvest" scenario in different forest

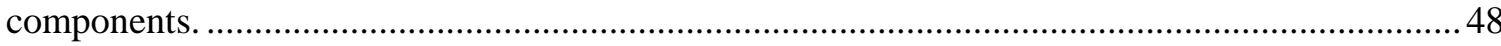

Figure 3.4 Carbon sequestration rate ( $\mathrm{tC} / \mathrm{ha} /$ year) under different harvesting strategies....................50

Figure 3.5 Forest $\mathrm{C}$ stock $(\mathrm{tC} / \mathrm{ha})$ as a result of different harvesting strategies.................................51

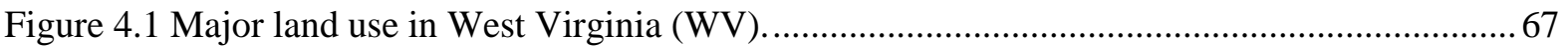

Figure 4.2 . Carbon emission from fossil fuel burning in WV between 1990 and 2007....................68

Figure 4.3 System model representing process and flows of carbon across major terrestrial ecosystem

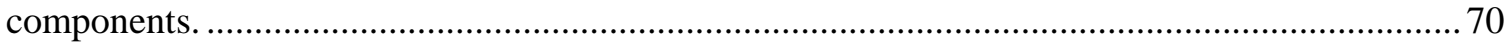

Figure 4.4 Carbon storage in West Virginia forest ecosystem components..................................... 78

Figure 4.5 Carbon stored in wood products under current level of harvest and use patterns............... 81

Figure 4.6 Carbon stored in wood products when all unused biomass are used to substitute fossil fuel to produce energy.

Figure 4.7 Annual estimate of current and potential emissions saving through biomass energy use... 84 Figure 4.8 Carbon stored in wood products when all unused biomass managed in land fill to prevent

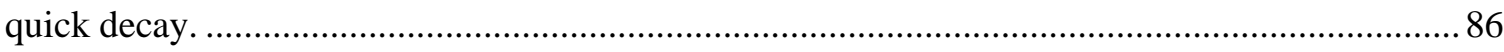

Figure 4.9 Terrestrial carbon stock under different management scenarios.................................... 87 Figure 4.10 Carbon stock in different terrestrial ecosystem components under different scenarios. Fig. a, b, c, d, e and f respectively represent scenario 1, 2, 3, 4, 5 and 6 described in Table (4.3). 
HWP, FS, AGS, AML respectively refers to carbon stock in harvested wood products, forests, agricultural lands and mine lands.

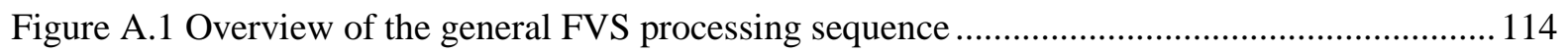

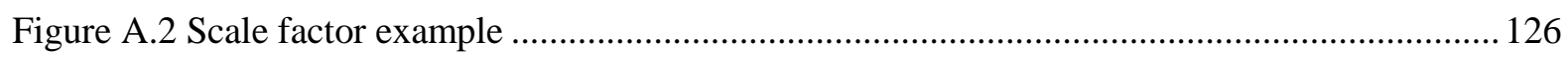

Figure A.3 Location of prediction points for three fractions of the normal distribution ................... 129

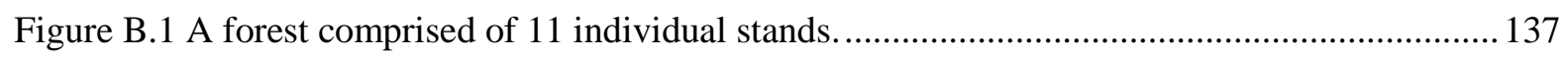

Figure B.2 Application interface of Forest Harvest Planning System............................................. 142

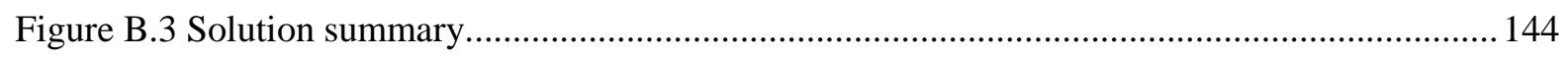

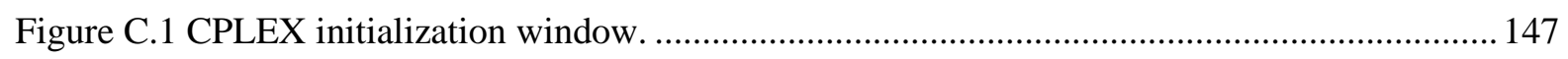

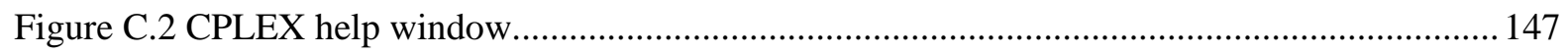

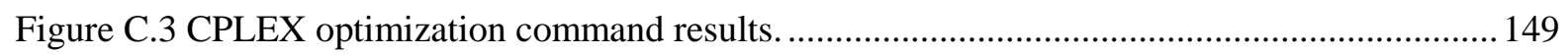

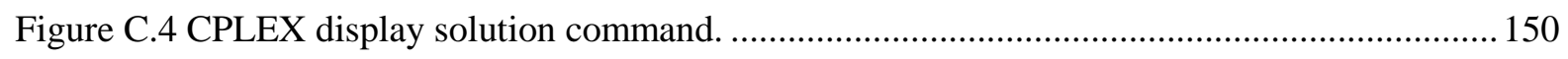

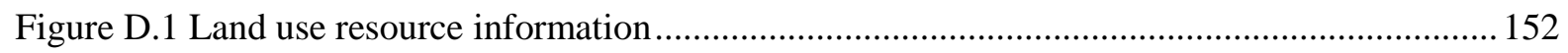

Figure D.2 Marginal agricultural land afforestation information .................................................. 153

Figure D.3 Abandoned mine land afforestation information ..................................................... 154

Figure D.4 Harvested wood products related information ......................................................... 155 


\section{I N T R O D U C T I O N}

Forestry is a major land use sector in the state of West Virginia (WV). Forest ecosystems cover over $80 \%$ of the state's total land area, followed by agricultural lands. The state has a large proportion of hardwood forests (approximately 95\%) with the oak-hickory species group as the dominant forest type (Table 1.1). These forests have a current carbon (C) stock of $191 \mathrm{tC} / \mathrm{ha}$ and currently hold 940 million tC in forests (USDA 2010). Developed areas, which include commercial, residential, quarries and transitional lands, cover about $2.5 \%$ of the state's total area. These land use types host most of the human activities which can be related to potential greenhouse gas (GHG) emissions. Forest and agricultural lands are available land use categories which can act as a potential sink of emitted GHGs. Given the large proportion of these terrestrial resources, sustainable management is likely to yield significant benefits in achieving the emission reduction and emission offsetting endeavors in West Virginia. 
Table 1. 1 Land use types in West Virgnia.

\begin{tabular}{|c|c|}
\hline Land use & Hectare \\
\hline Developed & 155,658 \\
\hline Commercial/Industrial/Transportation & 28,231 \\
\hline High Intensity residential & 1,036 \\
\hline Low Intensity Residential & 53,095 \\
\hline Quarries/Mines & 37,296 \\
\hline Transitional & 36,001 \\
\hline Forest & $5,244,208$ \\
\hline Deciduous Forest & $4,343,928$ \\
\hline Evergreen Forest & 225,070 \\
\hline Mixed Forest & 675,210 \\
\hline Pasture/Hay/Grasses & 691,009 \\
\hline Pasture/Hay & 689,455 \\
\hline Urban/Recreational Grasses & 1,554 \\
\hline Row Crops & 118,362 \\
\hline Row Crops & 118,362 \\
\hline Water & 51,023 \\
\hline Water & 51,023 \\
\hline Wetlands & 15,281 \\
\hline Emergent/Herb Wetlands & 5,957 \\
\hline Woody Wetlands & 9,324 \\
\hline Total & $6,275,541$ \\
\hline
\end{tabular}


The societal demand for timber has continued to increase along with production in the past few decades (Luppold and Baumgras 2000). Alongside this demand, the expectations for forests to mitigate increasing GHG emissions have also increased. Studies have shown that managed forests can increase C sequestration in the long run (Papadopol 2000, Ney at al. 2002, Meng et al. 2003) as compared to mature forests in biological equilibrium. Forests in such biological equilibrium often return carbon to atmosphere due to death, decomposition and other adverse outbreaks (Kurz and Apps 1999) and are often more vulnerable to natural disturbances. A significant proportion of mature old forest exists when forest growth to removal ratio stays over 1 for an extended period of time as in the case for forests in West Virginia. Forest harvests can be viewed as investments in order to establish a new stand with higher potential for biomass growth in the future (Hoen and Solberg 1994) and to reduce risks of adverse outbreaks (Routledge 1980) along with other direct benefits in terms of timber production and atmospheric C sequestration. Harvesting has also been an important forest management activity in WV (Table 1.2).

Table 1. 2 Forest harvest activities and corresponding removed volume in West Virginia.

\begin{tabular}{lrrrr}
\hline & 1997 & 2002 & 2007 & Mean \\
\hline Volume removed $\left(\mathrm{m}^{3}\right)$ & $4,786,856$ & $4,786,856$ & $4,634,525$ & $4,736,079$ \\
Available logging residue $\left(\mathrm{m}^{3}\right)$ & $3,042,714$ & $3,047,377$ & $2,850,967$ & $2,980,353$ \\
Available mill residue $\left(\mathrm{m}^{3}\right)$ & $1,827,338$ & $1,827,338$ & $1,583,216$ & $1,745,964$
\end{tabular}

Data source: USDA Timber Product Output Data $(1997,2002,2007)$

With these situations, forest management activities of managers now aim at simultaneously optimizing benefits from timber production and $\mathrm{C}$ sequestration. Harvesting in a sustainable forest management framework requires complying with several restrictions which include limits on maximum clearcut size, green-up delay, even flow of benefits from harvested products (Ware and Clutter 1971, Buongiorno and Gilless 2003) and others. When forests are managed for both timber production and 
carbon sequestration, management requires strategies that can enhance net $\mathrm{C}$ sequestration i.e., both harvested volume and standing C stock sustainably.

Different forms of mathematical programming have been used to generate harvest schedules as a bi-criteria objective function by combining $\mathrm{C}$ benefit from harvested volume and forest $\mathrm{C}$ stock at the time of harvest for the management plan period (Hoen and Solber 1994, Diaz-Balteiro and Romero 2003, Backeus et al. 2005). These studies have illustrated methods and subsequent results from regulated forests composed of one or two species where stand-to-stand C sequestration potential following harvest activities are likely to be similar. When forests grow with similar rates over different time periods and where stand-to-stand sequestration rates do not vary considerably following harvest activities, simply optimizing harvested volume and standing $\mathrm{C}$ stock on or after harvesting would be sufficient. However, when stand-to-stand growth characteristics and sequestration rates vary over time and also due to harvesting, stands would have different sequestration potentials determined by site quality, species composition, ability to tolerate disturbance effects and interactions of existing ecological conditions and processes such as competition, light availability, mortality and others. In such forests, if $\mathrm{C}$ stock is optimized merely at the harvest period without considering the future stocks, the $\mathrm{C}$ sequestration is high only for that time period and may have lower $\mathrm{C}$ sequestration in following years undermining the true $\mathrm{C}$ sequestration potential. Thus an objective function that is suitable for scheduling harvesting units in different time and place aiming at maximum $\mathrm{C}$ sequestration is needed along with other constraints. The actual scheduling process involves formulating objectives, generating constraints, obtaining solutions and generating insights. Once objectives are established and associated restrictions are identified, optimization of scheduling comes next.

Solving this optimization problem has been a challenge especially for large spatial units and multiple time periods (Murray and Church 1996). Initial work on solving this problem utilized heuristics (Hokans 1983, Lockwood and Moore 1993). More recently, several studies have used linear programming (Murray and Church 1996, McDill et al. 2002, Goycoolea et al. 2009), with several restrictive constraint formulation techniques. Successful application of optimization technologies depends on the ability to 
formulate problems in ways that can be addressed by software as well the availability of data and system capacity (Frakes and Bugg 2001). The problem formulation processes require skills on objective definition, and constraining the model and parameters. A need to integrate approaches from data generation to model optimization was deemed necessary to simplify the planning process of forest management.

The harvest scheduling activities would allow removing a portion of growing stock from the forest which would provide additional growing space in the forest and supply wood products. These wood products are also used for energy production, along with other long-lived wood materials. Increasing energy use globally, especially fossil fuels, combined with land use change activities that enhance C emissions have resulted in an increase of carbon dioxide $\left(\mathrm{CO}_{2}\right)$ - a major GHG component in the atmosphere. The rising GHG concentrations are creating negative impacts on the environment and global economy. Long-term solutions of reducing the atmospheric C such as geologic storage (IEA 2004) are still under development and are expected to be costly to implement (Galang et al. 2007). A terrestrial sequestration option on the other hand is cost efficient (Richards and Stokes 2004, USEPA 2005), which includes management of forest and agricultural land combined with emission source control (Cole et al. 1996, IPCC 2003) by substituting fossil fuels with renewable biomass resources wherever applicable. Thus, harvesting which provides growing space in forests also indirectly contributes to the GHG emission reduction strategies, if harvested materials do not immediately return $\mathrm{C}$ to the atmosphere. West Virginia, located around $38^{\circ} 36^{\prime} \mathrm{N}$ and $81^{\circ} 63^{\prime}$ in the US, is a land locked mountainous state where $99 \%$ of its area is land. The state has over $80 \%$ of the total land area covered with forest resources. Agricultural lands and abandoned mine lands are other major terrestrial land use components in the state with the potential to serve as a $\mathrm{C}$ sink. Anthropogenic carbon emissions due to fossil fuel use in the state accounts for approximately 29.88 million $\mathrm{tC} /$ year over the past decade with a high proportion from electric power generation (USEPA 2009).

There have been growing concerns over reducing the emission level and to stabilize the atmospheric $\mathrm{C}$ using several existing techniques and activities. A $\mathrm{C}$ sequestration method that relies on 
terrestrial ecosystem management is believed to be cost effective in West Virginia due to the availability of abundant land resources. The harvested wood pools provide additional storage of atmospheric $\mathrm{C}$ for a period of time depending on end use of these products. Given the mountainous topography, agricultural lands with severe limitations due to soil, slope, erodibility and other environmental factors make the primary agricultural activity less profitable. Approximately $60 \%$ of 809,000 ha of agricultural land in WV is considered marginal land and these lands can be used for afforestation activities to enhance terrestrial C sequestration (Sperow et al. 2003, Niu and Duiker 2006). Approximately 200,000 ha of abandoned mine lands in the state (WVDEP 2008) represent a significant portion of land use which can be brought under forest land use for additional C sequestration (Sperow 2006). Although studies focusing on individual components of these ecosystems with potential forest cover have been available in general (Sperow et al. 2003, Sperow 2006, Niu and Duiker 2006), an analysis by integrating these components together with carbon in harvested products - an important terrestrial carbon pool was not available in the region. It was believed that such a study could aid in our understanding of the possibilities and limitations of applicable terrestrial land based management to enhance $\mathrm{C}$ sequestration and consequently reduce $\mathrm{C}$ emission level at the state level.

This dissertation focuses on the issues of forest harvest scheduling and terrestrial carbon sequestration through three different chapters respectively dedicated to: (1) development of Spatiotemporal harvest scheduling optimization modeling, (2) application of a scheduling model under a range of management conditions to obtain the optimal long-term forest carbon sequestration rate, and (3) analyze the terrestrial $\mathrm{C}$ sequestration enhancement options utilizing the system modeling approach. The focus of the first paper is to demonstrate the modeling approaches for forest harvest scheduling and describe a stand-alone computer-system which generates, solves and presents forest management and C sequestration alternatives. The modeling approach to optimize long-term $\mathrm{C}$ sequestration potential of a forest is illustrated for a mixed central Appalachian hardwood forest. The results of this study are expected to help in understanding the dynamics of $\mathrm{C}$ stock forest after harvests and the way it can be maximized in the long term. The second paper is designed to evaluate different forms of harvesting 
strategies applicable in harvesting methods such as clearcuts or partial cuts, supply restrictions, and rotation period on net carbon sequestration capacity of the forest. This paper describes the net achievable sequestration rate under a continuous management cycle which complies with sustainable forest management standards such as green-up delays, maximum opening area restrictions and best management practice guidelines. The computer software developed and described in Chapter 2 could be used to implement the activities described in Chapter 3. The third paper (Chapter 4) is intended to illustrate how the terrestrial land use components modification help in enhancing $\mathrm{C}$ sequestration. This paper also takes into account the annual sequestration and emission from harvested wood products pools which stores an enormous amount of $\mathrm{C}$, and in several cases provides energy and reduces emission of $\mathrm{C}$ from fossil fuels. This paper describes a $\mathrm{C}$ sequestration modeling approach that can be applied to estimate the terrestrial $\mathrm{C}$ sequestration potential and enhancement strategies and investigates the limits of such strategies. The paper also describes how these terrestrial based approaches compare to other alternatives of carbon capture and storage (CCS) in terms of cost of $\mathrm{C}$ sequestration. In summary, this dissertation starts with the formulation of modeling framework to conduct forest harvest scheduling, generate optimal C sequestration rate under a range of conditions and applies that rate for possible carbon sequestration for the entire state of West Virginia. Finally, appendices at the end of this dissertation provide some overview of models, software and additional details used to produce this dissertation.

\section{References}

Backeus, S., Wikstrom, P., Lamas, T. 2005. A model for regional analysis of carbon sequestration and timber production. Forest Ecology and Management 216:28-40.

Buongiorno, J., Gilless, J.L. 2003. Decision Methods for Forest Resource Management, Academic Press, San Diego, CA.

Cole, V., Cerri, C., Minami, K., Mosier, A., Rosenberg, N., Sauerbeck, D. 1996. Agricultural options for mitigation of greenhouse gas emissions. In R.T. Watson, M.C. Zinyowera and R.H. Moss (eds.), 
Climate Change 1995: Impacts, Adaptations and Mitigation of Climate Change: ScientificTechnical Analyses, New York, Cambridge University Press.

Diaz-Balteiro, L., Romero, C. 2003. Forest management optimization models when carbon captured is considered: a goal programming approach. Forest Ecology and Management 174:447-457.

Frakes, I., Bugg, A.L. 2001. Optimizing algorithms for forest planning and decision-making. New Zeland Journal of Forestry 45:5-9.

Galang, J.S., Zipper, C.E., Prisley, S.P., Galbraith, J.M., Donovan, P.F. 2007. Evaluating terrestrial carbon sequestration options for Virginia. Environ Manage 39:139-150.

Goycoolea, M., Murray, A., Vielma, J.P., Weintraub, A. 2009. Evaluating alternative approaches for solving the area restriction model in harvest scheduling. Forest Science 55: 149-165.

Hoen, H.F., Solberg, B. 1994. Potential and economic efficiency of carbon sequestration in forest biomass through silvicultural management. Forest Science 40:429-451

Hokans, R.H. 1983. Evaluating spatial feasibility of harvest schedules with simulated stand selection decisions. Journal of Forestry 81:603-613.

IEA [International Energy Agency]. 2004. The prospects for CO2 capture and storage. Organization for Economic Cooperation and Development. Paris, France.

IPCC [Intergovernmental Panel on Climate Change]. 2003. Good Practice Guidance for Land Use, LandUse Change and Forestry. In: Penman J, Gytarsky M, Hiraishi T, Krug T, Kruger D, Pipatti R, Buendia L, Miwa K, Ngara T, Tanabe K, Wagner F, editors. Intergovernmental Panel on Climate Change (IPCC), IPCC/IGES, Hayama, Japan

Kurz, W. A., Apps, M.J. 1999. A 70-year retrospective analysis of carbon fluxes in the Canadian forest sector. Ecological Applications 9:526-547.

Lockwood C., Moore, T. 1993. Harvest scheduling with spatial constraints: a simulated annealing approach. Canadian Journal of Forest Research 23:468-478.

Luppold, W., Baumgras, J. 2000. The changing structure of the hardwood lumber industry with implications on technology adaptation. P. 89-94 in Proc. of. the twenty-eighth annual hardwood 
symposium, West Virginia now--the future for the hardwood industry? Meyer, D. A.(ed). National Hardwood Lumber Association, Memphis, TN.

McGill, D.E., Rebain, S., Braze, J. 2002. Harvest scheduling with area based adjacency constraints. Forest Science 48:631-642.

Meng, F., Bourque, C.P.A, Oldford, S.P., Swift, D.E., Smith, H.C. 2003 Combining carbon sequestration objectives with timber management planning. Mitigation and Adaptation Strategies for Global Change 8:371-403

Murray, A.T., Church, R.L. 1996. Analyzing cliques for imposing adjacency restrictions in forest models. Forest Science 42:166-175.

Ney, R.A., Schnoor, J.L., Mancuso, M.A. 2002. A methodology to estimate carbon storage and flux in forestland using existing forest and soil databases. Environmental Monitoring and Assessment 783:291-307.

Niu, X., Duiker, S.W. 2006. Carbon sequestration by afforestation of marginal agricultural land in Midwestern US. Forest Ecology and Management 223:415-427.

Papadopol, C.S. 2000. Impacts of climate warming on forests in Ontario: options for adaptation and mitigation. For. Chron. 76:139-149.

Richards, K.R., Stokes, C. 2004. A review of forest carbon sequestration cost studies: a dozen of research. Climate Change 63:1-48.

Routledge, R.D. 1980. The effect of potential catastrophic mortality and other unpredictable events on optimal forest rotation policy. Forest Science 26:389-399.

Sperow, M. 2006. Carbon sequestration potential in reclaimed mine sites in seven East-Central states. Journal of Environment Quality 35:1428-1438.

Sperow, M., Eve, M., Paustian, K. 2003. Potential soil C Sequestration on US agricultural soils. Climate Change 57:319-339.

USEPA [U.S. Environmental Protection Agency]. 2005. Greenhouse gas mitigation potential in U.S. forestry and agriculture. EPA 430-R-05-006. Office of Atmospheric Programs, Washington, DC. 
USEPA [United States Environmental Protection Agency] 2009. Inventory of U.S. Greenhouse Gas Emissions and Sinks: 1990 - 2007. USEPA Washington DC.

Ware, G.O., Clutter, J.L. 1971. A mathematical programming system for the management of industrial forests. Forest Science 17:428-445.

WVDEP [West Virginia Department of Environmental Protection] -Division of Mining and Reclamation] 2008. West Virginia Mining Permit Boundary Data. Available online http://gis.wvdep.org/data/omr.html (Accessed on April, 6, 2009). 


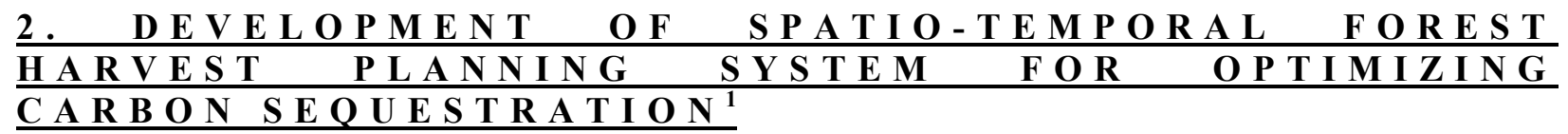

\title{
CARBON SEQUESTRATION ${ }^{1}$
}

\begin{abstract}
A computer-based forest planning system was developed for generating and visualizing spatial forest harvesting plans for given management objectives. The system adapted the twostaged block generation approach using maximal feasible blocks to formulate spatial, temporal and related restrictions. The mixed integer programming based solver was employed to optimize the problem which resides at the backend along with a relational database which stores different forest, operation and management related data. The system runs with minimal information required from user, such as management objective selected, time frame of the planning horizon and periods, and other management restrictions as binary inputs. Modeling processes and complexities were handled by the system using tested algorithms which are often the major challenges in the alternative planning processes. This integrated system simplifies the planning processes and ensures that the generated spatial plan meets the long term objectives of forest management. A case study illustrated the implementation of the system on a hardwood forest managed to maximize carbon sequestration highlighting components of the approaches, solution experience, and possible extensions.
\end{abstract}

\footnotetext{
${ }^{1}$ Paper accepted for publication in Intelligent Automation and Soft Computing
} 


\subsection{Introduction}

Societal demand for timber from forests has continued to increase along with production in the past few decades (Luppold 1996). Alongside this demand, the expectations from forests to mitigate increasing green house gas emissions have also increased. With these situations, forest management activities now aim at simultaneously optimizing benefits from timber production and carbon $(\mathrm{C})$ sequestration. Harvesting, an important component in forest management, has to comply with several restrictions which include limit on maximum clearcut size, green-up delay, even-flow of benefit from volume from harvested products and others (Buongiomo and Gilless 2003, Ware and Clutter 1971). Once objectives are established and associated restrictions are identified, optimization of scheduling comes next. Solving this optimization problem has been a challenge especially for large spatial units and multiple time periods (Murray and Church 1996). Initial work on solving this problem utilized heuristics (Hokans 1983, Lockwood and Moore 1993) and more recent studies have utilized linear programming (McGill et al. 2002). Successful application of optimization technologies depends on the ability to formulate problems in ways that can be addressed by software as well as the availability of data and system capacity (Frakes and Bugg 2001). The problem formulation processes require skills on objective definition, and constraining the model and parameters. A need to integrate approaches from data generation to model optimization was deemed necessary to simplify the planning process of forest management. The objectives of this paper are to demonstrate these modeling approaches and describe a standalone computer-system which generates, solves and presents forest management and $\mathrm{C}$ sequestration alternatives. The modeling approach to optimize long term $\mathrm{C}$ sequestration potential of forest is illustrated for a mixed central Appalachian hardwood forest. 


\subsection{Model structure}

\subsubsection{Analytical framework}

C stocks and fluxes in a forest stand were estimated using a full carbon accounting approach, i.e. calculating changes in carbon stocks in all forest ecosystem components over time (Noble et al. 2000) (Eq. 2.1).

$$
T C_{t}=T L_{t}+B L_{t}+B D_{t}+S D_{t}+D D W_{t}+S H_{t}+F F_{t}
$$

where, $T C_{t}$ is total $\mathrm{C}$ stock in forest at time $t, T L_{t}$ is total carbon stored in living biomass in trees (above ground including both merchantable and non-merchantable portions of tree biomass) at time $t$ in tons per hectare, $B L_{t}$ is carbon stored in live components on below ground biomass, $B D_{t}$ is carbon stored in dead below ground biomass components, $S D_{t}$, is carbon stored in standing dead tree biomass, $D D W_{t}$ is carbon stored as down dead wood above ground, $S H_{t}$, is carbon stored in shrubs and herbs, and $F F_{t}$ is the carbon stored in the forest floor. The benefits from future harvests were discounted back to present value (Eq. 2.2).

$$
C_{p v}=\frac{C_{t}}{(1+r)^{P_{l}(t-1)}}
$$

where, $C_{p v}$ is the present value of $C, C_{t}$ is $\mathrm{C}$ stock in planning period $t, r$ is discount rate applied in percentage, $P_{l}$ is length of planning period.

C sequestration along with timber production can be combined in different ways depending on the forest composition and growth characteristics. The formulation of three different alternative objective functions was embedded into the system as described in (Sharma et al. 2009). Let a stand be harvested at time period $t$. Let carbon in harvested merchantable volume be $H C$. The $\mathrm{C}$ stock initially could decline due to death and decay following harvest activities. With regeneration and new growth, the stand $\mathrm{C}$ stock would begin to increase (net $\mathrm{C}$ sequestration becomes positive) and equal or exceed $\mathrm{C}$ level after certain period of time. Let function $f(x)$ be a function of time on $\mathrm{C}$ stock of forest stand following harvest, i.e., 
$f(x=0)$ is $\mathrm{C}$ stock remaining in the stand at the time of harvest. As C stock declines following harvest, $f(x=0)$ is greater than $f(x \geq 0)$ for certain time periods during which $\Delta f(x>0)$ is negative and continues to be negative until sometime $\Delta t$ has passed at which time i.e., at $\mathrm{x}=t>0, \Delta f(x=t>0)$ becomes positive and net sequestration becomes positive which continues to rise until biological maturity is reached at time $T$.

Between $t$ and $T$, there is point $t^{\prime}$ in this function such that:

$$
f(x=0) \geq f(x=t>0) \text { and } f(x=t) \leq f\left(x=t+\Delta t=t^{\prime}\right)
$$

The $t^{\prime}$ is considered a recovery time period at which point, the stands have regained $\mathrm{C}$ stock to level at the time of harvest. From time $t$ to $T$, the net sequestration continues to increase when there are no other disturbance and outbreaks. Traditional harvest scheduling activities maximize $H C$ from a stand. Some recent studies have combined $\mathrm{C}$ stock of the stand at the time of harvest into the objective function. If $\mathrm{C}$ stock of the stand is maximized at $x=0$, the $\mathrm{C}$ stock will decline after the end of the planning period. However, if $\mathrm{C}$ stock is maximized at $x=t^{\prime}$, the $\mathrm{C}$ stock will be increasing in all the stands. If an average recovery time period is identified for all the stands harvested in different time period and $\mathrm{C}$ stock at time $t^{\prime}$ after the last harvest is maximized, the net sequestration rate for the forest remains high. This happens because at the time when optimization process achieves a maximization solution, none of the stands would have negative phase of C. Such schedule allows harvesting stands that have high potential of sequestering $\mathrm{C}$ earlier and delays the harvesting of stands that have low potential of net sequestration. When this future stock is combined with benefits from harvested materials, both the objectives are maximized.

The model utilizes information known for different stands regarding $\mathrm{C}$ stocks, flows and growth over time in different ecosystem components. This information can be obtained by using different models available for major forest types. Alternatively, a stand simulation system such as Forest Vegetation Simulator (FVS) with extension can be used (such as in this study) to simulate stand level stocks over time based on available inventory data (Sharma et al. 2009). After FVS is run for a given stand, carbon 
estimates for harvested and un-disturbed forests were fitted into a non-linear exponential function with "age" as the dependent variable in CurveExpert (Hyams 1997).

\subsubsection{System design}

Object-oriented modeling technique (OMT) was used in designing the system (Fig. 2.1). A hierarchical structure among different modules is useful while modifying the program with OMT. The Graphical User Interface (GUI) layer consists of multiple modules that deal with GUI support for functions such as defining parameters, generating models, viewing data and enabling/disabling system parameters and editing defaults. This layer is usually enacted by users as well by underlying active modules which communicate with underlying class layers that follow the system hierarchy (Wang and LeDoux 2003). The module layer provides implementation mechanisms to objects, controls and data. This layer contains interactive forms, classes and standard modules. The module layer talks to data layer to obtain persistent data support through Dynamic Data Exchange (DDE), Dynamic Link Libraries (DDL), and Windows Application Programming Interface (API). 


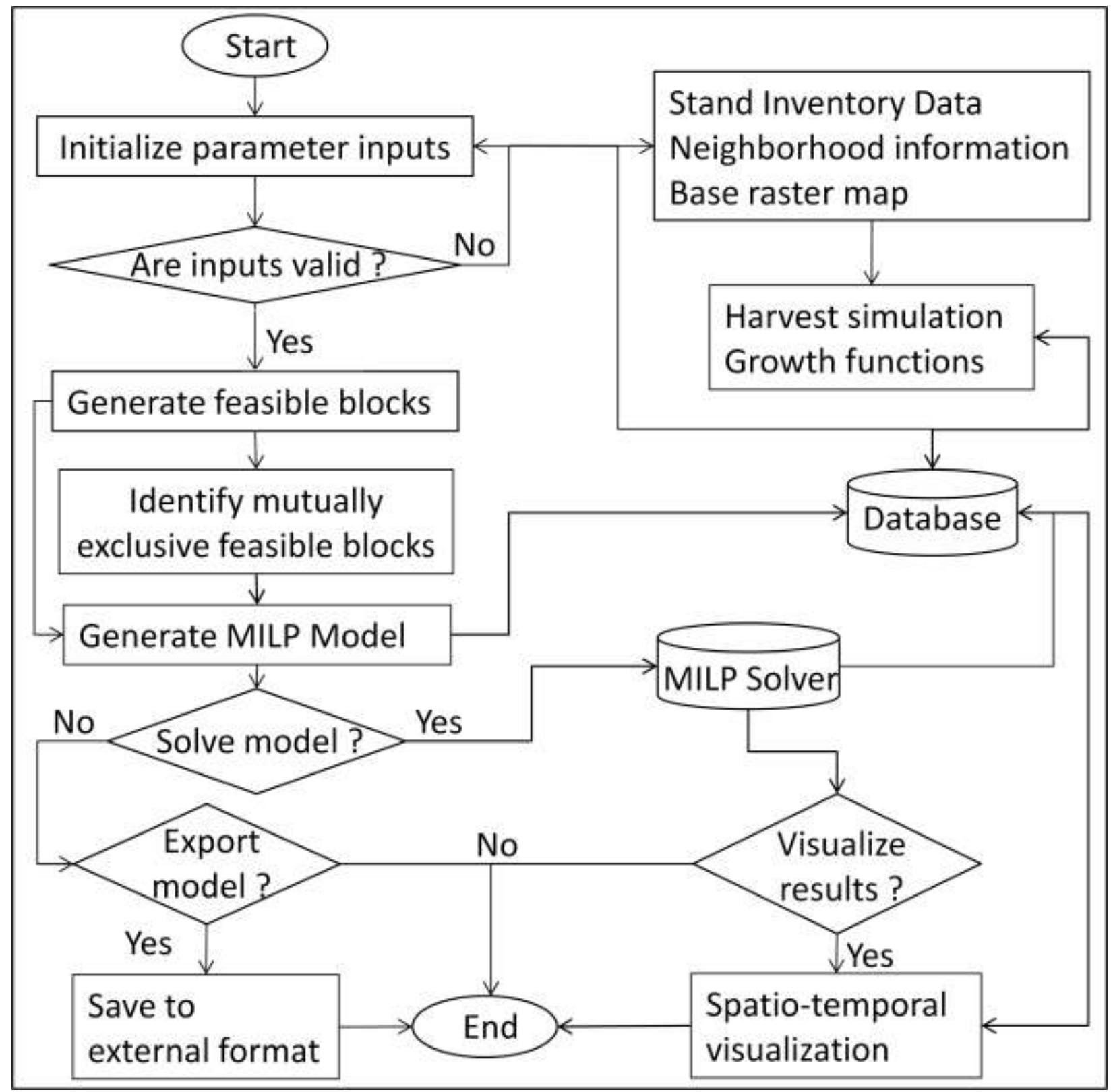

Figure 2.1 Modeling architecture of the system.

The Microsoft Visual C++ 6 was used to develop the system along with built-in jet database engine of relational data model in the backend (Fig. 2.2). The optimization engine used in the program is based on the Mixed Integer Programming solver, lp_solve system licensed under the GNU Lesser GPL available at http://groups.yahoo.com/group/lp_solve. Visualization of the stand and harvest were made using OpenGL and associated libraries approaches described in Wang et al. (2009). 


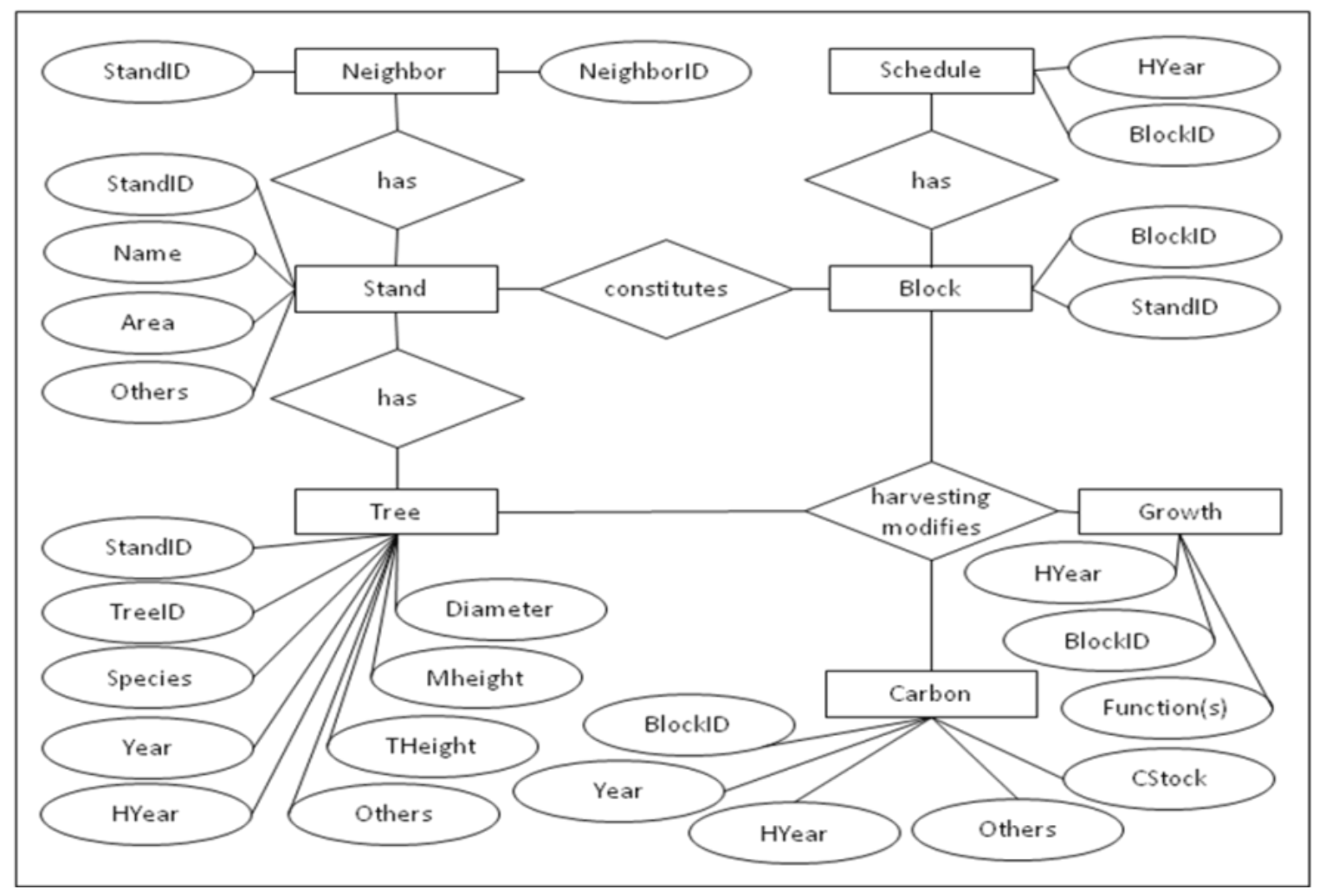

Figure 2.2 Entity-Relationship (ER) Model implemented in the system.

(Rectangle represents entity type, diamond represents relationship and oval represents attribute. Attribute "others" denotes that there are several other attributes in that entity type.)

\subsubsection{Initialization}

Maximum opening area is read from the user supplied variable. A default value of 40 hectares of opening area is provided. Stand ID and stand area values are retrieved from the database. Adjacency information is provided by a specified text file or stand table. The model development process first generates feasible blocks of stands based on the maximum opening size and adjacency relationships. These blocks are then sent through a series of processes to achieve a final set of constraints at runtime. The intermediate outcome of this process is a mixed integer linear programming (MILP) model. 


\subsubsection{Block formulation}

Stands are spatially contiguous management units in forest. For harvest planning, when a maximum clearcut size restriction is placed multiple contiguous stands can only be harvested together if the combined area does not exceed maximum allowable clearcut size. Such combinations of stands are considered feasible blocks. Several feasible blocks can be formulated depending on size of individual stand and neighborhood relationship. For example, stand 1 is neighbor to stands 2, 3, and 4 for a forest in Fig. (2.3). When the maximum opening size is 50 hectares, the combined block of stands 1,2 and 3 does not exceed the limit and, therefore, can be harvested together. In this forest, there are eight feasible blocks constituted of stands (1),(2),(3), (4), (1,2), (1,3), (2,3) and (1,2,3) for a given rotation.

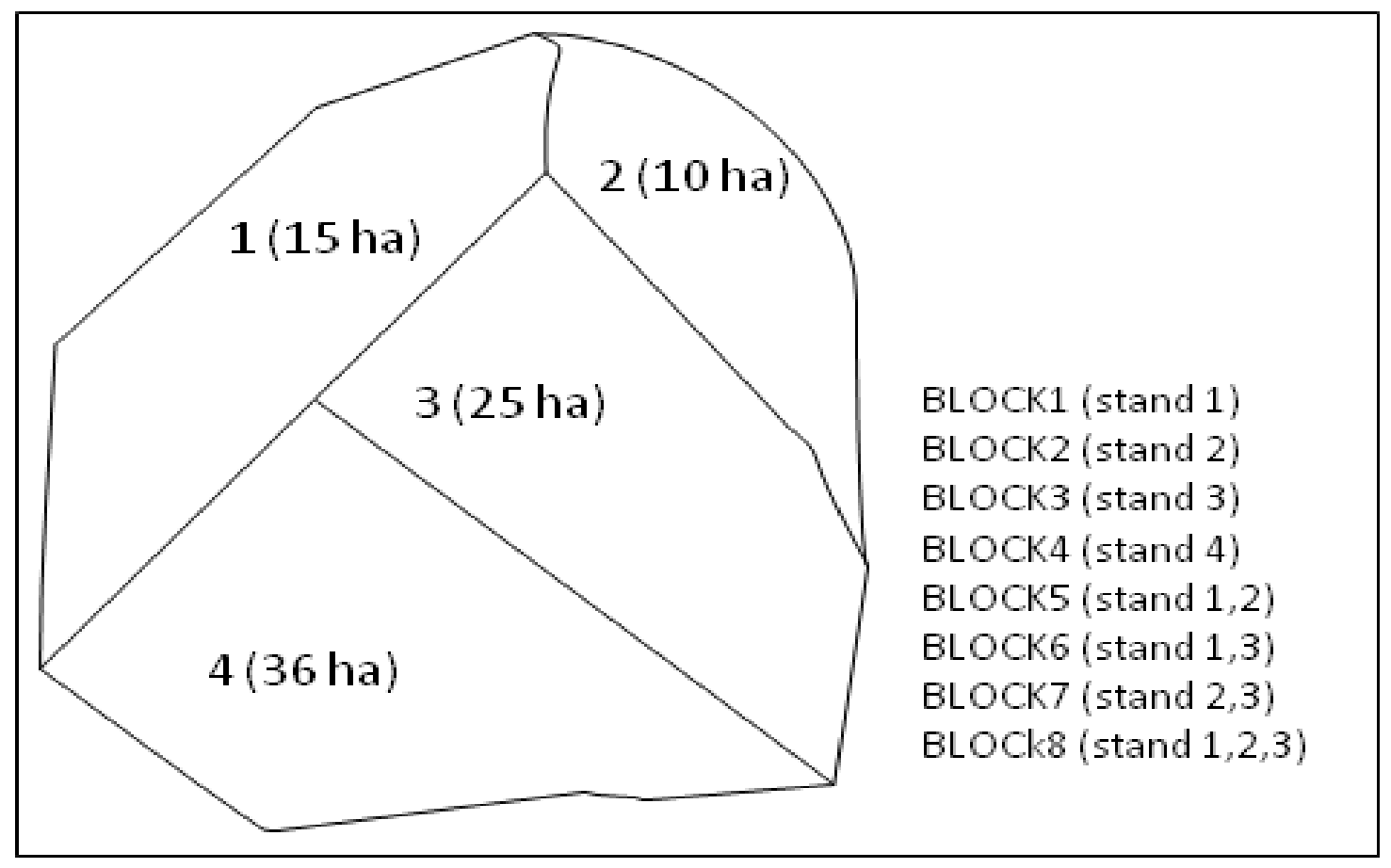

Figure 2.3 Block relationship of forest consisting of 4 stands.

(Stands are identified with numbers with their area in parenthesis. Feasible blocks with constituting stands are shown in text) 
When two or more stands are combined to form one feasible block, then each stand is considered a member of that block. In order to identify the total number of feasible blocks, initially a number of blocks are formed from individual stands, i.e., if there are $\mathrm{n}$ stands, the total number of feasible blocks will be $\mathrm{n}$ at the beginning. Neighboring stands are tested one at a time for their combined area and if the combined area is less than the maximum opening area, then these adjacent stands are considered as feasible block and are added to the set of BLOCK. A recursive function based on growth in the number of feasible blocks was implemented to generate sets of feasible blocks. Once the process does not show any improvement of the block growing, it simply indicates that there are no more feasible blocks can be formulated. Once all the feasible blocks are formulated, the next step is to identify mutually exclusive sets of blocks (MEB). For example, given the adjacency restriction in place, if BLOCK 1 is harvested, BLOCK 2 and BLOCK 5 cannot be harvested because this will lead to harvesting BLOCK 1 twice which is not practicable. Thus, BLOCKs 1,2 and 5 are a set of mutually exclusive blocks to enter into MEB. Similarly, given the adjacency restriction, if BLOCK 2 is harvested, only BLOCK 4 can be harvested as other blocks share a boundary with this block. Thus, there might be more than one MEB for one feasible block. MEB and FB are generated using the following two-step algorithms.

Step I: Algorithm for generating feasible blocks

FB: FB stores feasible block information and it is a set of stands set FB to null for each stand: stands range from 0 to $S$ i.e. number of stands in forest generate individual blocks by adding stand to $F B$ next stand MAX = maximum opening size area (i.e. 40 hectares) begin process $n=$ number of block at the beginning of process $(=S$ i.e., number of stands) for each member in FB obtain constituting stands 
obtain block area (by adding area of constituting stands in this block)

for each constituting stands in $F B$

obtain neighbors (i.e., set of neighboring stands)

for each neighbor

if neighboring stand is already in constituting stands in FB

remove from neighbor set

if $([$ block area + neighboring stand area $]<=$ MAX)

add neighboring stand to $F B$

next neighbor

next constituting stand

next member in $F B$

obtain $N(N=$ number of blocks $)$

If $N>n$ (i.e. checks if there is improvement)

set $n=N$ and repeat the process i.e., go to line begin process

end process

Step II: Algorithm for generating mutually exclusive feasible blocks (MEB)

TFB is temporary storage of set of blocks

set TFB to null : initially this storage is set to empty

for each member in $F B(i): 1<=i<=$ number of $F B$

if block $i$ is not in TFB, add block $i$ to TFB

for each member in $F B(j): 1<=j<=$ number of $F B$

if $j$ is not equal to $i$

if block $j$ is connected with all the blocks in TFB, add block $j$ to TFB

next $j$

if TFB is not already in MEB and TFB is not a subset of any member in MEB 
add TFB to MEB:

clear TFB: set this object to null and prepare for next block

next member in $F B$

\subsubsection{Model generation}

The program generates the MILP model in required format by the solver. The objective function formulation simply is the enumeration of benefits from harvesting a particular block in different time periods (Eq. 2.4) which is subject to several sets of constraints (Eq. 2.5 - 2.9).

$$
\text { Maximize } z=\sum_{j=1}^{T} \sum_{i=1}^{F B} C_{p v i j} * B_{i j}
$$

Subject to: $\sum_{j=1}^{T-1} \sum_{i=1}^{F B} B_{i j}+B_{i j+1} \leq 1 \forall M E B$

$$
\begin{gathered}
\sum_{b=1}^{F B} B_{i} \leq 1 \forall T \\
\sum_{i=1}^{F B} \sum_{j=1}^{T}(1-v) H_{i j} B_{i j} \leq \sum_{i=1}^{F B} \sum_{j=1}^{T-1} H_{i j+1} B_{i j+1} \leq \sum_{i=1}^{F B} \sum_{j=1}^{T}(1+v) H_{i j} B_{i j} \\
B_{i j} \in 0,1 \forall F B \\
C_{p v i j} \notin S M Z \forall F B
\end{gathered}
$$

where $C_{p v i j}$ is net present value of $\mathrm{C}$ by harvesting block $i$ at plan period $j$. $B_{i j}$ is 1 if block $i$ is harvested at plan period $j, 0$ otherwise. If the objective is to maximize the stand carbon at the time of 
harvest then equation (4) is modified with the addition of $S C_{i j} * B_{i j}$. Finally, if the objective is to manage the long term $\mathrm{C}$ stock of the forest, then Eq. (2.4) is modified by adding $S C_{i(P * P i+R P)} * B_{i j} . T$ is the total number of planning periods, $P_{i}$ is planning interval, $R P$ is the mean recovery period. $H_{i j}$ is benefits from harvested wood products from block $i$ at time period $j . v$ is allowable deviation in harvested wood product benefits in percentage. $F B$ is the total number of feasible blocks. $M E B$ is the total number of mutually exclusive feasible blocks. $B_{i}$ is the area of block $i$. SMZ is stream side buffer where harvesting or machine operation is limited as per best management practice (BMP) guidelines.

Objective function formulation is simply enumeration of all the benefits from different stands and different harvesting periods. Spatio-temporal adjacency relationships (Eq. 2.5) were formulated using sets of mutually exclusive blocks. Constraints for restricting multiple harvests of the same stands in different time periods (Eq. 2.6) and evenflow benefits from harvests (Eq. 2.7) were generated using available feasible blocks. Objective function and constraints were obtained from the following algorithms.

\section{Objective function formulation algorithm}

let $C_{i, j}$ be variable to denote harvest benefit by harvesting block $i$ at time period $j$

let $S_{i, j}$ be variable to denote stand $C$ stock at time $j$ by harvesting block $i$ at time period $j$

let $S R_{i, j}$ be variable to denote stand $C$ stock at time $j+r$ by harvesting block $i$ at time period $j$

let $B_{i, j}$ be variable to denote harvest of block $i$ at time period $j$

let $\mathrm{Z}$ be variable to store objective function

for each plan period $(j): 1<=j<=P(P$ is total number of plan period $)$

for each $F B(i)$

for each model types (i.e.,I, II, or III)

$$
Z=Z+C_{i, j} * B_{i, j}+S_{i, j} * B_{i, j}+S R_{i, j} * B_{i, j}
$$

Next objective type

next $F B$

next plan period 
write $Z$ to memory

Adjacency and green up restriction constraints formulation algorithm.

let CONSTRAINT be temporary storage for constrains.

let $B_{i, j}$ be variable to denote harvest of block $i$ at time period $j$

for each plan period $(j): 1<=j<=P(P$ is total number of plan period $)$

for each $M E B$

set constraint to null

for each member block in $M E B(i)$

if $(j+1<P)$, constraint $=$ constraint $+B_{i, j}+B_{i, j+1}$

next member block $i$

write CONSTRAINT as "CONSTRAINT $=$ CONSTRAINT $+"<=1$ " to memory next $M E B$

next plan period $j$

Unique harvest in planning period constraint formulation algorithm let CONSTRAINT be temporary storage for constrains.

let $B_{i, j}$ be variable to denote harvest of block $i$ at time period $j$

for each $F B(i)$

set CONSTRAINT $=$ null

for each plan period $(j)$

$$
\text { CONSTRAINT }=\text { CONSTRAINT }+B_{i, j}
$$

next plan period

write CONSTRAINT as "CONSTRAINT $=$ CONSTRAINT $<=1$ " to memory

next FB 
Non declining volume flow of harvest constraint formulation algorithm

Let CONS1 and CONS2 be temporary storage for constrains.

let $C_{i, j}$ be variable to denote harvest benefit by harvesting block $i$ at time period $j$ (can be read from database or growth function)

let $B_{i, j}$ be variable to denote harvest of block $i$ at time period $j$

for each plan period $(j): 1<=j<=P(P$ is total number of plan period $)$

Set CONSTRAINT, CONS1 and CONS2 to null

for each $F B(i)$

if $([j+1]<P), C O N S 1=C O N S 1+C_{i, j} * B_{i, j}$ and $\operatorname{CONS} 2=\mathrm{CONS} 2+C_{i, j+1} * B_{i, j+1}$ next $F B$

write constraint to memory as "CONS1 <=CONS2" to memory

next plan period

Integer restrictions are imposed by assigning all the variables ( $B_{i j}$ to integer type) in MILP model. The SMZ and BMP related constraints were included in stand preparation and harvest simulations.

\subsection{System interface and application}

The system runs on MS Windows compatible machines. Upon execution of the program, an input screen is displayed (Fig. 2.4) in which parameters described in Table 2.1 are to be either entered or selected. 
Table 2.1 Description of inputs in the system.

\begin{tabular}{|c|c|}
\hline Parameter & Description \\
\hline Make neighbor & $\begin{array}{l}\text { Neighborhood information is retrieved from a text file and stored in } \\
\text { database. }\end{array}$ \\
\hline Adjacency restriction & If adjacency restriction is required, it needs to be enabled. \\
\hline Maximum opening area & Enter maximum allowable clear cut size. \\
\hline Enforce green-period & If green up restriction is required. \\
\hline $\begin{array}{l}\text { Temporal optimization } \\
\text { model }\end{array}$ & $\begin{array}{l}\text { (a) Harvest as soon as possible - This method will generate a schedule in } \\
\text { such a way that all the stands are harvested based on given spatial } \\
\text { restrictions without having to distribute harvesting activities throughout } \\
\text { the planning horizon; } \\
\text { (b) Harvest when values are maximized under given restrictions. }\end{array}$ \\
\hline Discount rate & $\begin{array}{l}\text { Discount rate in the range of 0-100 applicable to obtain NPV from } \\
\text { harvesting. }\end{array}$ \\
\hline $\begin{array}{l}\text { Objective type } \\
\text { (maximizes) }\end{array}$ & $\begin{array}{l}\text { (a) - Model type I : Benefits from timber harvesting; (b) - Model type II : } \\
\text { Benefits from timber harvesting and C stock at the time of harvest; (c) - } \\
\text { Model type III: Benefits from timber harvesting and long term C } \\
\text { sequestration. }\end{array}$ \\
\hline Allowed deviation & $\begin{array}{l}\text { Relates to non-declining benefits from harvested volume. Enter } 0 \text { if strict } \\
\text { restrictions are imposed; Enter "-9" for disabling this restriction; Enter any } \\
\text { value in range of } 1-100 \text { for allowable deviation percent. }\end{array}$ \\
\hline
\end{tabular}




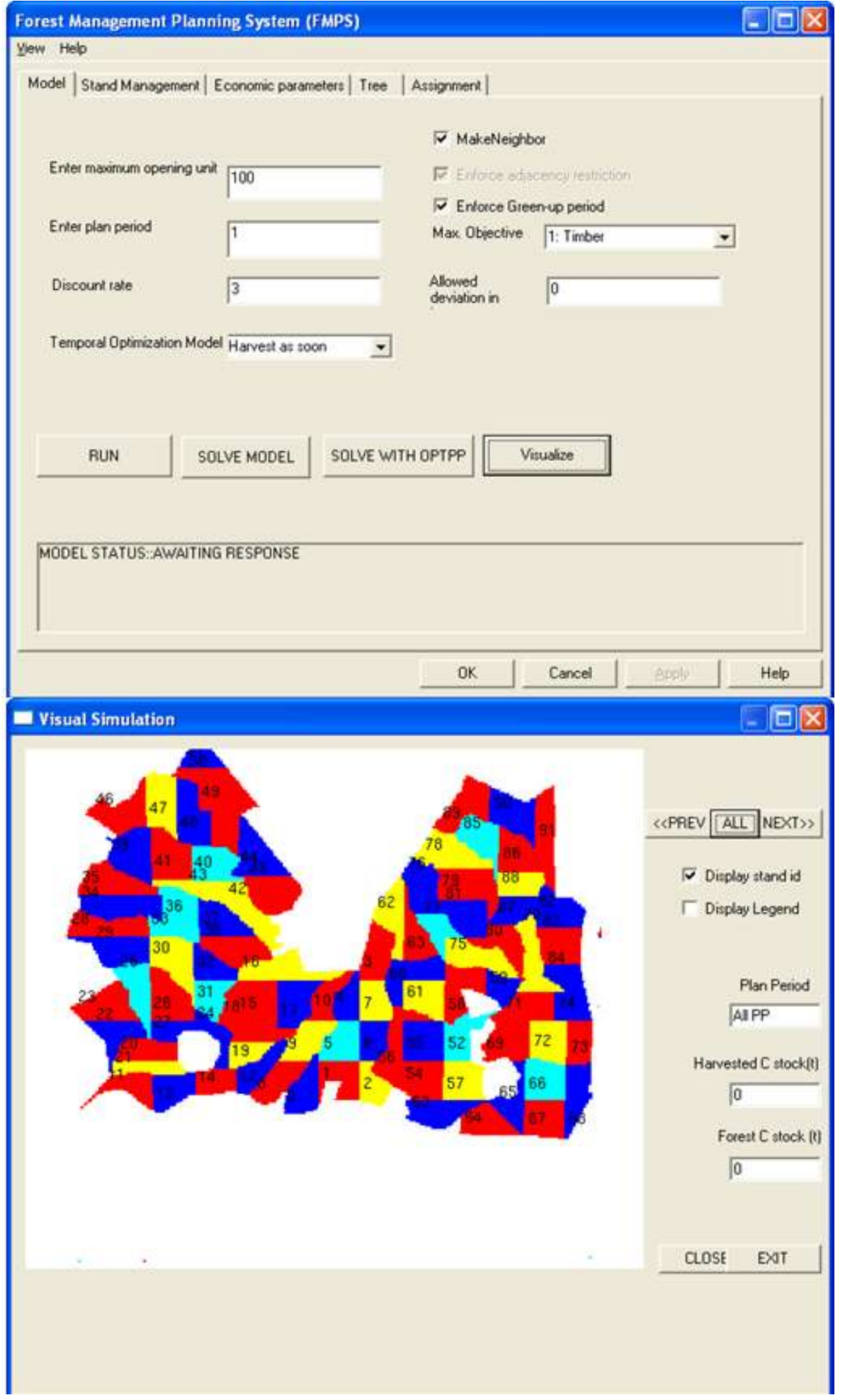

Figure 2.4 System interface and visualization window. 
Three execution modes are available. Button "Run" will generate the model of structure described earlier, which can be exported and saved. Button "Solve" will solve the model and save the resulting schedule in the database. Once schedules were generated, visual simulation window can be activated by clicking "Visualize" button. Different planning periods can be navigated in the visual window with information on removed $\mathrm{C}$ and existing $\mathrm{C}$ for the entire forest. Menu "Help" opens general help topics related to system applications. This system has been used to generate 6 different harvest scenarios for 3,035 hectares mixed hardwood forest comprised of 92 different stands in West Virginia, USA. The forest is an uneven aged forest with variability in species composition, structures, growing stock and age.

Different sets of harvest situations were created following the modeling approaches (Table 2.2).

Table 2.2 Descriptions of different clear-cut harvesting strategies.

\begin{tabular}{|c|c|c|c|c|c|c|c|}
\hline \multirow{2}{*}{ Description } & \multicolumn{6}{|c|}{ Harvest Strategy (Model) } & \multirow[b]{2}{*}{6} \\
\hline & 0 & 1 & 2 & 3 & 4 & 5 & \\
\hline Maximizes timber production at harvest year & N/A & Y & $\mathrm{Y}$ & $\mathrm{Y}$ & $\mathrm{Y}$ & Y & $\mathrm{Y}$ \\
\hline Maximizes stand carbon at harvest year & N/A & Y & $\mathrm{Y}$ & $\mathrm{Y}$ & $\mathrm{N}$ & $\mathrm{N}$ & $\mathrm{N}$ \\
\hline Maximizes stand carbon after recovery period & N/A & $\mathrm{N}$ & $\mathrm{N}$ & $\mathrm{N}$ & $\mathrm{Y}$ & Y & $\mathrm{Y}$ \\
\hline Adjacency restriction & N/A & Y & $\mathrm{Y}$ & $\mathrm{Y}$ & $\mathrm{Y}$ & Y & $\mathrm{Y}$ \\
\hline Enforce green up restriction and BMP* & N/A & Y & $\mathrm{Y}$ & $\mathrm{Y}$ & $\mathrm{Y}$ & Y & $\mathrm{Y}$ \\
\hline Enforce even flow of volume $* *$ & N/A & $\mathrm{N}$ & $\mathrm{Y}$ & $\mathrm{N}$ & $\mathrm{Y}$ & $\mathrm{N}$ & $\mathrm{Y}$ \\
\hline Number of planning periods\# & N/A & 8 & 8 & 8 & 8 & 8 & 8 \\
\hline Maximum opening restriction+ & N/A & Y & $\mathrm{Y}$ & $\mathrm{Y}$ & $\mathrm{Y}$ & $\mathrm{Y}$ & $\mathrm{Y}$ \\
\hline Discount rate for NPV estimation & N/A & Y & $\mathrm{Y}$ & $\mathrm{Y}$ & $\mathrm{Y}$ & Y & $\mathrm{Y}$ \\
\hline Model type & N/A & I & I & II & II & III & III \\
\hline
\end{tabular}

Y: yes; N: no; *Green-up restriction of 5 years or 1 plan period; ** Even flow of volume with $15 \%$ deviation; \# planning period is of 5 year long; + opening size of 40.47 ha. Model 0 is "no-harvest" case. 
The average annual $\mathrm{C}$ sequestration rate and long term total $\mathrm{C}$ stock i.e., $\mathrm{C}$ in harvested wood and standing C in forest after 200 years is higher in harvested forest than in forest without harvest (Table 2.3). Although all models representing different objective functions and restrictions described in Table 2.2 eventually cumulate towards one flat line after a long time period, their dynamics were completely different prior to achieving the final stable rate. For example, model 1 showed high early $\mathrm{C}$ stock, followed by a low $\mathrm{C}$ stock and model 5 had early lower net $\mathrm{C}$ stock followed by higher $\mathrm{C}$ stock in later years (Fig 2.5). C stock in harvested volume and harvested areas were similar in different strategies, implying that either of the strategies can be used from a production perspective.

Table 2.3 Summary of $C$ sequestration rate, standing $C$ stock and harvested $C$ stock.

\begin{tabular}{|c|c|c|c|c|c|c|c|}
\hline & \multicolumn{7}{|c|}{ Strategies } \\
\hline & 0 & 1 & 2 & 3 & 4 & 5 & 6 \\
\hline & \multicolumn{7}{|c|}{ C stock $(1000$ tC) } \\
\hline $\mathrm{C}$ in harvested wood & - & 267 & 267 & 268 & 265 & 252 & 256 \\
\hline $\mathrm{C}$ stock after stands are recovered & - & 275 & 287 & 268 & 270 & 311 & 298 \\
\hline C stock after 200 years period & 767 & 562 & 565 & 560 & 560 & 575 & 570 \\
\hline \multicolumn{8}{|c|}{ Mean annual C Sequestration rate (tC/ha/year) } \\
\hline Maximum & 0.72 & 1.43 & 1.43 & 1.51 & 1.46 & 1.48 & 1.41 \\
\hline Average & 0.44 & 0.52 & 0.62 & 0.47 & 0.49 & 0.79 & 0.69 \\
\hline Median & 0.44 & 0.86 & 0.86 & 0.89 & 0.89 & 0.89 & 0.86 \\
\hline Minimum & 0.15 & -4.82 & -2.94 & -6.05 & -4.32 & -1.73 & -2.77 \\
\hline
\end{tabular}

Strategy 0 is "no-harvest case", negative minimum sequestration depicts emission

The forest remains as a net emitter of carbon for an extended period of time if the stands are harvested to maximize the stand $\mathrm{C}$ at harvesting time (models 3 and 4 ) or only timber production (models 1 and 2) is maximized. On the other hand, net sequestration of forest stands becomes positive earlier if stands are harvested by including future $\mathrm{C}$ stock in objective function (models 5 and 6 ) as stands that have 
high potential for future $\mathrm{C}$ sequestration are harvested earlier rather than to wait for benefits from timber. Even flow of volume restrictions had negative consequences in terms of net annual sequestration. If the forests are managed for $\mathrm{C}$ sequestration and timber production, overly regulating the forests would reduce the sequestration capacity of forests. The non-declining yield pattern might be advantageous for forests managed solely for timber production but not if the objective is also to sequester more carbon.

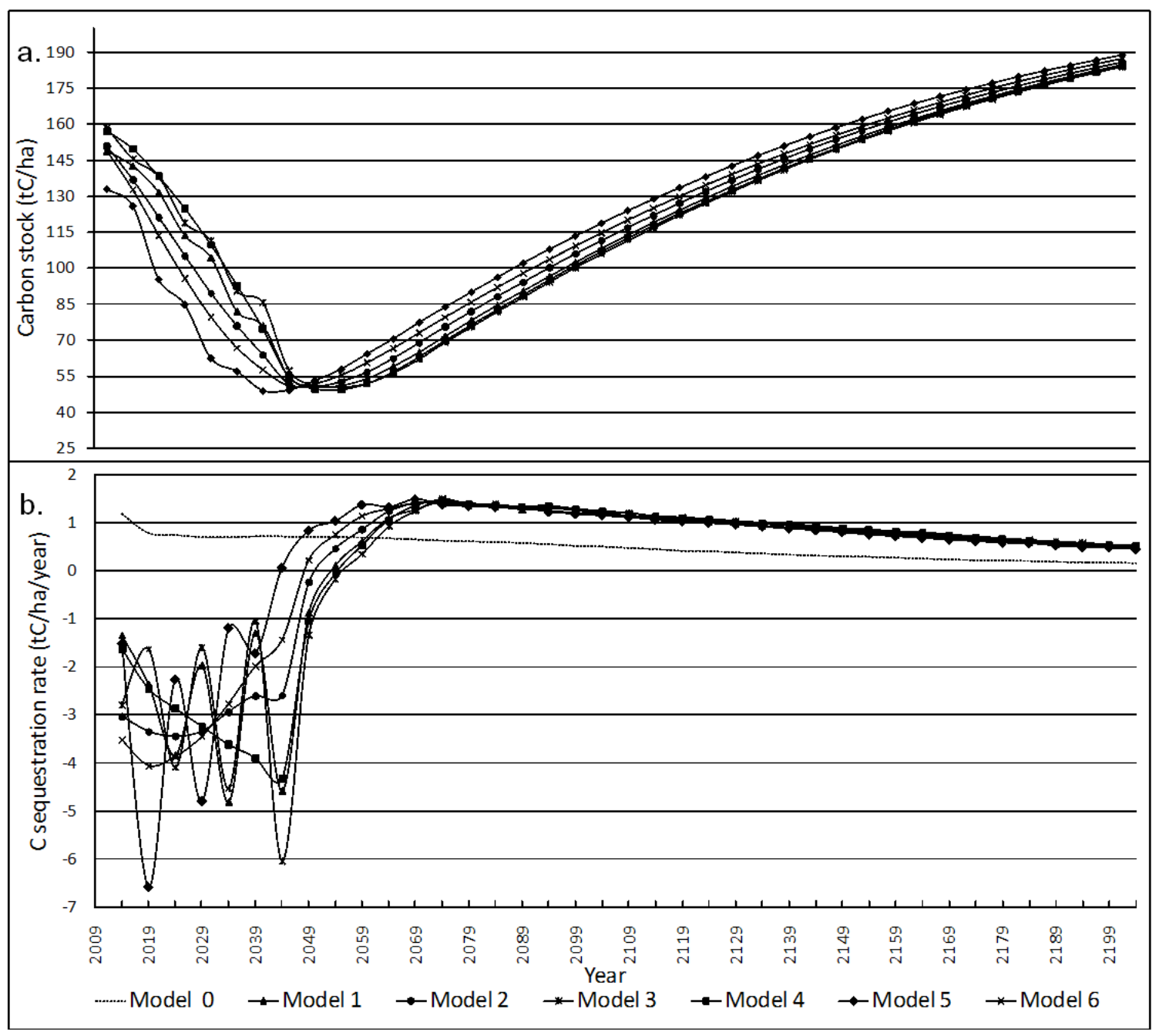

Figure 2.5 Carbon sequestration rate (tC/ha/year) (a) and long term carbon stocks (b) under different harvesting strategies. 
It was shown that if timber and/or stand carbon is considered only at the time of harvest, the future carbon of the forests is unknown to the model during optimization process and thus may result in lower C stock of the stand in the future. Resources planners and managers rarely examine the long-term consequences of specific harvest strategies or compare the impacts of alternative approaches in both a spatial and temporal context because of lack of such analytical tools and basic scientific information (Gustafson and Crow 1994). At the present time, simulation systems are available built upon knowledge acquired throughout the past half century on growth dynamics of forest ecosystems which allow us to predict the effect of certain management activities on the future of forest and to optimize activities as demonstrated in this study. In dealing with uncertainty with $\mathrm{C}$ projections, several approaches have been applied in this study such as using large sample size and multiple simulation results. Sampling error was assumed minimum given the size of the sample for the entire forest. Estimates of growth and yield were obtained from Forest Vegetation Simulator (FVS) which contains a self-calibration feature to reflect local deviations from the regional growth trends and default randomization to account for stochastic variations in forest growth (Crookston and Dixon 2005) to deal with uncertainty in projection.

\subsection{Conclusions}

The system can be used in generating, solving and interpreting results and visualization of harvesting for different forest operational problems without having to understand the complexities of the optimization process. The possible future enhancements to the current system include embedding partial cut methods and cost estimation of applicable activities under a range of conditions. Currently, visualization has only been made at the stand level in 2 dimensions. This component is under development and a future version will incorporate trees with diameter and height as well as topography to generate a 3-dimensional visualization model for this system. Such enhancements would greatly improve the system's applicability. The software (current and future versions) is and will be available to researchers and interested users upon request. 


\section{References}

Buongiorno, J., Gilless, J.L. 2003. Decision Methods for Forest Resource Management, Academic Press, San Diego, CA.

Crookston, N.L, Dixon, G.E. 2005. The forest vegetation simulator: A review of its structure, content, and applications. Computer and Electronics in Agriculture 49:60-80.

Frakes, I., Bugg, A.L. 2001. Optimizing algorithms for forest planning and decision-making. New Zeland Journal of Forestry 45: 5-9.

Gustafson, E.J., Crow, T.R. 1994. Modeling the effects of forest harvesting on landscape structure and the spatial distribution of cowbird brood parasitism. Landscape Ecology 9:237-248.

Hokans, R.H. 1983. Evaluating spatial feasibility of harvest schedules with simulated stand selection decisions. Journal of Forestry 81:603-613.

Hyams, D.G. 1997. CurveExpert Version 1.3 - A comprehensive curve fitting system for Windows. available at http://curveexpert.webhop.biz/.

Lockwood C., Moore, T. 1993. Harvest scheduling with spatial constraints: a simulated annealing approach. Canadian Journal of Forest Research 23:468-478.

Luppold, W. 1996. Structural changes in the Central Appalachian hardwood sawmilling industry. Wood and Fiber Science 23:346-355.

McGill, D.E., Rebain, S., Braze, J. 2002. Harvest scheduling with area based adjacency constraints. Forest Science 48:631-642.

Murray, A.T., Church, R.L. 1996. Analyzing cliques for imposing adjacency restrictions in forest models. Forest Science 42:166-175.

Noble, I., Apps, M., Houghton, R., Lashof, D., Makundi, W., Murdiyarso, D., Murray, D., Sombroek, W., Valentini, R. 2000. Implications of different definitions and generic issues. IPCC Special Report Land Use, Land-Use Change and Forestry, Cambridge University Press, NY. 
Sharma, B.D., Wang, J., Brooks, J.R. and Miller, G. 2009. Optimizing forest harvest strategies for timber production and carbon sequestration. Paper presented at 2009 Society of American Forester's Annual Convention, in Orlando, FL.

Wang, J., Ledoux, C.B. 2003. Estimating and validating ground-based timber harvesting production through computer simulation. Forest Science 49:64-76.

Wang, J., Sharma, B.D., Li, Y., Miller, G. 2009. Modeling and validating spatial patterns of a 3D stand generator for central Appalachian hardwood forests. Computer and Electronics in Agriculture 68: 141-149.

Ware, G.O., Clutter, J.L. 1971. A mathematical programming system for the management of industrial forests. Forest Science 17:428-445. 
\begin{tabular}{lllllll} 
3. EVALUATING FOR EST HARVEST STRA TEGIES TO \\
\hline
\end{tabular}

\begin{tabular}{lllll} 
ENHANCE & TIMBER PRODUCTION & A N D & CAR B O N \\
\hline
\end{tabular}

$\underline{\text { SE Q U E S T R A T I O N }}$

\begin{abstract}
With increasing concerns on global green house gases and emerging carbon markets, additional carbon (C) sequestered as a result of sustainable forest management activities can be of significant benefit to forestland owners. Different harvesting strategies under clearcut and selection cut methods were developed and evaluated to obtain optimal benefits in terms of timber production and carbon sequestration applicable to large scale forest management practices for a mixed hardwood forest in West Virginia. Each of these objectives was optimized using mixed integer linear programming (MILP) models under a set of constraints. Higher $\mathrm{C}$ sequestration rate can be achieved by maximizing current harvested volume and future $\mathrm{C}$ stock when stands recover from the disturbance effects of harvesting in both selection cut and clearcut methods without undermining the potential benefits from merchantable timber production.
\end{abstract}

\footnotetext{
${ }^{2}$ Planned for submission to Forest Science
} 


\subsection{Introduction}

Studies have shown that managed forests can increase carbon (C) sequestration in the long run (Papadopol 2000, Ney at al. 2002, Meng et al. 2003) as compared to mature forests in biological equilibrium. Forests in such biological equilibrium often return $\mathrm{C}$ to the atmosphere due to death, decomposition and other adverse outbreaks (Kurz and Apps 1999) and are often more vulnerable to natural disturbances. A significant proportion of mature old forest exists when forest growth to removal ratio stays over 1 for an extended period of time, as in the case of forests in West Virginia (WV). Forest harvests can be viewed as investments in order to establish a new stand with higher potential for biomass growth in the future (Hoen and Solberg 1994) and to reduce risks of adverse outbreaks (Routledge 1980) along with other direct benefits in terms of timber production and atmospheric $\mathrm{C}$ sequestration. When forests are managed for both timber production and $\mathrm{C}$ sequestration, management requires strategies that can enhance net $\mathrm{C}$ sequestration i.e. both harvested volume and standing $\mathrm{C}$ stock sustainably. Different forms of mathematical programming have been used to generate harvest schedules as bi-criteria objective function by combining $\mathrm{C}$ benefit from harvested volume and forest $\mathrm{C}$ stock at the time of harvest for the management plan period (Hoen and Solber 1994, Diaz-Balteiro and Romero 2003, Backeus et al. 2005). These studies have illustrated methods and subsequent results from regulated forests composed of one or two species where stand to stand $\mathrm{C}$ sequestration potential following harvest activities are likely to be similar. When forests grow with similar rates over different time periods and where stand to stand sequestration rates do not vary considerably following harvest activities, simply optimizing harvested volume and standing $\mathrm{C}$ stock on or after harvesting would be sufficient. However, when stand to stand growth characteristics and sequestration rates vary over the time periods and also due to harvesting, stands would have different sequestration potentials determined by site quality, species composition, ability to tolerate disturbance effects and interactions of existing ecological conditions and processes such as competition, light availability, mortality and others. In such forests, if $\mathrm{C}$ stock is optimized merely at the harvest period without considering the future stocks, the $\mathrm{C}$ sequestration is high only for that time 
period and may have lower $\mathrm{C}$ sequestration in following years undermining the true $\mathrm{C}$ sequestration potential. Therefore appropriate techniques to incorporate the dynamics of stand carbon stock after harvesting into harvest schedule optimization for mixed forest was deemed necessary. This paper illustrates one possible approach that has not been described in the literature and which showed promising results to optimize $\mathrm{C}$ sequestration in mixed forests in WV.

\subsection{Methods}

\subsubsection{Forest harvest optimization problem}

Forest management for timber and $\mathrm{C}$ sequestration aims at maximizing the yields from harvest volume and $\mathrm{C}$ sequestration over time. In such a forest management, the harvest schedule optimization process has to deal with spatially distributed stands and its benefits over a temporal planning horizon. This space-time problem was approached with mixed integer linear programming (MILP) model to generate schedules to identify combinations of available stands and time periods within planning horizon (i.e. the length of rotation) for harvesting so that timber benefits and forest $\mathrm{C}$ stock are simultaneously maximized under prevailing restrictions. In MILP model, the result is determined by the defined objective function and subjected constraints. There are several ways objective functions can be formulated to maximize timber benefits and $\mathrm{C}$ sequestration in forest. The first method uses net present value (NPV) of harvested timber (or $\mathrm{C}$ equivalent) from different stands and in different time periods. This approach, which has been used in traditional harvest schedule generation, is suitable for enhancing $\mathrm{C}$ sequestration when stands in forests are of same size and sequestering carbon at the same rate, irrespective of timing of harvest which can be expected in plantation forests where trees are grown in similar patches, in uniform spacing and under short rotation. This situation is a rare case of forest management but theoretically it is possible that such a forest can exist. In the second method, the objective function combines the NPV of removed carbon and residual stand $\mathrm{C}$ at the time of harvest. When all the stands have similar or equal 
potential of $\mathrm{C}$ sequestration rate over time but their sizes are different then harvesting one stand at one time may have different $\mathrm{C}$ sequestration potential than harvesting that stand at other time period. When stand to stand $\mathrm{C}$ sequestration potential varies only by size and not by disturbing effects of harvesting i.e., stands would grow approximately at similar rates after harvests in different time periods. Such growth can be expected in regulated industrial plantations with little species diversity. In such forests, maximizing C sequestration at any time (on or after harvest time) and timber benefits at harvesting time would give similar results.

These two methods have been found useful in forests composed of one or two species (Van Deusen 1999, Diaz-Balteiro and Romero 2003, Maness and Ferrel 2004). Related with these two methods, a third method can be derived in which NPV of harvested carbon and stand C stock after stands have regained the $\mathrm{C}$ stock to the harvest level is maximized which can give better schedule in situations when stand to stand $\mathrm{C}$ sequestration potential vary over different time periods i.e., stand would behave differently following any disturbance, typical characteristics of mixed hardwood forests. In such forests, C sequestration potentials of different stands do not remain consistent for a long time period. One stand could have more carbon than another stand at one time period and this trend may reverse at another time period once harvested. Thus, optimal $\mathrm{C}$ stock at one point of time may not remain optimal at another point. When stands obtain the full growth potential, they start to show differences in $\mathrm{C}$ sequestration potentials if applicable. The difference in $\mathrm{C}$ sequestration is likely to remain wider until stands reach biological maturity. Thus, if harvesting activities are scheduled such that $\mathrm{C}$ stock is maximized after stands have surpassed the inconsistent growth and before they have reached biological maturity points, the obtained schedule would remain optimal for the entire duration. This approach is further illustrated with sample and applicable mathematical formulations.

In Fig. (3.1), two different scenarios are presented involving two different stands. Fig. 3.1b shows $\mathrm{C}$ sequestration by two stands which are similar in terms of their $\mathrm{C}$ sequestration potentials. Two harvest scenarios are created that will give the same results irrespective of what future point of time is selected to maximize the $\mathrm{C}$ sequestration. However, it can be seen in Fig. 3.1a that maximizing any point in the 
future for $\mathrm{C}$ sequestration may result in different optimal schedules depending on where the $\mathrm{C}$ stock is maximized. Thus, if future $\mathrm{C}$ stock of stand after harvest is maximized at a point in time when stand to stand C sequestration is widely differentiated, then the chosen schedule is likely to be optimal. Such a point can be observed in the mid-successional stage of the stand because stands show similar growth characteristics during early and late-successional stages. For example, stand 1 is always sequestering $\mathrm{C}$ at a higher rate than stand 2 if it is harvested in 2009 or in 2044. But the presence of mixed species and tolerance of different species may change the dynamics of forest and it may start growing differently i.e. stand 2 may be sequestering more C than stand 1 if harvested in 2044 rather than in 2009.
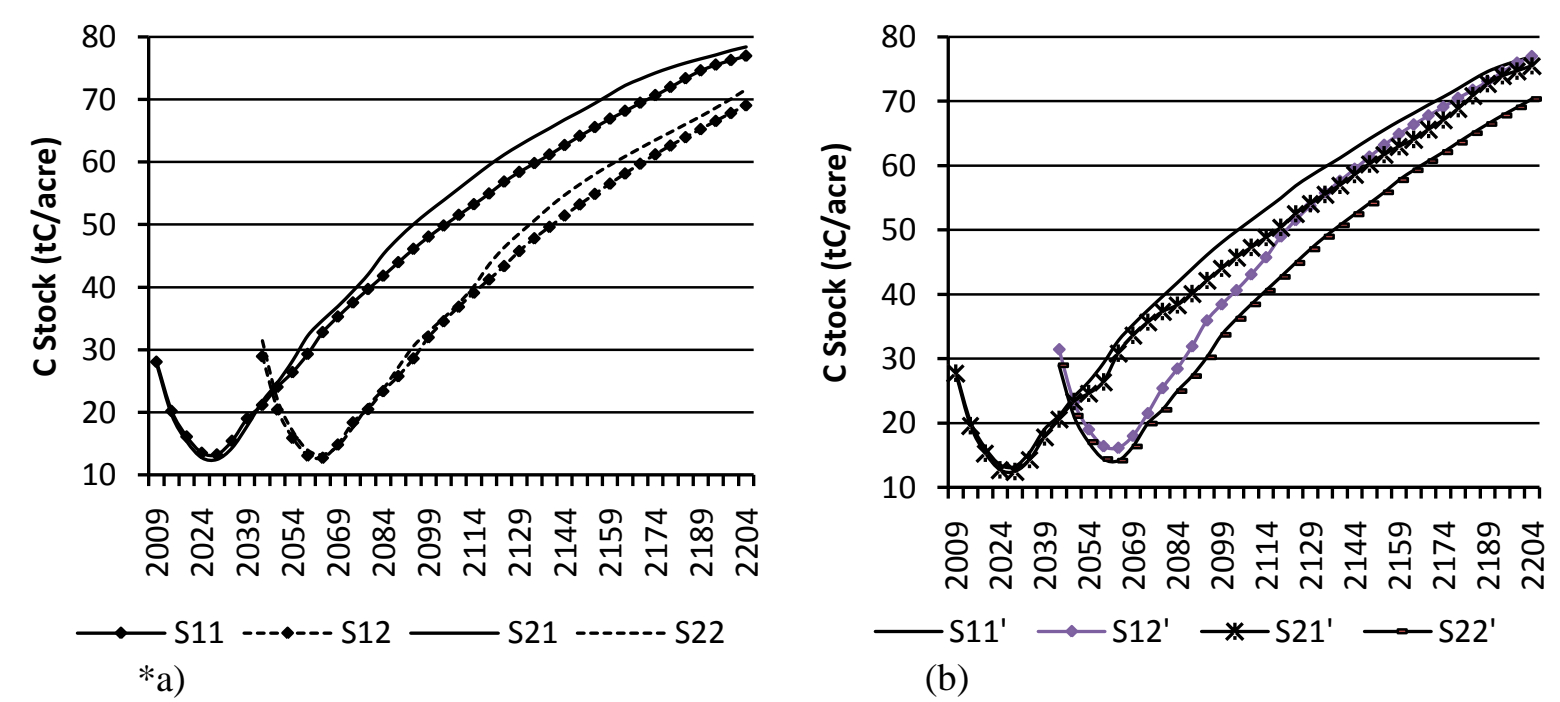

Figure 3.1 Growth characteristic illustrations of 2 pairs of stands. (a) Stand 1 and 2 show different growth characteristics after they are harvested in different time periods (b) Stand 1 and 2 show similar growth characteristics after harvesting at any time period.

The illustrated approach can be defined in mathematical formulations. The approach is briefly illustrated in section 2.2.1 but for clarity, a quick overview is also presented here. Let a stand be harvested in time period $t$ and merchantable volume removed is $H C$. The $\mathrm{C}$ stock initially could decline due to death and decay following harvest activities. The decline in $\mathrm{C}$ stock in the forest comes from decaying roots, branches, and leaves as well as small understory cover which has been sheltered by the overstory. The 
decline in $\mathrm{C}$ stock following harvests has been supported by several other authors (Plantinga and Birdsey 1993, Liu and Han 2009). When the forest stand is clear-felled, the non-merchantable live growing stock which would have been sequestering carbon in the forest would eventually be removed which would start emitting carbon lowering the net $\mathrm{C}$ sequestration of forest immediately after harvest. New growth over time may accrue until the net emission from decaying biomass is surpassed by net sequestration live components. The decline might be less severe in conifers in which the forest floor is relatively covered with resinous litter. The understory vegetation upon harvesting is assumed to be removed during site preparation for the next rotation. Thus, with regeneration and new growth, the stand $\mathrm{C}$ stock would begin to increase (net $\mathrm{C}$ sequestration becomes positive) and equal or exceed the $\mathrm{C}$ level that was present at the time of harvest after certain period of time. Let function $f(x)$ be a function of time on $\mathrm{C}$ stock of forest stand following harvest, i.e. $f(x=0)$ is $\mathrm{C}$ stock remaining in the stand at the time of harvest. As $\mathrm{C}$ stock declines following harvest, $f(x=0)$ is greater than $f(x>=0)$ for certain time periods during which $\Delta f(x>0)$ is negative and continues to be negative until sometime $t$ has passed at which time i.e. at $x=t>0, \Delta f(x=t>0)$ becomes positive and net sequestration becomes positive which continues to rise until biological maturity is reached at time $T$. Between $t$ and $T$, there is point $t^{\prime}$ in this function such that mentioned in Eq. (3.1).

$$
f(x=0) \geq f(x=t>0) \text { and } f(x=t) \leq f\left(x=t+\Delta t=t^{\prime}\right)
$$

The $t$ ' is considered a recovery time period at which point, the stands have regained $\mathrm{C}$ stock to a level it had at after harvesting merchantable volume. From time $t$ to $T$, the net sequestration continues to increase given that there are no other disturbances and outbreaks. Traditional harvest scheduling activities maximize $H C$ from a stand. Some recent studies have combined $\mathrm{C}$ stock of the stand at the time of harvest into the objective function (Meng et al. 2003, Diaz-Balteiro and Romero 2003). If C stock of the stand is maximized at $x=0$, the $\mathrm{C}$ stock will decline after the end of the planning period. However, if $\mathrm{C}$ stock is maximized at $x=t^{\prime}$, the $\mathrm{C}$ stock will keep increasing in all the stands in the next planning horizon or rotation. If an average recovery time period is identified for all the stands harvested in different time 
period and $\mathrm{C}$ stock at time t' after the last harvest occurs is maximized, the net sequestration rate for the forest would remain high. This happens because at the time when optimization process achieves a maximization solution, none of the stands would have $\mathrm{C}$ negative phase, all the stands would have surpassed disturbance effects, and stands are growing at their fullest potential. So future stock at any time between $t$ and $T$ can be used to optimize the future $\mathrm{C}$ stock but time $t^{\prime}$ can easily be identified from the simulation. In this paper, this quantitative measure of such a future time is called "recovery period" to imply that at this point all the stands would have recovered from the disturbance effect of harvesting. For model simplification, instead of using stand to stand recovery rate, average recovery period for the entire forest can be used. The Spatio-temporal optimization process thus can generate schedules that direct harvesting stands from different spatial location in different time period with a given harvesting method to simultaneously maximize benefits from timber harvests and $\mathrm{C}$ sequestration potential of the forest.

Several restrictions which include limits on maximum clearcut size, green-up delay, evenflow of volume from harvested products (Ware and Clutter 1971; Buongiorno and Gilless 2003) and others to meet the desired management practices are included as constraints in the MILP model. Maximum clearcut size restriction requires that multiple contiguous stands cannot be harvested if their combined area exceeds the allowable clearcut size. The green-up delay restriction imposes a restriction on harvesting neighboring stands that have been harvested within delay period. Even flow of volume restriction is usually imposed when a continuous supply is sought from the forest for the duration of the management plan.

\subsubsection{C stock estimation and projection}

Full carbon accounting approach by calculating $\mathrm{C}$ stocks in different forest ecosystem components were (Noble et al., 2000) used in estimating sequestered C stocks (Eq. 3.2).

$$
T C_{t}=T L_{t}+B L_{t}+B D_{t}+S D_{t}+D D W_{t}+S H_{t}+F F_{t}
$$


where $T C_{t}$ is total $\mathrm{C}$ stock in forest at time $t, T L_{t}$ is total carbon stored in living biomass in trees (above ground including both merchantable and non-merchantable portions of tree biomass) at time $t$ in tons, $B L_{t}$ is carbon stored in live component on below ground biomass, $B D_{t}$ is the carbon stored in dead below ground biomass component, $S D_{t}$ is carbon stored in standing dead tree biomass, $D D W_{t}$ is carbon stored as down dead wood above ground, $S H_{t}$ is the carbon stored in shrub and herbs, and $F F_{t}$ is the carbon stored in the forest floor. The benefits from future harvests were discounted back to present value (Eq. 3.2).

$$
C_{p v}=\frac{C_{t}}{(1+r)^{P} l^{*(t-1)}}
$$

where $\mathrm{C}_{\mathrm{pv}}$ is the present value of $\mathrm{C}, C_{t}$ is $\mathrm{C}$ stock at time $t, r$ is discount rate applied in percentage (i.e. $3 \%), P_{l}$ is length of planning period, $t$ is planning period.

\subsubsection{Data}

Data for this study comes from West Virginia University Research Forest, a mixed hardwood forest, located approximately at $39.66^{\circ} \mathrm{N}, 79.78^{\circ}$ in WV. The forest has 92 cutting units (i.e. equivalent to stands) with areas varying from 7 ha to 41 ha. Forest inventory data from the year 2000 were acquired from West Virginia University (WVU), Division of Forestry and Natural Resources. Each stand had at least over 5 cruise points and altogether 14,008 tree records were available for this study. A description of these stand parameters is given in Table 3.1.

The Forest Vegetation Simulator (FVS) Northeast Variant (NE) with Fire and Fuels Extension (FFE) program was run for the inventoried stand data to simulate the impact of harvesting in different time periods. Outputs requested from simulation were tree records, basal area, volume and $\mathrm{C}$ in different forest components. A planning horizon of 50-year for clear-cut and selection-cut method was selected and another 80-year long horizon for clear-cut was selected for harvest simulations to mimic a long-and short- term management length. Plan periods were 5-years long. Stand harvest simulation were conducted for each stand and for each plan period beginning in 2009. Clearcut simulation included removal of all the 
trees from the stand. Selection cut simulation utilized a structural goal method (Marquis 1978, Guldin 1991), with a q-factor of $3.56 \mathrm{~cm}$ on 5.08 -cm dbh classes, a residual maximum diameter goal of $60.96 \mathrm{~cm}$, and a target residual basal area of $13.77 \mathrm{~m}^{2} / \mathrm{ha}$. Volumes were estimated using National Cruise System (NATCRS) available in FVS-NE-FFE. Several runs of FVS were conducted to account for projection variability. Natural regeneration was assumed to take place beginning in the same plan period after harvest. Besides the harvest simulation, a base case - no harvest scenario for the same forest was simulated where no harvesting activities was allowed.

Table 3.1 Descriptive statistics for the stand inventory data used in simulation.

\begin{tabular}{lcccccc}
\hline & $\mathrm{N}$ & Mean & StdDev & Maximum & Minimum & Median \\
\hline Number of measurement points & 92 & 21 & 6 & 31 & 5 & 22 \\
\hline Tree height (meter) & 14008 & 18 & 11 & 42 & 0 & 22 \\
\hline Diameter at breast height (cm) & 14008 & 36 & 15 & 132 & 3 & 36 \\
\hline Quadratic mean diameter (cm) & 14008 & 28 & 3 & 36 & 21 & 28 \\
\hline Tree per ha & 92 & 497 & 210 & 1505 & 232 & 439 \\
\hline Basal area (m $/$ ha) & 92 & 30 & 11 & 72 & 11 & 28 \\
\hline Merchantable volume (m ${ }^{3}$ ) & 92 & 1784 & 625 & 4802 & 557 & 1668 \\
\hline Forest C stock (tC/ha) & 92 & 147 & 49 & 363 & 74 & 136 \\
\hline Merchantable C stock (tC/ha) & 92 & 69 & 24 & 170 & 21 & 64 \\
\hline
\end{tabular}

Inventory data collected in year 2000

\subsubsection{Model development}

Three different objective functions, illustrated earlier, were developed in which the first was to maximize the harvested timber benefits; second is to combine stand C stock at the time of harvest and third is to combine stand $\mathrm{C}$ stock at future time (i.e. recovery period) in the objective function. Several 
common restrictive practices were also included (Table 3.2). Two planning horizons i.e., one 50-year long and another 80-year long for clearcut methods and one 50-year long for selection cut method was evaluated. The model type in Table 3.2 is numbered from 0 to 18 and this will be used to denote different harvest strategies throughout this paper.

Table 3.2 Description of different harvesting strategies. This table should be referrenced to identify the applicable constraints and maximization objectives to interpret results in this paper.

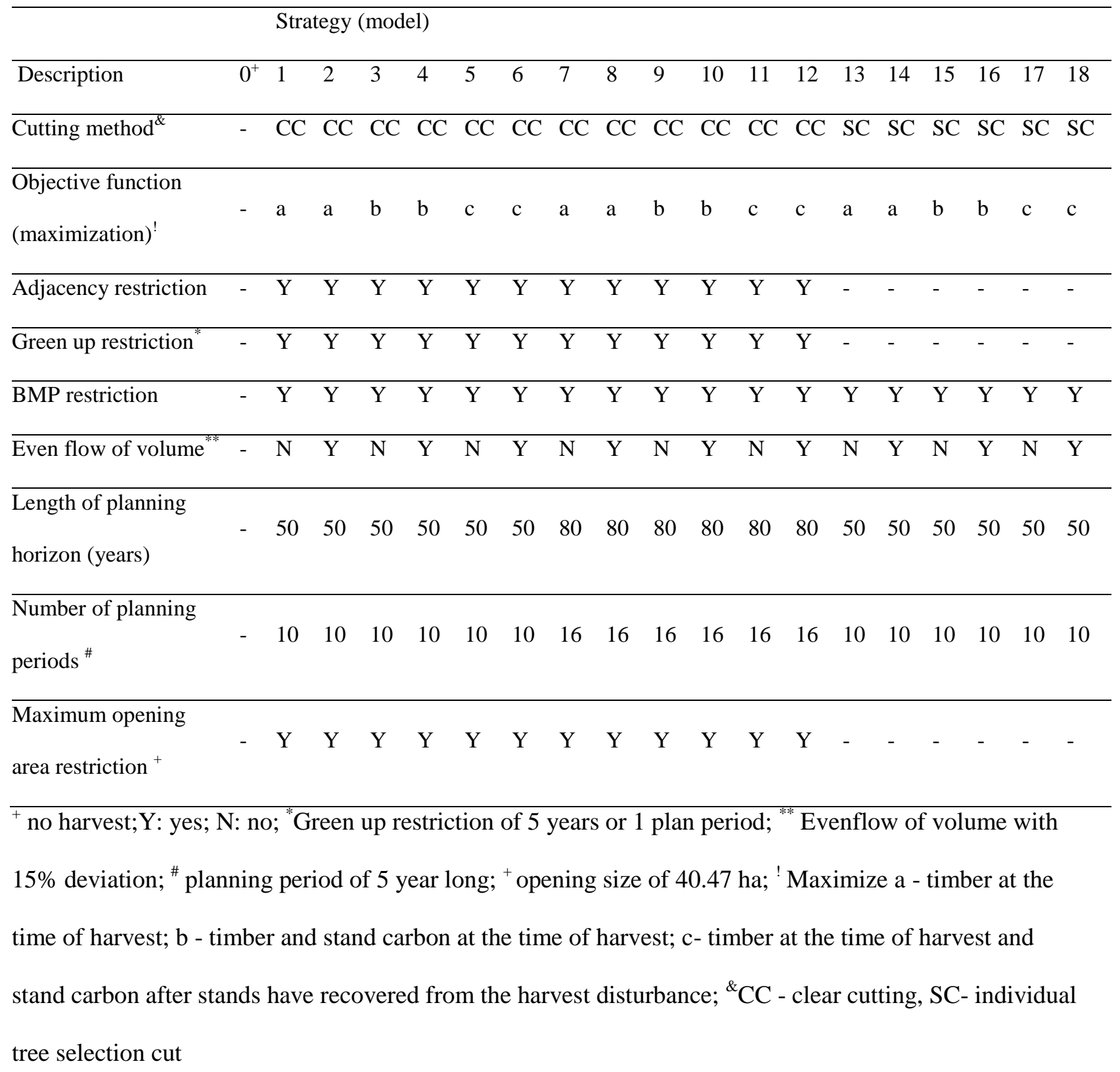


Harvestable units are treated as integer variables in the MILP model. For the clearcut harvest method, multiple contiguous stands can only be harvested at once, only when combined area does not exceed the allowable maximum clearcut size. Such combinations of stands are considered feasible blocks. Several feasible blocks can be formulated depending on the size of individual stand and neighborhood relationship. For example, stand 1 is a neighbor to stands 2, 3, and 4 for the forest in Figure 3.2. When the maximum opening size is 50 hectares, combining stand 1, 2 and 3 does not exceed the limit and therefore, can be harvested together. In this forest, there are eight feasible blocks constituted of stands (1),( 2), (3), $(4),(1,2),(1,3),(2,3)$ and $(1,2,3)$. When two or more stands are combined to form one feasible block, then each stand is considered a member of that block. In order to identify total number of feasible blocks, initially a number of blocks are formed from individual stands, i.e., if there are $\mathrm{n}$ stands, the total number of feasible blocks will be $\mathrm{n}$ at the beginning.

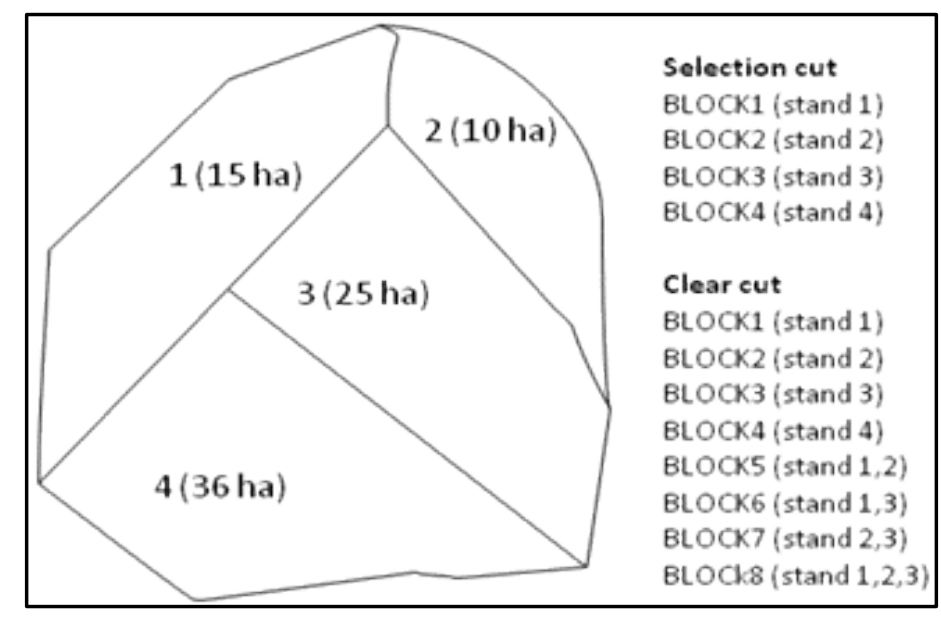

Figure 3.2 Stand and bock relationship under clear cut and partical cut.

(A forest is comprised of 4 stands. Stands are identified with numbers with their area in parenthesis.

Feasible blocks with constituting stands are shown in text. Multiple stands can be included in one feasible block in clear cut method. One stand is one feasible block for selection cut method). 
Once initial blocks are formed (see algorithm in Appendix 3.1) using neighborhood relationship of stands constituting a feasible block, all the neighboring stands are tested one at a time for their combined area. If their combined area is less than the maximum opening area, then these adjacent stands are considered as feasible blocks and are added to the set of BLOCK. Once all the feasible blocks are formulated, mutually exclusive sets of blocks (MEB) are identified. For example, given the adjacency restriction in place, if BLOCK1 is harvested, BLOCK 2 and BLOCK 5 cannot be harvested because this will lead to harvesting BLOCK 1 twice, which is not desirable. Thus, BLOCKs 1,2 and 5 are set of mutually exclusive blocks to enter into MEB. Similarly, given the adjacency restriction, if BLOCK 2 is harvested, only BLOCK 4 can be harvested as other blocks share boundary with this block. Thus, there exist several MEBs for each feasible block (Fig. 3.2).

This formulation technique to model spatial adjacency restriction was described as superior to other comparable methods (Goyocoolea et al. 2009). For the selection cut, there is no restriction on spatial adjacency and green-up delay as none of the stand would be clear-cut and there will always be some green trees in the harvested stand at any time. This also means that for selection cut methods, individual stands are feasible blocks and combination of multiple stands is not necessary. MILP models were generated following the descriptions mentioned in Table 3.2. Objective function formulation is the enumeration of benefits from harvesting particular blocks in different time periods (Eq. 3.4) which is subject to several sets of constraints (Eq. 3.5 - 3.9). A computer program was developed in C++ programming language to generate MILP model and CPLEX 11 (ILOG CPLEX 2008) was utilized to obtain optimal solutions. 
Maximize $z=a * \sum_{j=1}^{T} \sum_{i=1}^{F B} C_{p v_{i j}} * B_{i j}+b * \sum_{j=1}^{T} \sum_{i=1}^{F B} S_{C_{i j}} * B_{i j}+c * \sum_{j=1}^{T} \sum_{i=1}^{F B} S_{C_{i j+r}} * B_{i j}$

If objective is to maximize timber benefits, $a=1, b=0$ and $c=0$;

If objective is to maximize timber benefits and stand $\mathrm{C}, \mathrm{a}=1, \mathrm{~b}=1$ and $\mathrm{c}=0$;

If objective is to maximize timber benefits and stand $\mathrm{C}$ after recovery period, $\mathrm{a}=1, \mathrm{~b}=0$ and $\mathrm{c}=1$

Subject to:

$$
\begin{gathered}
\sum_{j=1}^{T-1} \sum_{i=1}^{F B} B_{i, j}+B_{i, j+1} \leq 1 \forall M E B \\
\sum_{b=1}^{F B} B_{i} \leq 1 \forall T \\
\sum_{i=1}^{F B} \sum_{j=1}^{T}(1-v) H_{i, j} B_{i, j} \leq \sum_{i=1}^{F B} \sum_{j=1}^{T-1} H_{i, j+1} B_{i, j+1} \leq \sum_{i=1}^{F B} \sum_{j=1}^{T}(1+v) H_{i, j} B_{i, j} \\
B_{i, j} \in\{0,1\} \forall F B \\
C_{p v i j} \notin\{S M Z\} \forall F B
\end{gathered}
$$

where $C_{p v i j}$ is net present value of $\mathrm{C}$ by harvesting block $\mathrm{i}$ at plan period j. $B_{i, j}$ is 1 if block $i$ is harvested at plan period $j, 0$ otherwise. $S_{C_{i j}}$ is $\mathrm{C}$ in block $i$ at time $j$ if harvested in time $j . S_{C_{i j+r}}$ is $\mathrm{C}$ in block $i$ after recovery period if harvested in time $j$. $T$ is the total number of planning periods, $R P$ is mean recovery period. $H_{i, j}$ is benefits from harvested wood products from block $i$ at time period $j . v$ is allowable deviation in harvested wood product benefits in percentage. $F B$ is the total number of feasible blocks. $M E B$ is the total number of mutually exclusive feasible blocks. $B_{i}$ is area of block $i$. SMZ is stream side buffer where harvesting or machine operation is limited as per best management practice (BMP) guidelines. The feasible blocks take care of the maximum opening size restriction. Spatio- 
temporal adjacency relationships (Eq. 3.5) were formulated applying the following algorithm from the sets of mutually exclusive blocks. Constraints for restricting multiple harvests of the same stands in different time period (Eq. 3.6) and evenflow benefits from harvest (Eq. 3.7) were generated using available feasible blocks. $F B$ can include more than 1 stand in clearcut method while it can only include 1 stand in selection cut method i.e. for selection cut one stand is same as one feasible block.

\subsubsection{Evaluation}

The generated schedules and resultant $\mathrm{C}$ stock in both harvested timber and stand $\mathrm{C}$ stock were first evaluated descriptively using average, maximum and minimum values. The significance of difference in the achievable timber benefits and stand $\mathrm{C}$ stock under different harvest schedules were tested using a t-test. The effect of different constraints in the schedule generation process was evaluated based on their applicability in different situations. The evaluation process of generated schedules also considered the applicability, potential limitations as well as sensitivity of the model.

\subsection{Results}

\subsubsection{Recovery period}

As expected from a mixed hardwood forest, individual stands would recover at variable time periods. The variability in the recovery periods is higher if the stands are managed for 80 years than that for stands managed for the 50 year planning horizon (Table 3.3). The mean recovery period was lower i.e., 30 years in selection cut method. The low recovery period in selection cut methods is probably due to the fact that only a portion of the standing growing stock is removed which would have thinning-like effect in the stand due to the gap created from the removal. 
Table 3.3 Summary of recovery period in years in two different cutting types.

\begin{tabular}{lccc}
\hline & \multicolumn{2}{c}{ Clearcut } & Selection cut \\
\hline Planning horizon & 50 years & 80 years & 50 years \\
\hline Mean & 45 & 55 & 30 \\
Median & 48 & 50 & 22 \\
Maximum & 75 & 115 & 80 \\
Minimum & 30 & 30 & 15 \\
Standard Deviation & 9 & 14 & 16 \\
\hline
\end{tabular}

\subsubsection{C sequestration under "no-harvest" situation}

When the studied forest was grown without conducting harvest, the net $\mathrm{C}$ sequestration was in the range of $0.13 \mathrm{tC} / \mathrm{ha} /$ year $-0.40 \mathrm{tC} / \mathrm{ha} /$ year. $\mathrm{C}$ stored in dead components is usually emitted to the atmosphere and the new growth occupies the space. C stored in dead components (both below and above ground) remained consistent in the long run i.e. proportion of growth and mortality was similar (Fig. 3.3). Over the years, the stand's merchantable portion remains half of the total C stock in the forest which is candidate removable portions which would otherwise die. 


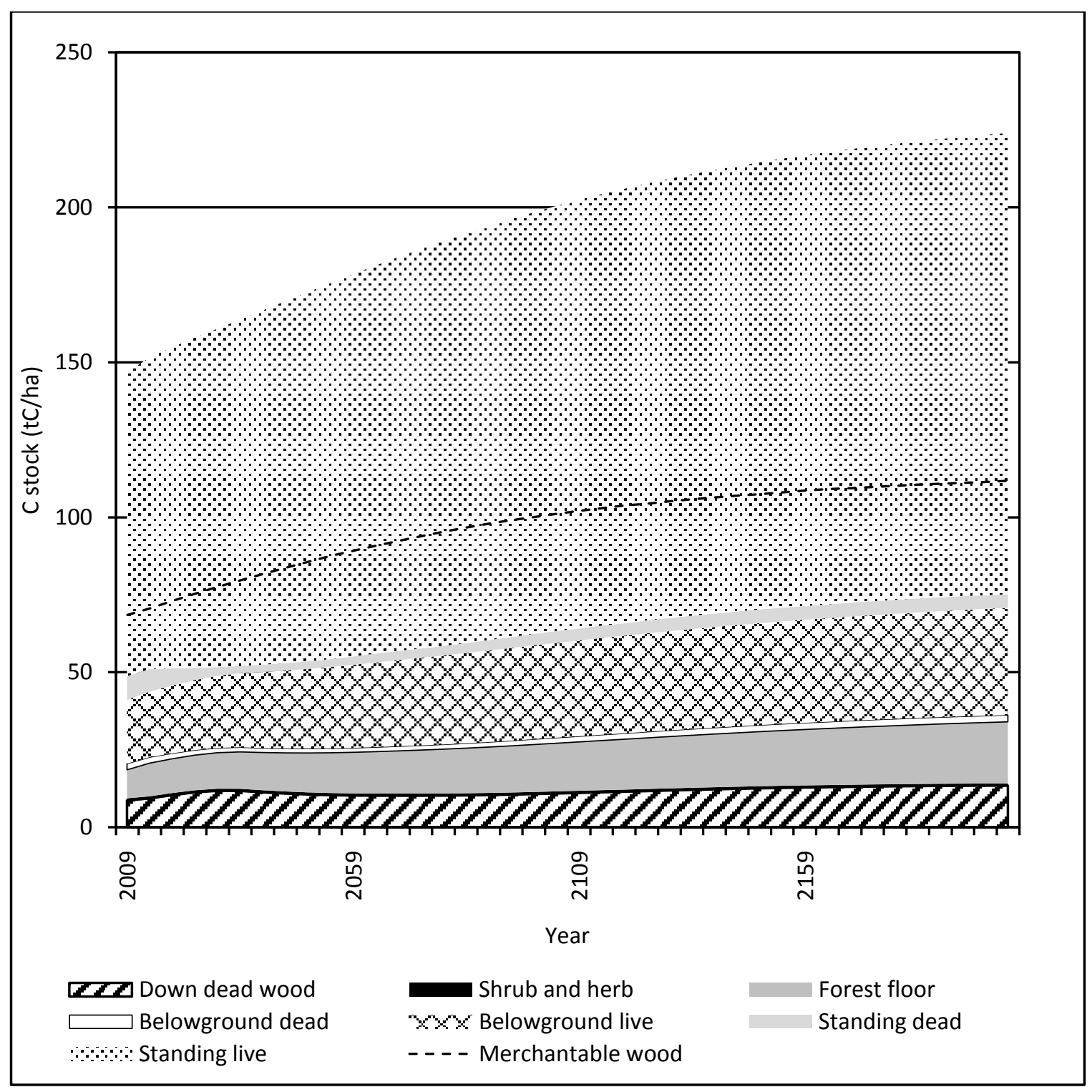

Figure 3.3 C growth in forest for 200 years under "no harvest" scenario in different forest components.

\subsubsection{C stock and sequestration under harvest situation}

Harvested stands show considerately higher $\mathrm{C}$ sequestration rate than "no-harvest" situation. The annual change in forest $\mathrm{C}$ stock varied considerably in different harvest schedules generated. Positive net annual change (Fig. 3.4) and stand C stock (Fig. 3.5) is higher in clearcut methods than in selection cut 
methods. Harvest schedules which have combined timber benefits and $\mathrm{C}$ stock after the recovery period showed highest $\mathrm{C}$ sequestration rate than schedules that used only timber benefits and schedules that used both timber benefits and highest $\mathrm{C}$ stock in residual stands in both clearcut and selection cut methods i.e. model 5, 6, 11, 12, 17 and 18. Although all the strategies tend to achieve similar sequestration rate after a long time period i.e., biological maturity point, their sequestration rate took different path to reach that point. 


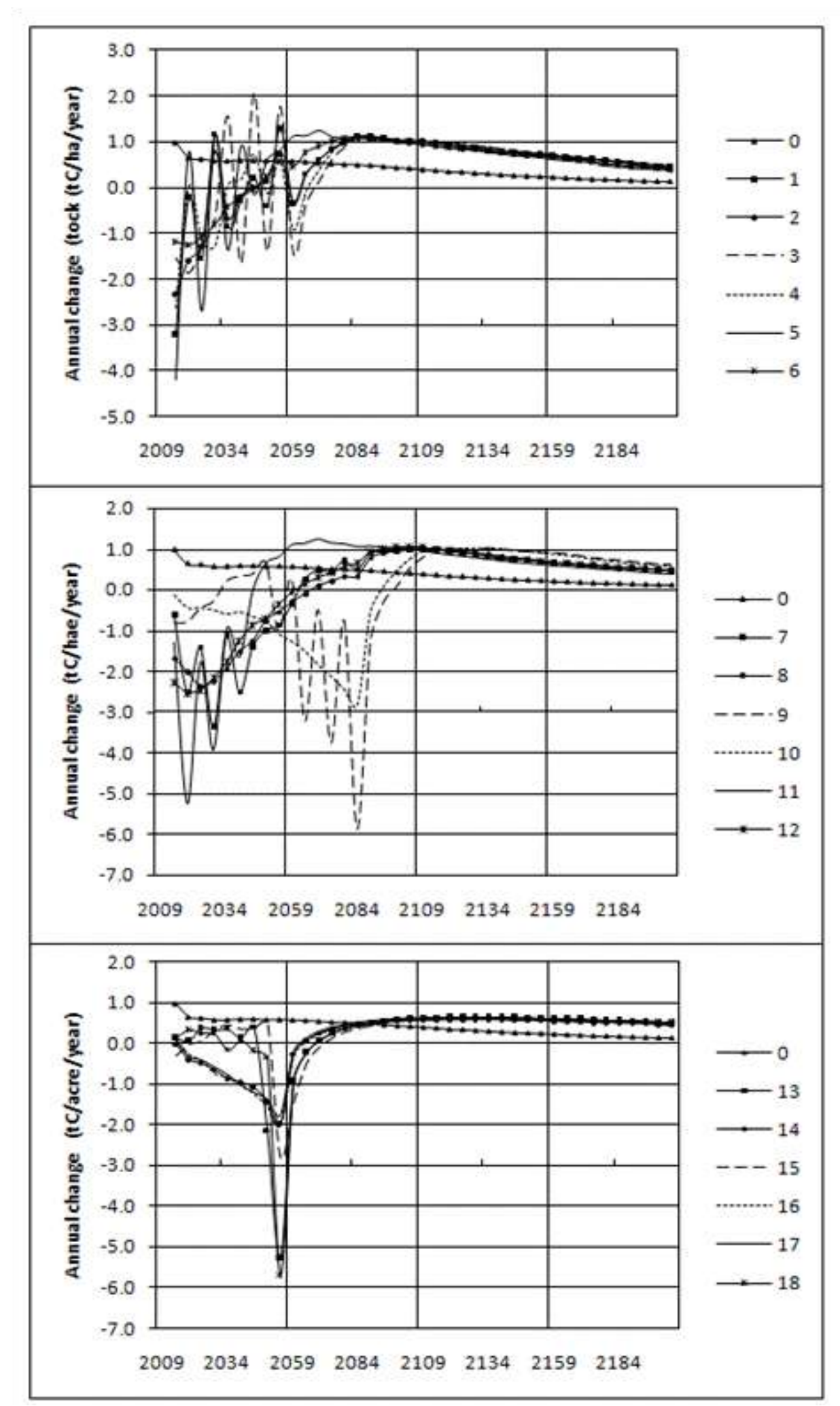

Figure 3.4 Carbon sequestration rate (tC/ha/year) under different harvesting strategies. 


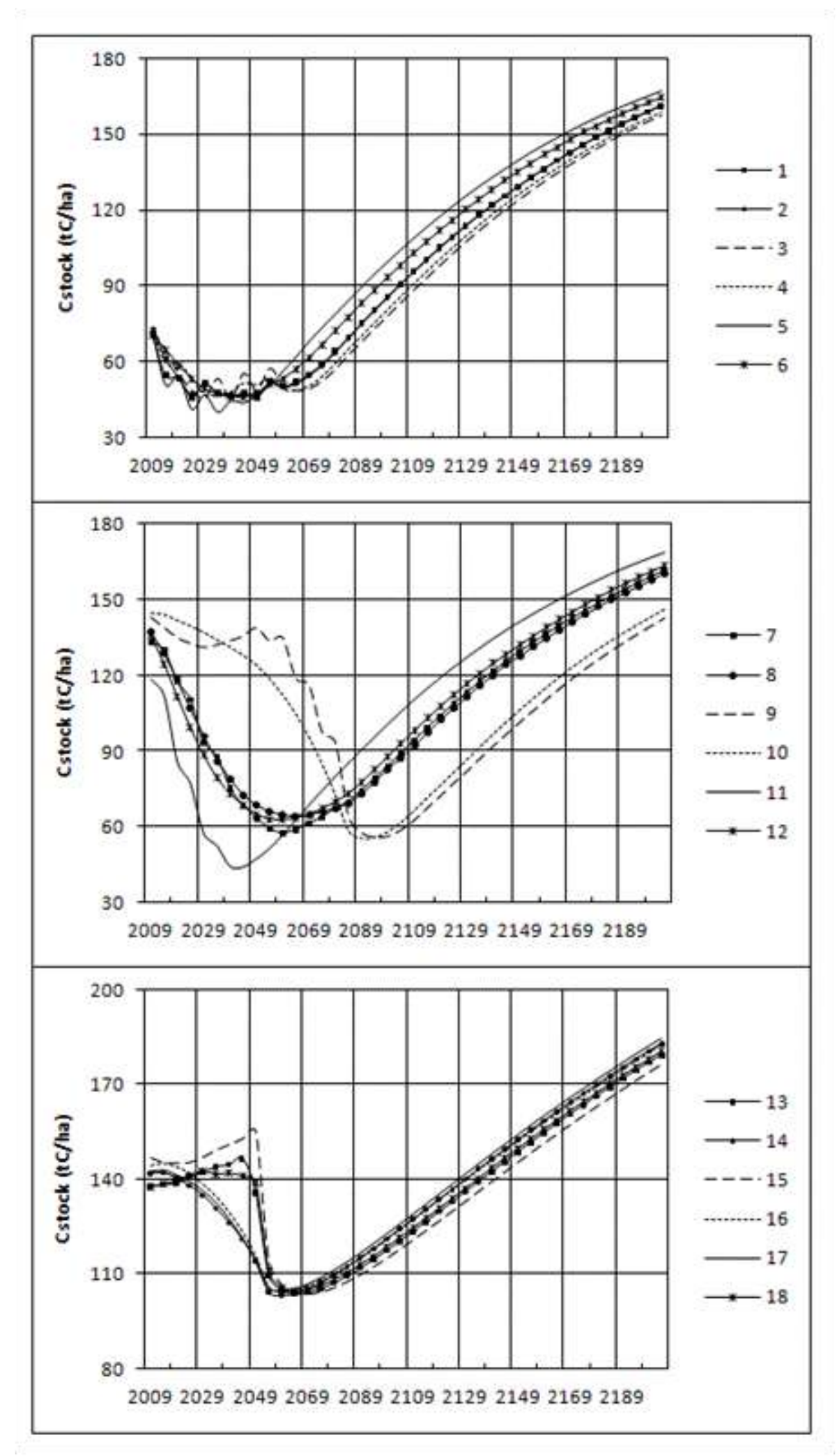

Figure 3.5 Forest $\mathrm{C}$ stock (tC/ha) as a result of different harvesting strategies. 


\subsubsection{C stock in harvested volume}

The spatio-temporal optimization of schedules resulted in different stand and harvest year combinations resulting in different amount of $\mathrm{C}$ in harvested wood from the forest (Table 3.4). Net present value (NPV) of harvested carbon (or correspond ending volume) obtained by implementing different models did not differ significantly $(\mathrm{P}<=0.95)$. But the NPV was significantly different between clearcut and selection methods $(\mathrm{P}<=0.001)$ with clearcut methods yielding higher timber benefits than selection methods. The standing $\mathrm{C}$ stock, however, differ significantly $(\mathrm{P}<0.01)$ among different schedules. This implies that individual harvest strategies i.e. model 1 through 12 were similar for clear-cut methods and model 13 through 18 for selection cut methods were similar by timber production view point. 
Table 3.4 C stock removed in merchantable volume for different models.

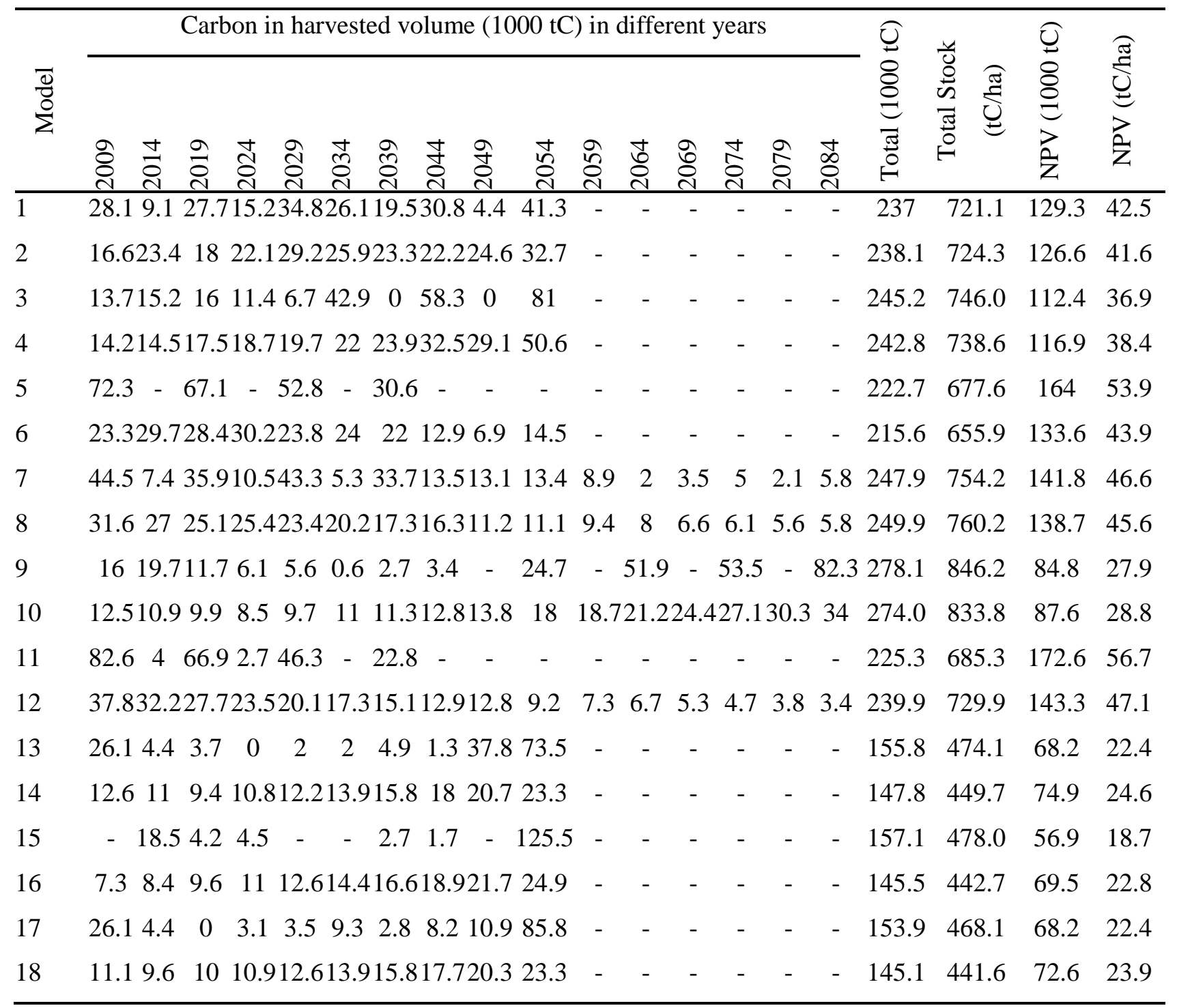

\subsection{Discussions and conclusions}

The sequestration rate varied between schemes of long term i.e. 80 -year long planning horizon and short term i.e. 50-year long planning horizon. Net sequestration of the stands become positive earlier in stands harvested to maximize the residual $\mathrm{C}$ stock in both clearcut and selection methods. The forest remains a net emitter of carbon for an extended period of time if the stands are harvested to maximize the 
stand $\mathrm{C}$ at harvesting time. On the other hand, if the schedule is maximized for timber production, it will never look at the future growth potential and the resultant schedule may either be better or worse by the view point of future $\mathrm{C}$ sequestration capability of the forest. The inclusion of stand $\mathrm{C}$ stock after recovery period in the MILP allows harvesting stand in such a way that the forest has enhanced C sequestration potential making forests net sinks of atmospheric $\mathrm{C}$ sooner, without undermining the benefits from harvested volume.

Evenflow of volume had negative consequences in terms of net annual sequestration. If the even flow of volume constraint is enforced, the optimization process renders some of the mature stands as unavailable for harvest so as to comply with this restriction which lowers net annual sequestration potential. Instead of leaving mature trees in forest, they can be removed to allow a younger forest to occupy the available growing space to enhance the sequestration potential. Few studies have addressed the requirements of the non-declining trend of wood volume production as promising for economic and legal reasons (Buongiorno and Gilless 2003) or a reasonable pattern (Ware and Clutter 1971) or for obtaining a good schedule (Vielma et al. 2007). The non-declining yield pattern might be advantageous for forests managed solely for timber production but if the management objective is also to sequester more carbon, the yield should not be constrained by any pattern. Another possible use of non-declining flow of volume could be in instances when supply is higher than the demand for timber which is not the present case as demands for hardwood lumber products have continued to increase along with production in past few decades (Luppold and Baumgras 2000). However, with the fluctuation of demands in the market, it is possible that the increase in timber production in one particular time period in absence of non declining flow of volume of wood would entail additional storage cost.

Traditional timber harvest schedules have focused on net revenue from timber harvesting which is comparable to model 1, 2, 7, 8, 13 and 14 evaluated in this study. Such schedules would result in lower $\mathrm{C}$ sequestration potential of the forests. Some studies have combined $\mathrm{C}$ sequestration objectives with timber harvesting (for example Hoen and Solberg 1994; Backeus et al. 2005) which is comparable to model $3,4,9,10,15$, and 16 in this paper. This schedule would improve the total $\mathrm{C}$ sequestration capacity 
of the forest if future $\mathrm{C}$ is taken into consideration in the maximization objective. Model 5, 6, 11, 12, 17 , and 18 used future stand $\mathrm{C}$ stock after stands have recovered from harvesting proved to be reliable future points. Models constrained by even-flow volume, i.e., 6, 12 and 18 within the models that utilized future C stock in objective functions, gave lower sequestration compared to models where this constraint is relaxed. In this paper, we used recovery period as a future time period to maximize the $\mathrm{C}$ sequestration for a mixed hardwood forest and prove that such a time would give better results than alternative methods for the forest type studied.

Harvested timber volumes are $\mathrm{C}$ storage outside the forest. When harvested carbon over the planning horizon and standing carbon at the end of 200 years long term period are compared, the net effect would be higher $\mathrm{C}$ sequestration for harvested stand than non harvest stands. In the harvested situation, long term higher $\mathrm{C}$ sequestration could be achieved by implementing optimization MILP model that combined timber benefits and $\mathrm{C}$ stock after stands have recovered $\mathrm{C}$ stock in both clearcut and selection cut methods (Table 3.5) as stand would start to become net sink of $\mathrm{C}$ earlier after harvest. The decision on cutting methods, i.e. clear-cutting or selection cut, to use in any given stand is based on management objectives, stand conditions, and the silvical characteristics of the species present or desired. Selection cut method is appropriate on areas with high public use or areas with special environmental sensitivity, or to provide services such as wildlife, aesthetic, and ecological values while the clearcut method is excellent for increasing intolerant species and can be used to harvest over mature, diseased or insect -inhabited stands. The study did not go into details of assessing the appropriateness of either of the harvesting methods but demonstrated that incorporation of $\mathrm{C}$ stock after the recovery period in the optimization model give better results in both clearcut and selection cut methods in the studied forest. 
Table 3.5 Summary of total C stock (tC/ha) in different schedules over different years.

\begin{tabular}{lrlllllllllllllllllll}
\hline & \multicolumn{11}{c}{ Strategies } \\
\cline { 2 - 3 } & 0 & 1 & 2 & 3 & 4 & 5 & 6 & 7 & 8 & 9 & 10 & 11 & 12 & 13 & 14 & 15 & 16 & 17 & 18 \\
\hline Total C at the beginning & 149 & 149 & 149 & 149 & 149 & 149 & 149 & 149 & 149 & 149 & 149 & 149 & 149 & 149 & 149 & 149 & 149 & 149 & 149 \\
Harvested C (tC/ha) & 0 & 78 & 78 & 81 & 80 & 73 & 71 & 73 & 69 & 30 & 39 & 74 & 69 & 51 & 49 & 52 & 48 & 51 & 48 \\
Total C after 50 years & 180 & 128 & 128 & 131 & 129 & 130 & 124 & 130 & 133 & 165 & 151 & 131 & 132 & 156 & 152 & 158 & 152 & 156 & 154 \\
Total C after 100 years & 204 & 174 & 173 & 169 & 171 & 182 & 174 & 167 & 161 & 93 & 106 & 185 & 167 & 175 & 176 & 173 & 175 & 180 & 173 \\
Total C after 200 years & 225 & 239 & 240 & 238 & 238 & 240 & 235 & 234 & 229 & 173 & 185 & 243 & 232 & 231 & 232 & 228 & 231 & 236 & 229 \\
\hline
\end{tabular}

The described approach to incorporate future $\mathrm{C}$ stock at the time equivalent to mean recovery period after the last harvest period has some limitations which is worth mentioning. The approach is highly sensitive to this recovery time period and may not provide better results if stand management rotation age is smaller than the mean recovery period or larger than twice the applicable management rotation age. In such situations, the maximization point would lie beyond the time where stand to stand C stock is widely differentiated or beyond the second rotation age which does not exist and thus makes no contribution to enhance the $\mathrm{C}$ sequestration in the solution. However, for most hardwood forests the rotation age is neither too short and nor too long. The two different planning horizons i.e. 50 years and 80 years were evaluated to assess this limitation. In order for this approach to function, effect of harvesting on residual stand $\mathrm{C}$ stock is needed in advance. Resources planners and managers rarely examine the long-term consequences of specific harvest strategies or compare the impacts of alternative approaches in both a spatial and temporal context because of lack of such analytical tools and basic scientific information to do so (Gustafson and Crow 1994). At present, simulation systems such as FVS, are available and are built upon the knowledge acquired throughout the past half century on growth dynamics of forest ecosystem. These simulation tools allow us to predict the effect of management actions on the future of forest with some level of certainty. The described approaches are sensitive to the projection data and thus the error and uncertainty associated with growth projection resides in the final results in the 
analysis. In dealing with uncertainty, several approaches have been applied in this study such as using large sample sizes and multiple simulation results. Sampling error was considered minimum given the size of sample for the entire forests. Estimates of growth and yield were obtained from FVS which contains self-calibration feature to reflect local deviations from the regional growth trends (Crookston and Dixon 2005). Along with default randomization of tree records available in FVS, the projected results were manually randomized to produce the variation in projection results to account for stochastic variations in forest growth as suggested by Dixon (2002).

Several variations in either of the cutting methods i.e. selection cut and clearcut exist which were not included in this study. These variations may arise when using different target basal area in selection cut methods and different maximum opening size in clearcut methods. These variations can be studied with silvicultural enhancement objectives in the forest. Similarly, no dollar price was tagged in the benefit arising from harvested material; rather a unit price approach was used. In the future these aspects can be studied by including dollar prices in dynamic price range in the same model. Although our study reported results from clearcut and selection cut methods, there is a possibility of enhancing $\mathrm{C}$ sequestration potential further by mixing these two cutting methods and allowing variable maximum clearcut size in the forest to seek further $\mathrm{C}$ enhancement potentials in developing harvest strategies. 


\section{References}

Backeus, S., Wikstrom, P., Lamas, T. 2005. A model for regional analysis of carbon sequestration and timber production. Forest Ecology and Management 216:28-40.

Buongiorno, J., Gilless, J. K. 2003. Decision Methods for Forest Resource Management. Academic Press, San Diego, CA.

Crookston, N.L, Dixon, G.E., 2005. The forest vegetation simulator: A review of its structure, content, and applications. Computer and Electronics in Agriculture 49:60-80.

Diaz-Balteiro, L., Romero, C. 2003. Forest management optimization models when carbon captured is considered: a goal programming approach. Forest Ecology and Management 174:447-457.

Dixon, G.E. (comp.). 2002. Essential FVS: A user's guide to the Forest Vegetation Simulator. Internal Report. U.S. Department of Agriculture, Forest Service, Forest Management Service Center, Fort Collins, CO.

Goycoolea, M., Murray, A., Vielma, J.P., Weintraub, A. 2009. Evaluating alternative approaches for solving the area restriction model in harvest scheduling. Forest Science 55: 149-165.

Guldin, J.M. 1991. Uneven-aged BDq regulation of Sierra Nevada mixed conifers. West. J. Appl. For. $6: 27-32$.

Gustafson, E.J., Crow, T.R. 1994. Modeling the effects of forest harvesting on landscape structure and the spatial distribution of cowbird brood parasitism. Landscape Ecology 9:237-248.

Hoen, H.F., Solberg, B. 1994. Potential and economic efficiency of carbon sequestration in forest biomass through silvicultural management. Forest Science 40:429-451

ILOG CPLEX. 2008. Division, ILOG CPLEX 11.0 Reference Manual. Available at http://www.cplex.com.

Kurz, W. A., Apps, M.J. 1999. A 70-year retrospective analysis of carbon fluxes in the Canadian forest sector. Ecological Applications 9:526-547. 
Liu, G., Han, S. 2009. Long-term forest management and timely transfer of carbon into wood products help reduce atmospheric carbon. Ecological Modelling 220:1719-1723.

Luppold, W., Baumgras, J. 2000. The changing structure of the hardwood lumber industry with implications on technology adaptation. P. 89-94 in Proc. of. the twenty-eighth annual hardwood symposium, West Virginia now--the future for the hardwood industry? Meyer, D. A.(ed). National Hardwood Lumber Association, Memphis, TN.

Maness, T., Farrell, R. 2004. A multi-objective scenario evaluation model for sustainable forest management using criteria and indicators. Canadian Journal of Forest Research 34:2004-2017.

Marquis, D.A. 1978. Application of uneven-aged silviculture and management on public and private lands. P. 25-61 in proceeding of uneven-aged silviculture and management in the United States. USDA Forest Service Gen. Tech. Rep. WO-24.

Meng, F., Bourque, C.P.A, Oldford, S.P., Swift, D.E., Smith, H.C. 2003 Combining carbon sequestration objectives with timber management planning. Mitigation and Adaptation Strategies for Global Change 8:371-403

Ney, R.A., Schnoor, J.L., Mancuso, M.A. 2002. A methodology to estimate carbon storage and flux in forestland using existing forest and soil databases. Environmental Monitoring and Assessment 78: 291-307.

Noble, I., Apps, M., Houghton R., Lashof, D., Makundi, W., Murdiyarso, D., Murray, B., Sombroek, W., Valentini, R. 2000. Implications of different definitions and generic issues. P. 53-126 in IPCC Special Report Land Use, Land-Use Change and Forestry. Watson, R.T., I. Noble, B. Bolin, N.H. Ravindranath, D.J. Verardo, and D. J. Dokken (eds). Cambridge University Press, New York.

Papadopol, C.S. 2000. Impacts of climate warming on forests in Ontario: options for adaptation and mitigation. For. Chron. 76:139-149.

Plantinga, A.J., Birdsey, R.A. 1993. Carbon fluxes resulting from U.S. private timberland management. Climate Change 23:37-53. 
Routledge, R.D. 1980. The effect of potential catastrophic mortality and other unpredictable events on optimal forest rotation policy. Forest Science 26:389-399.

Van Deusen, P.C. 1999. Multiple solution harvest scheduling. Silva Fennica 33: 207-216.

Vielma, J.P., Murray, A.T., Ryan, D.M., Weintraub, A. 2007. Improving computational capabilities for addressing volume constraints in forest harvest scheduling problems. European Journal of Operational Research 176:1246-1264.

Ware, G.O., Clutter, J.L. 1971. A mathematical programming system for the management of industrial forests. Forest Science 17:428-445. 


\section{Appendix 3.1 Algorithm implemented to generate scheduling MILP model.}

Step I: Algorithm for generating feasible blocks

FB: FB is stores feasible block information and it is a set of stands)

set FB to null

for each stand: stands range from 0 to $S$ i.e. number of stands in forest

generate individual blocks by adding stand to $F B$

next stand

let MAX be maximum opening size area (i.e. 100 acres)

begin process

$n=$ number of block at the beginning of process $(=S$ i.e., number of stands)

for each member in $F B$

obtain constituting stands

obtain block area (by adding area of constituting stands in this block)

for each constituting stands in $F B$

obtain neighbors (i.e., set of neighboring stands)

for each neighbor

if neighboring stand is already in constituting stands in FB, remove from neighbor set

if $([$ block area + neighboring stand area $]<=M A X)$, add neighboring stand to $F B$

next neighbor

next constituting stand

next member in $F B$

obtain $N(N=$ number of blocks $)$

If $N>n$ (i.e. checks if there is improvement)

set $n=N$ and repeat the process i.e., go to line begin process

end process 
Step II: Algorithm for generating mutually exclusive feasible blocks (MEB)

TFB is temporary storage of sets of blocks

set TFB to null : initially this storage is set to empty

for each member in $F B(i): 1<=i<=$ number of $F B$

if block $i$ is not in TFB, add block $i$ to TFB

for each member in $F B(j): 1<=j<=$ number of $F B$

if $j$ is not equal to $i$

if block $j$ is connected with all the blocks in TFB, add block $j$ to TFB

$n e x t j$

if TFB is not already in MEB and TFB is not a subset of any member in MEB, add TFB to MEB:

clear TFB: set this object to null and prepare for next block

next member in $F B$

STEP III: Objective function formulation algorithm

let $C_{i, j}$ be variable to denote harvest benefit by harvesting block $i$ at time period $j$

let $S_{i, j}$ be variable to denote stand $C$ stock at time $j$ by harvesting block $i$ at time period $j$

let $S R_{i, j}$ be variable to denote stand $C$ stock at time $j+r$ by harvesting block $i$ at time period $j$

let $B_{i, j}$ be variable to denote harvest of block $i$ at time period $j$

let $Z$ be variable to store objective function

for each plan period $(j): 1<=j<=P(P$ is total number of plan period $)$

for each $F B(i)$

for each objective type (i.e., $a, b$, or $c$ )

$$
Z=Z+C_{i, j} * B_{i, j}+S_{i, j} * B_{i, j}+S R_{i, j} * B_{i, j}
$$

Next objective type

next FB 
next plan period

write $Z$ to memory

STEP IV: Adjacency and green up restriction constraints formulation algorithm.

let CONSTRAINT be temporary storage for constrains.

let $B_{i, j}$ be variable to denote harvest of block $i$ at time period $j$

for each plan period $(j): 1<=j<=P(P$ is total number of plan period $)$

for each $M E B$

set constraint to null

for each member block in MEB (i)

if $(j+1<P)$, onstraint $=$ constraint $+B_{i, j}+B_{i, j+1}$

next member block $i$

write CONSTRAINT as "CONSTRAINT = CONSTRAINT + " $<=1$ ” into memory

next MEB

next plan period $j$

STEP V: Unique harvest in planning period constraint formulation algorithm

let CONSTRAINT be temporary storage for constrains.

let $B_{i j}$ be variable to denote harvest of block $i$ at time period $j$

for each $F B(i)$

set CONSTRAINT $=$ null

for each plan period $(j)$

$$
\text { CONSTRAINT }=\text { CONSTRAINT }+B_{i, j}
$$

next plan period

write CONSTRAINT as "CONSTRAINT = CONSTRAINT <=1";

next $F B$ 
STEP VI: Non declining volume flow of harvest constraint formulation algorithm

Let CONS1 and CONS2 be temporary storage for constrains.

let $C_{i, j}$ be variable to denote harvest benefit by harvesting block $i$ at time period $j$ (can be read from database or growth function)

let $B_{i, j}$ be variable to denote harvest of block $i$ at time period $j$

for each plan period $(j): 1<=j<=P(P$ is total number of plan period $)$

Set CONSTRAINT, CONS1 and CONS2 to null

for each $F B(i)$

$$
\text { if }([j+1]<P), \text { CONS } 1=\text { CONS1 }+C_{i, j} * B_{i, j} \text { and CONS2 }=\text { CONS } 2+C_{i, j+1} * B_{i, j+1}
$$

next FB

write constraint to memory as "CONS1 <= CONS2;"

next plan period 


\title{
4. MODELING TERRESTRIAL CARBON SEOUESTRATION
} \begin{tabular}{lllllllll} 
ENHAN CEM ENT & POTENTIAL IN WEST VIRGINIA \\
\hline
\end{tabular}

\begin{abstract}
The potential of West Virginia's forests in sequestering atmospheric carbon and in mitigating anthropogenic emission was determined to be a cost effective as compared to other available sequestration techniques. Carbon sequestration in the four terrestrial ecosystem components including forests, agricultural lands, abandoned mine lands and harvested wood products were modeled using system modeling approach utilizing information of stock and flow of carbon across different components that are available from simulation modeling, data archives and existing literature. The carbon stored in harvested forest product pools was estimated using existing as well as potential, growth-to-removal ratios followed by decay functions applicable for different forest products types. Potential enhancements in the terrestrial carbon sequestration were obtained by generating several management scenarios including afforestation activities in marginal agricultural lands and abandoned mine lands. The study found that current terrestrial ecosystem components in West Virginia sequester carbon at the rate of 4.99 million tC with a possibility of achieving an enhanced sequestration of 7.62 million tC per year when all the available options are implemented. The results also indicated that sustainable terrestrial ecosystem management can provide higher carbon sequestration rates at lower cost than available alternative options and can also provide a path to utilize this green energy as a substitute to the corresponding amount of fossil fuel to meet the long term objectives of emission control in the state.
\end{abstract}

\footnotetext{
${ }^{3}$ Planned for submission to Carbon Balance and Management
} 


\subsection{Introduction}

Increasing global energy use, especially fossil fuels, combined with land use change activities that enhance carbon $(\mathrm{C})$ emissions have resulted in an increase of carbon dioxide $\left(\mathrm{CO}_{2}\right)$ - a major green house gas (GHG) component in the atmosphere. The rising GHG concentrations are creating negative impacts on environment and the global economy. Long term solutions of reducing atmospheric $\mathrm{C}$ such as geologic storage (IEA 2004) are still under development and expected to be costly to implement (Galang et al. 2007). A terrestrial sequestration option, on the other hand, is cost efficient (Richards and Stokes 2004, USEPA 2005) which includes management of forest and agricultural land combined with emission source control (Cole et al. 1996, IPCC 2003) by substituting fossil fuel with renewable biomass resource where ever applicable. This option is recognized as a strategic part to GHG emissions mitigation (Moulton and Richards 1990, Marland and Schlamadinger 1995). West Virginia (WV), located around $38^{\circ} 36^{\prime} \mathrm{N}$ and $81^{\circ} 63^{\prime}$ in the US, is a land locked mountainous state where 99 percent of total area is land. The state has over 80 percent of the total land area covered with forest resources. Agricultural lands and abandoned mine lands are other major terrestrial land use components with the potential to serve as $\mathrm{C} \mathrm{a}$ $\operatorname{sink}$ (Fig. 4.1). 


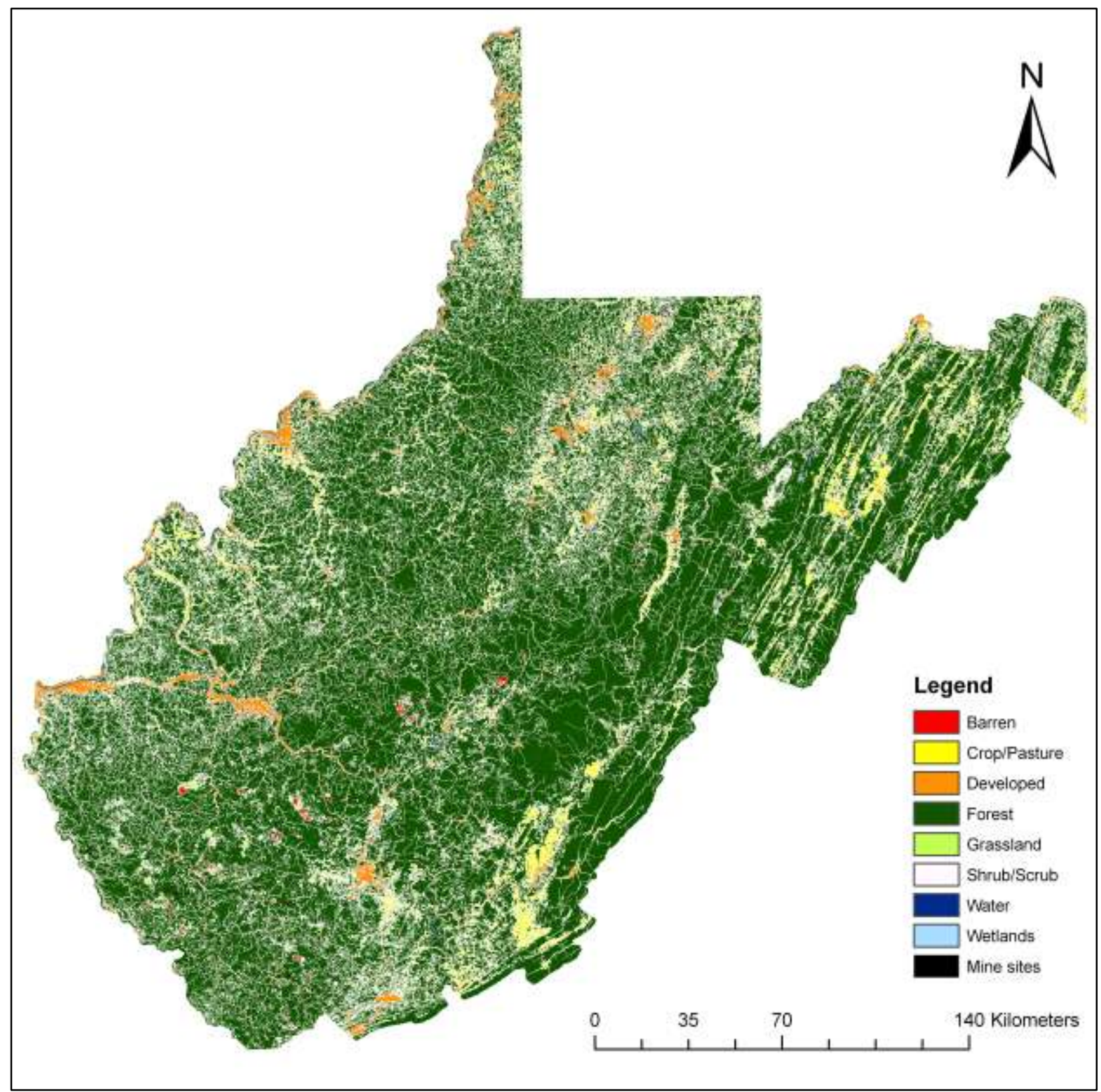

Figure 4.1 Major land use in West Virginia (WV).

(Source: USGS NLCD 2001)

Over the past decade, anthropogenic carbon emissions due to fossil fuel use in the state accounts for approximately 29.88 million tC/year (Fig. 4.2) with a high proportion based on electric power generation (USEPA 2009). 


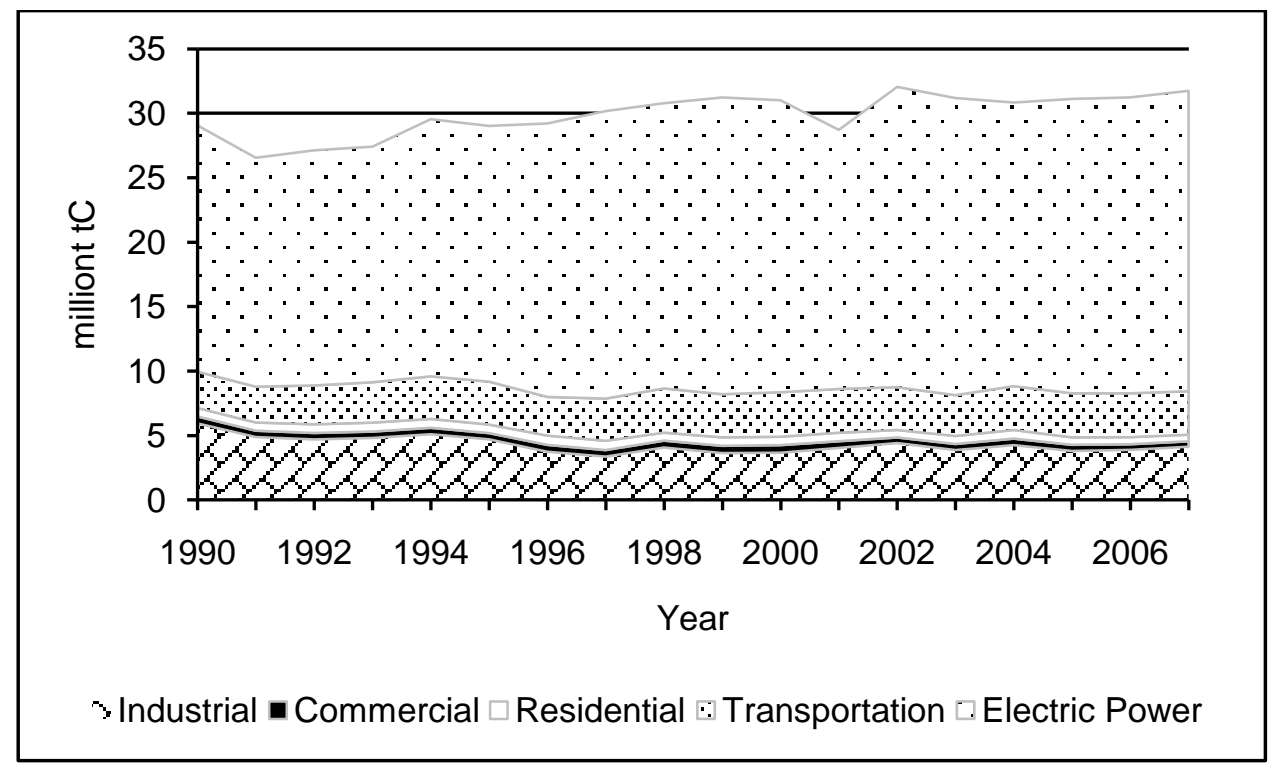

Figure 4.2 . Carbon emission from fossil fuel burning in WV between 1990 and 2007. (Source: USEPA 2009)

There have been growing concerns over reducing the emission level and to stabilize the atmospheric $\mathrm{C}$ using several existing techniques and activities. A $\mathrm{C}$ sequestration method that relies on terrestrial ecosystem management is believed to be cost effective in West Virginia due to the availability of abundant land resources. Forest harvesting is an inherent part of forest management activities in the state from which products are continuously removed and harvested areas are regenerated to grow new forests. The harvested wood pools provide additional storage of atmospheric $\mathrm{C}$ for a period of time depending on the end use of these products (IPCC 2005). The mountainous topography in the state includes agricultural lands with severe limitations due to soil, slope, erodibility and other environmental factors. Agricultural lands with such limitations make primary agricultural activities are less profitable and are considered marginal. Approximately 60 percent of the 809,000 ha of agricultural lands in WV are considered marginal land and these lands can be used for afforestation activities to enhance terrestrial $\mathrm{C}$ sequestration (Sperow et al. 2003, Niu and Duiker 2006). There are 200,000 ha of abandoned mine lands in the state (WVDEP 2008) representing a significant portion of land which can be brought under forestry 
for additional C sequestration (Sperow 2006). Although studies focusing on individual components of these ecosystems are generally available (Sperow et al. 2003, Sperow 2006, Niu and Duiker 2006), an analysis conducted by integrated of all available components was not available for the state of WV. It was believed that such a study could aid in our understanding of the possibilities and limitations of applicable terrestrial land based management strategies to enhance $\mathrm{C}$ sequestration and consequently reduce $\mathrm{C}$ emission levels in the state. The objective of this paper is to illustrate and describe the $\mathrm{C}$ sequestration modeling approach that can be applied to estimate the terrestrial $\mathrm{C}$ sequestration potential and enhancement strategies. In essence, this paper describes potential strategies for use from terrestrial resources that can help enhance the $\mathrm{C}$ sequestration and to investigate the limits of such strategies. The paper also describes how these components are cost efficient as compared to other alternative options of carbon capture and storage (CCS).

\subsection{Methods}

C stock in 4 major terrestrial pools which includes forests, agricultural lands, abandoned mine lands and harvested wood products and related modifying processes were modeled using a system modeling approach (Fig. 4.3) utilizing the Java programming language. Land cover statistics were obtained from United States Geological Survey National Land Cover Data 2001 (Homer et al. 2004). Estimates of forest $\mathrm{C}$ stock were obtained using the Carbon On Line Estimator (COLE) available at http://ncasi.uml.edu/COLE/ (USDA 2010). Forest growths, as well as sequestration rates, were obtained through simulation of the test datasets in the FVS with Fire and Fuelwood extension. Mine land data and statistics were obtained from WVDEP (2008). C in harvested volume and associated end uses were obtained from Timber Products Output (TPO) data. C sequestration rates from afforestation activities in abandoned mine lands and marginal agricultural land were obtained from previous studies. 


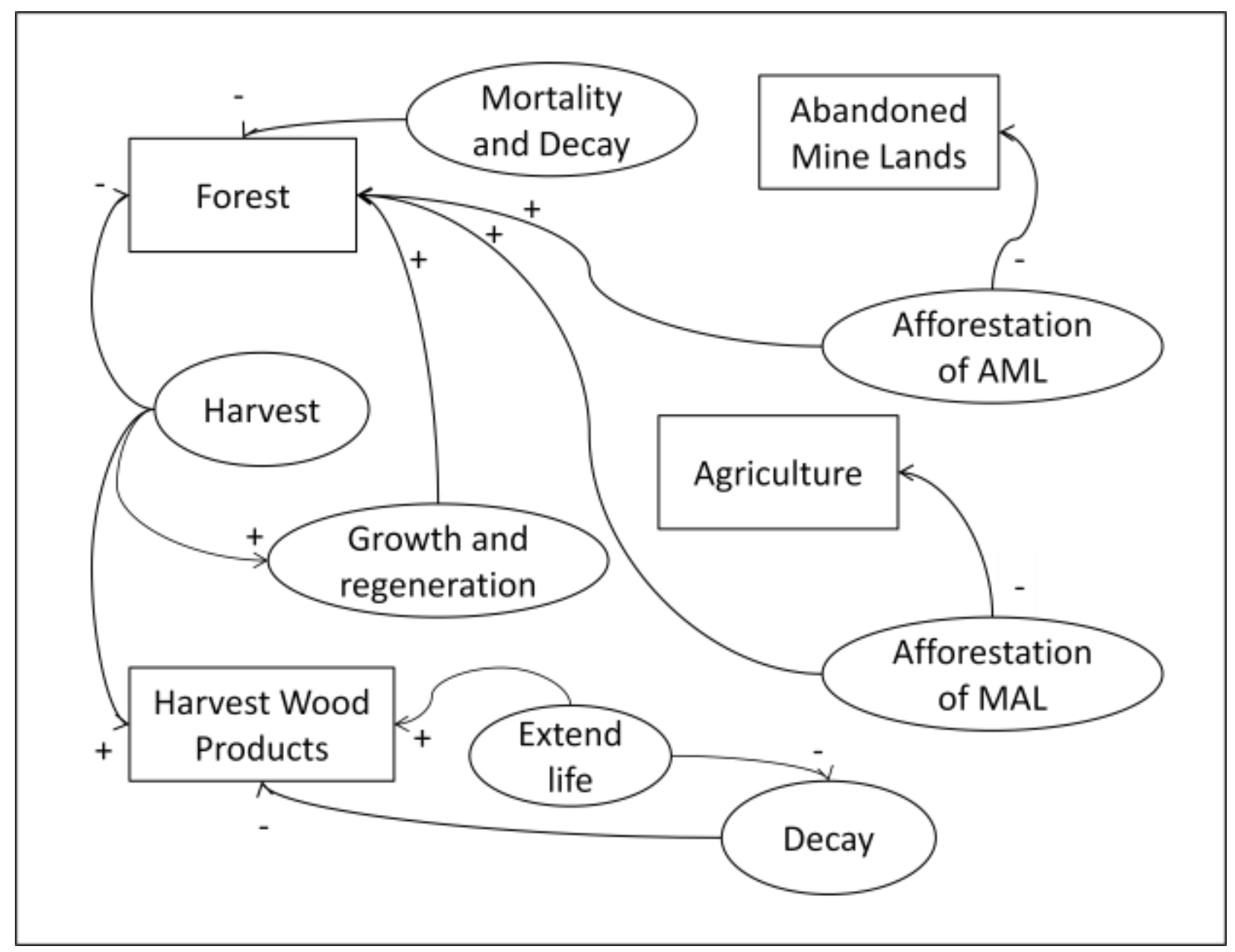

Figure 4.3 System model representing process and flows of carbon across major terrestrial ecosystem components.

C content in wood is estimated as half of the total dry biomass weight, which was estimated by using volume-density relationship of applicable species (USDA-FPL 1953, Grantham and Ellis 1974, Smith 1991) (Eq. 4.1 and 4.2). GRR is net growth over net removal of $C$ from the forest (Eq. 4.3). C sequestration by the forest was estimated using Eq. (4.4) based on the current growth and removal ratio by allocating different sequestration rates in young (recently harvested) and old stands. The C sequestration rate for forests utilized in these models represent the net accumulation of $\mathrm{C}$ after deducting mortality and intermittent emissions that was obtained from optimized forest harvest strategies for 
enhanced C sequestration (Sharma et al. 2010). Carbon stocks in harvested wood were estimated using Eq. (4.5) which is a function of weighted species density information. Harvested wood products after several primary and secondary processing in mills go through several cycles of processing as well as recycling upon final use for a range of products. At the end, these products would either be used as biofuel or reside in landfills. The amount remaining in any given product was estimated using an exponential decay function with half-life of C (Karjalainen et. al. 2002) for a particular product type using Eq. (4.6). The estimated half-life in years for different product categories were 30, 15, 1, 5, and 145 for products in long term use, medium term use, short term use, product left to decay in forest floor, and products in landfills (Karjalainen et al. 2002, Schelhaas et al. 2004, Zeng 2008) respectively. The description of different forest products, their longevity and expected half-lives are shown in table 4.1. Eq. (4.7) was used to account for C in HWP added in current year to the previously existing pool. The C stock change through afforestation activities conducted in marginal agricultural lands and mine lands was estimated using Eq. (4.8) and Eq. (4.9) respectively. The net $\mathrm{C}$ sequestration by all the terrestrial components was obtained using Eq. (4.10). Energy saving from biomass use is simply the amount of energy that can be produced from the unused biomass resources (Eq. 4.11). Carbon emission saving from biomass utilization for energy production is estimated as fraction of emission that would be produced to generate the equivalent amount of energy from fossil based fuels plus the amount of emission that would be produced from the unused biomass left to decay (Eq. 4.12).

$$
\begin{aligned}
& B_{S}=V_{B_{i}} D_{B_{i}} \text { for } \mathrm{i}=1 \ldots \ldots \text { species groups, } \mathrm{s} \\
& B_{c}=0.5 \mathrm{~B} \\
& G R R=\frac{C_{f}}{C_{h}}
\end{aligned}
$$




$$
\begin{aligned}
& \left.C_{f}=A \frac{1}{G R R+1}\left(G R R * r_{1}+r_{2}\right)\right\} \\
& C_{h}=\frac{C_{f}}{G R R} \\
& \left.Q_{y}=\sum_{n=1}^{N} Q_{n} *\left[1-\frac{\ln (2)}{h_{n}}\right]^{(y-1)}\right\}
\end{aligned}
$$

$$
\begin{gathered}
\left.Q_{y}=\sum_{n=1}^{N} Q_{n} *\left[1-\frac{\ln (2)}{h_{n}}\right]^{(y-1)}+c \sum_{i=2}^{y} \Delta Q_{n}\left[1-\frac{\ln (2)}{h_{n}}\right]^{(i-2)}\right\} \\
C_{a g}=r_{a g} *\left(A_{a g}-A_{m a g}\right)+r_{m a g} * A_{m a g} \\
C_{m l}=r_{m l} * A_{m l}
\end{gathered}
$$

$$
T c=C_{f}+C_{h}+C_{a g}+C_{m l}
$$

$$
\begin{aligned}
& S_{e b}=B * B_{e} \\
& S_{c b}=\frac{B_{c}}{C_{c}} * \frac{B_{e}}{C_{e}}+B_{c}
\end{aligned}
$$

where $C_{f}$ is annual $\mathrm{C}$ accrual (in million tons) in forest ecosystems, $A$ is total area of forests (in million acres), GRR is growth-removal ratio (>0), $r_{1}$ is $\mathrm{C}$ sequestration rate from forest growth in $\mathrm{tC} / \mathrm{ha}$ in old and over mature stands, $r_{2}$ is growth tC/ha in young to mature stands (i.e. less than 100. Both $r_{1}$ and $r_{2}$ are calculated using the stock change method, where the $\mathrm{C}$ stock in time 2 minus the stock in time 
1 , divided by the time interval, equals average annual sequestration in forest, $C_{h}$ is annual carbon removed (million tons) from forest ecosystem, $Q_{t+1}$ is quantity of carbon at time $y, Q_{n}$ is quantity of carbon at the beginning for the $n^{\text {th }}$ product, $Y$ is number of years, $y$ is any future time period between 1 and $Y, N$ is number of different products from forest harvest, $n=$ any product between 1 and $\infty, h_{n}$ is expected half-life of product $\mathrm{n}, t$ is time period (year), $\Delta Q_{n}$ is the added quantity of $\mathrm{C}$ in the current year from the $\mathrm{n}^{\text {th }}$ product category to existing stock, $\mathrm{c}=0$ if $\mathrm{y}<2$ and 1 otherwise, $C_{a g}$ is carbon sequestered in agricultural lands, $C_{m l}$ is carbon sequestered in mine lands, $T_{c}$ is total carbon sequestered in terrestrial components, $S_{e b}$ is the energy saving form biomass used for fuel, and $S_{c b}$ is carbon emission saving from biomass used for fuel. A brief overview of derivation of Eq. (4.4) and (4.5) is provided in Appendix 4.1. The parameters used in the models were obtained from several sources listed in Table 4.2.

Table 4.1 Harvested wood products, use longevity and half-lives.

\begin{tabular}{lll}
\hline \multicolumn{1}{c}{ Product category } & Product longevity & Half life (years) \\
\hline Composite products (cp) & Long term & 30 \\
Fuelwood (fw) & Short term & 1 \\
Post, poles and pilings (ppp) & Medium term & 15 \\
Pulpwood (pw) & Short term & 1 \\
Sawlogs (sl) & Long term & 30 \\
Veneer logs (vl) & Medium term & 15 \\
Fiber (f) & Long term & 30 \\
Misc. products (mp) & Short term & 1 \\
Unused products (up) & Dump and decay & 5 \\
\hline
\end{tabular}


Table 4.2 Definition of model parameters.

\begin{tabular}{|c|c|c|}
\hline$\underline{\text { Parameter }}$ & Definition & Source \\
\hline$A$ & Area of forest land (million ha) & Homer et al. 2004 \\
\hline$r_{1}$ & Forest $\mathrm{C}$ sequestration rate in old stands ( $\mathrm{tC} / \mathrm{ha} / \mathrm{year}$ ) & Sharma et al. 2010, FVS model \\
\hline$r_{2}$ & Forest $\mathrm{C}$ sequestration rate in young stands (tC/ha/year) & Sharma et al. 2010, FVS model \\
\hline GRR & Growth to removal ratio & $\begin{array}{l}\text { USDA-FS } 2009 \\
\text { Homer et al. } 2004 \text {, Niu and Duiker }\end{array}$ \\
\hline$A_{a g}$ & Area of Agricultural Land (million ha) & 2006 \\
\hline$A_{\text {mag }}$ & Area of marginal agricultural lands (million ha) & Niu and Duiker 2006 \\
\hline$r_{a g}$ & $\begin{array}{l}\mathrm{C} \text { sequestration rate in agricultural lands (tC/ha/year) } \\
\mathrm{C} \text { sequestration rate in agricultural lands with } \\
\text { afforestation (tC/ha/year) }\end{array}$ & $\begin{array}{l}\text { Sperow et al. } 2003 \\
\text { Sperow et al. 2003, Niu and Duiker } \\
2006\end{array}$ \\
\hline$A_{M L}$ & Area of abandoned mine lands (million ha) & WVDEP 2008 \\
\hline$r_{a m}$ & $\begin{array}{l}\mathrm{C} \text { sequestration in abandoned mine lands (tC/ha/year) } \\
\mathrm{C} \text { sequestration in abandoned mine lands with }\end{array}$ & Sperow 2006 \\
\hline$r_{m l f}$ & afforestation (tC/ha/year) & Sperow 2006 \\
\hline$V_{B i}$ & Volume of biomass $\left(\mathrm{m}^{3}\right)$ in species i & $\begin{array}{l}\text { TPO data, } \\
\text { USDA-FPL 1953, Grantham and }\end{array}$ \\
\hline$D_{B i}$ & Density of biomass $\left(t / \mathrm{m}^{3}\right)$ in species $\mathrm{i}$ & Ellis 1974, Smith 1991 \\
\hline$B_{c}$ & $\mathrm{C}$ content in wood biomass ( $\mathrm{tC} / \mathrm{t}$ of biomass) & IPCC 2005 \\
\hline$C_{c}$ & $\begin{array}{l}\mathrm{C} \text { content in coal ( } \mathrm{tC} / \mathrm{t} \text { of coal) } \\
\text { Energy yield of woody biomass (million } \mathrm{kJ} / \mathrm{t} \text { of }\end{array}$ & WVPF 2009 \\
\hline$B_{e}$ & biomass) & USDA-FPL 2004, Wang et al. 2007 \\
\hline$\underline{C_{e}}$ & Energy yield from coal burning (million $\mathrm{kJ} / \mathrm{t}$ of coal) & WVPF 2009 \\
\hline
\end{tabular}

The sequestration rate in agricultural lands was obtained from (Sperow et al. 2003) and the rate of sequestration in afforestation projects was assumed similar to that of a young forest stand as described in Sharma et al. (2010). The energy content of wood was estimated based on energy equivalent of biomass wood as described in USDA-FPL (2004) and Wang et al. (2007). Energy emission saving from biomass utilization was obtained by adjusting the equivalent $\mathrm{C}$ emission that would have to be burned to produce the same amount of energy. Since coal energy is the basic energy source that can be substituted with forest biomass, equivalent energy yields and $\mathrm{C}$ emission for coal in WV was used by applying the energy yield of coal in WV estimated from WVPF (2009). Once the annual value was estimated, the model was allowed to estimate the amount of future $\mathrm{C}$ in different categories. The model was used to generate 
different scenarios (Table 4.3) by utilizing different combinations of these processes and options that can be implemented. These scenarios represent the current status of terrestrial $\mathrm{C}$ sequestration, assumed to be a base-case and potential future scenarios. This analysis was conducted to understand the variations in the estimated potentials, finding the limit of the potential, and to evaluate the sensitivity of the model. 
Table 4.3 Description of scenarios.

\begin{tabular}{|c|c|c|}
\hline Scenario & Description & Remarks \\
\hline \multirow{4}{*}{$\begin{array}{l}1 . \\
\text { Base Case }\end{array}$} & Growth to removal ratio equal to 1.56 & Current harvest level \\
\hline & Proportion of utilization remains current & Current utilization level \\
\hline & Agricultural lands remains as current & Current ag. land use \\
\hline & Mine lands remains as current & Current mine lands \\
\hline \multirow{4}{*}{ 2. Conservative } & Growth to removal ratio increases to 2 & Harvesting is limited \\
\hline & Proportion of utilization remains current & Current utilization level \\
\hline & Agricultural lands remains as current & Current ag. land use \\
\hline & Mine lands remains as current & Current mine lands \\
\hline \multirow{4}{*}{ 3. Progressive } & Growth to removal ratio equals 1.25 & Increased yet sustainable harvest \\
\hline & Proportion of utilization remains current & Current utilization level \\
\hline & Agricultural lands remains as current & Current ag. land use \\
\hline & Mine lands remains as current & Current mine lands \\
\hline \multirow{5}{*}{ 4. Intermediate } & Growth to removal ratio equals 1.25 & Increased yet sustainable harvest \\
\hline & $\begin{array}{l}\text { Unused biomass is disposed off in landfills instead of } \\
\text { current dump and decay method }\end{array}$ & $\begin{array}{l}\text { Delay the emission from unused } \\
\text { wood products }\end{array}$ \\
\hline & Agricultural lands remains as current & Current ag. land use \\
\hline & $50 \%$ of abandoned mine lands are converted to forest & \\
\hline & land use & Afforestation in marginal lands \\
\hline \multirow{5}{*}{$\begin{array}{l}5 . \\
\text { Balanced }\end{array}$} & Growth to removal ratio equals 1.25 & Increased yet sustainable harvest \\
\hline & Unused biomass is utilized to substitute fossil fuel & Reduced emission from fossil fuel \\
\hline & $\begin{array}{l}50 \% \text { of the marginal agricultural lands are converted to } \\
\text { forest land use }\end{array}$ & Afforestation in marginal lands \\
\hline & $50 \%$ of abandoned mine lands are converted to forest & \\
\hline & lands & Afforestation in marginal lands \\
\hline \multirow{4}{*}{$\begin{array}{l}6 . \\
\text { Aggressive }\end{array}$} & Growth to removal ratio decreases to 1 & $\begin{array}{l}\text { Increased harvest level, sustainable } \\
\text { but comes with risk }\end{array}$ \\
\hline & Unused biomass is utilized to substitute fossil fuel & Reduced emission from fossil fuel \\
\hline & $\begin{array}{l}100 \% \text { of marginal agricultural lands are converted to } \\
\text { forest land use }\end{array}$ & $\begin{array}{l}\text { Maximum use of marginal lands for } \\
\text { carbon sequestration }\end{array}$ \\
\hline & $\begin{array}{l}100 \% \text { of abandoned mine lands are converted to forest } \\
\text { land use }\end{array}$ & $\begin{array}{l}\text { Maximum use of marginal lands for } \\
\text { carbon sequestration }\end{array}$ \\
\hline
\end{tabular}




\subsection{Results}

\subsubsection{Terrestrial carbon stock and sequestration}

A total of 5.24 million hectares of forest land in WV store approximately 940 million tons of carbon. The mean forest C stock is $191 \mathrm{tC} /$ ha in different forest types. The state's hardwood forests store a relatively high proportion of total forest carbon as compared to softwood components (Table 4.4).

Table 4.4 Amount of carbon (million t) stored in forests in WV by major species group.

\begin{tabular}{lccc}
\hline Forest type/group & tC/ha & Area (million ha) & Total (million tC) \\
\hline Aspen / Birch Group & 93.48 & 0.02 & 1.51 \\
Elm/Ash/Cottonwood Group & 242.91 & 0.02 & 3.93 \\
Loblolly/Shortleaf Pine Group & 163.38 & 0.02 & 2.64 \\
Maple/Beech/Birch Group & 215.00 & 1.58 & 340.21 \\
Oak/Hickory Group & 176.40 & 3.09 & 544.68 \\
Oak/Pine Group & 200.16 & 0.14 & 28.35 \\
Spruce/Fir Group & 197.97 & 0.01 & 1.60 \\
White/Red/Jack Pine Group & 199.63 & 0.03 & 6.46 \\
\hline All & 191.06 & 4.90 & 937.12
\end{tabular}

(Source: USDA 2010)

C stocks in different forest ecosystem components are shown in Fig. 4.4. The model estimated that the standing forest is sequestering atmospheric $\mathrm{C}$ at the rate of 3.54 million tons per year. This sequestration includes intermittent emission but does not include removed biomass. On the agricultural side, 1 million ha of crop lands in WV annually sequester 0.32 million $\mathrm{tC}$ per year. Agricultural land sequestration basically includes $\mathrm{C}$ stored in soil components as above ground crops are removed in the same year. The surface mine lands in WV (WVDEP 2008) sequester negligible C in absence of perennial 
biomass cover. Thus net annual sequestration in the land based component is currently about 3.86 million tC per year.

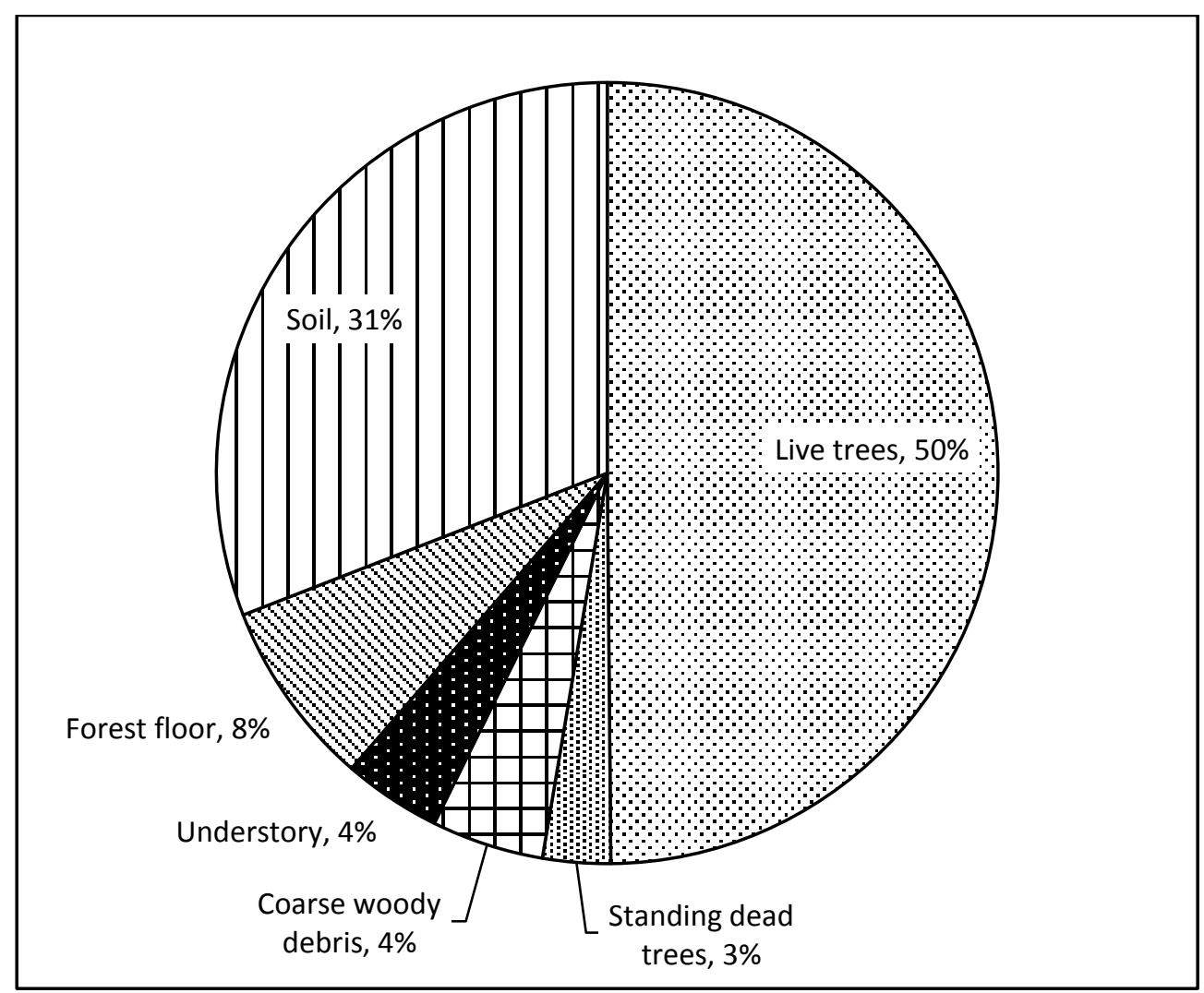

Figure 4.4 Carbon storage in West Virginia forest ecosystem components.

(Source USDA 2010)

\subsubsection{Carbon stored in harvested wood products}

Harvested wood products (HWP) constitute C stock which is sequestered in the forest from the atmosphere through the process of photosynthesis and sequestered in wood products, thus contributes to lower atmospheric C (Dixon et al. 1994). The scale of net reduction in C depends on the final end use of the wood product. Forest harvests in the state have been consistent at the rate of about 7.71 million $\mathrm{m}^{3}$ per year which includes logging residue left on forest floor, and mill residues after primary processing but does not include removal from cultural operations conducted during the forest rotation cycle. The 
average estimated ratio of merchantable volume removed from forest to available residue in the forest is about 1.6, i.e., for 100 cubic meters of merchantable volume extracted, there will be approximately 66 cubic meters of volume of logging residue left in the forest. The merchantable volumes, upon processing at a mill facility, are estimated to leave about $1 / 3^{\text {rd }}$ of raw wood by volume as mill residues. These mill residues have been used for several by-products such as fiber, and fuel wood. The harvested wood is then transformed to different product types and a proportion of the harvested wood products end up as "unused" products such as mill residues and logging residues which is estimated to be approximately 34 percent of the total harvested wood by volume (Table 4.5).

The harvested volume from the existing forest growing stock amounts to 2.26 million tons of $\mathrm{C}$ per year. These removed products are not considered "a loss" if they can be put to different uses other than disposal by burning. The net carbon storage over a 100 year period assumes an equal amount of harvest every year (i.e., annual removal of 2.26 million tons of carbon the forest would make a total of 226 million t $\mathrm{C}$ stocked in wood products). Due to decay and several short term uses and consequent emission, this stock would shrink to a total of 43.33 million t $\mathrm{C}$ under the base case scenario (Fig. 4.5). If the forest can sustainably grow this amount and use patterns remain the same for a defined period of time, almost $4 / 5^{\text {th }}$ of $C$ in HWP is emitted back to the atmosphere, and remaining $1 / 5^{\text {th }}$ remains stored, assuming that the cycle continues with the same level of utilization. 
Table 4.5 Annual estimate of volume of wood products from different sources.

\begin{tabular}{|c|c|c|c|c|c|}
\hline \multirow[b]{2}{*}{ Wood products } & \multicolumn{3}{|c|}{ Volume $\left(\mathrm{m}^{3}\right)$} & \multirow{2}{*}{ Total $\left(\mathrm{m}^{3}\right)$} & \multirow{2}{*}{ percent } \\
\hline & Round wood & Mill residue & Logging residue & & \\
\hline Composite products (cp) & 333,346 & - & - & 333,346 & 3.52 \\
\hline Fuelwood (fw) & 116,999 & 582,256 & - & 699,255 & 7.39 \\
\hline \multicolumn{6}{|l|}{ Post, Poles, and Pilings } \\
\hline (ppp) & 106,948 & - & - & 106,948 & 1.13 \\
\hline Pulpwood (pw) & 615,459 & - & - & 615,459 & 6.50 \\
\hline Sawlogs (sl) & $3,327,767$ & - & - & $3,327,767$ & 35.17 \\
\hline Veneer logs (vl) & 222,281 & - & - & 222,281 & 2.35 \\
\hline Fiber (f) & - & 563,497 & - & 563,497 & 5.96 \\
\hline Misc products (mp) & 13,280 & 354,290 & - & 367,570 & 3.88 \\
\hline Unused (u) & - & 245,921 & $2,980,353$ & $3,226,273$ & 34.10 \\
\hline Total & $4,736,079$ & $1,745,964$ & $2,980,353$ & $9,462,396$ & 100 \\
\hline
\end{tabular}

Source: USDA Timber Product Output data $(1997,2002,2007)$ 


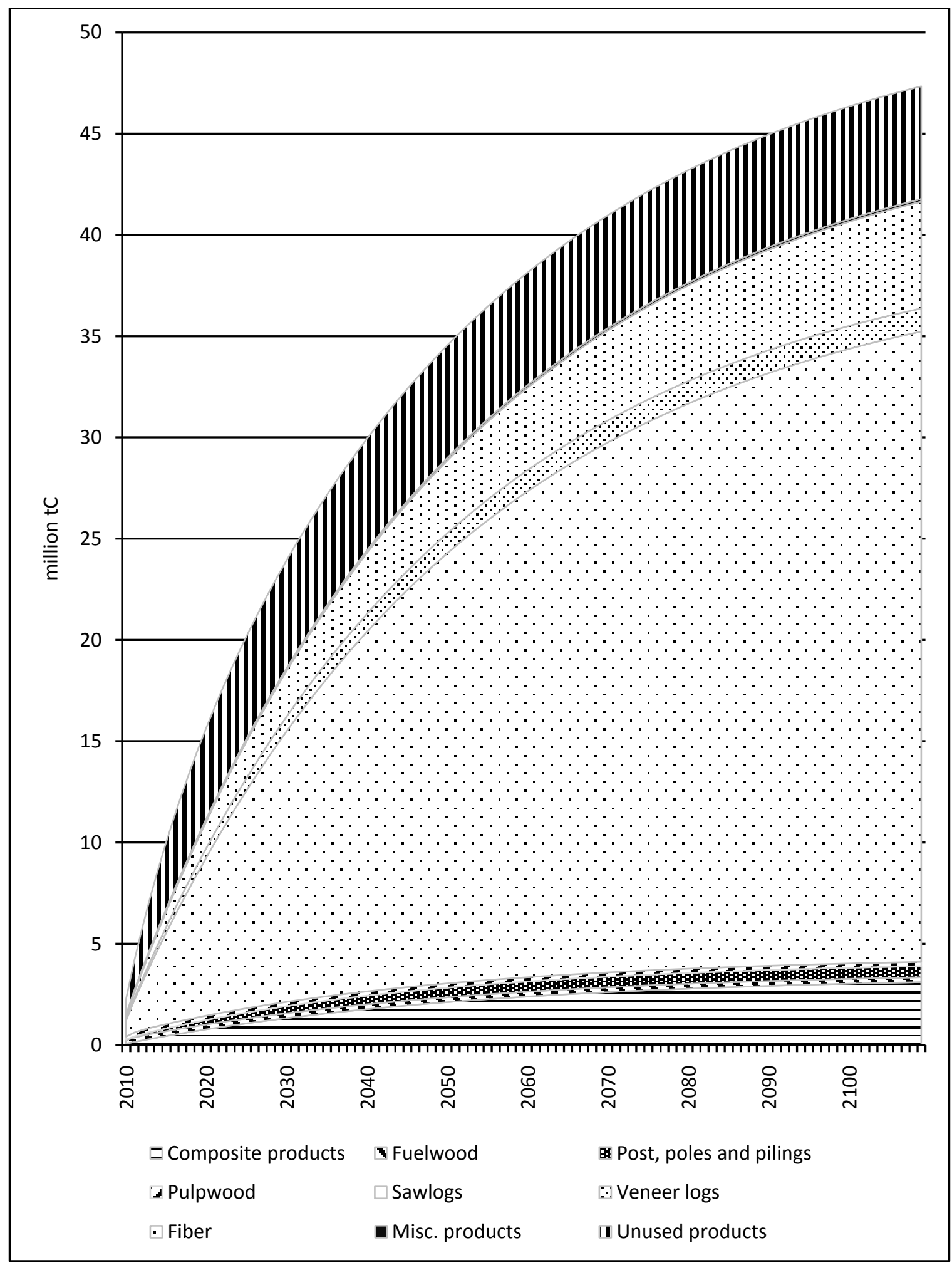

Figure 4.5 Carbon stored in wood products under current level of harvest and use patterns. 


\subsubsection{Carbon emission reduction through biomass utilization}

Presently, approximately 7.39 percent of harvested forest product equivalents are being used as fuel wood to produce energy which emit approximately 0.17 million $\mathrm{tC}$ in the atmosphere and supply about $5862 \mathrm{~kJ}$. If this amount of energy had to be produced from fossil fuel i.e., coal, it would emit approximately 0.11 million $\mathrm{tC}$ to the atmosphere. Since these mill residues would be left unused, they would eventually decay and emit $\mathrm{C}$ in the atmosphere, thus making the net emission of 0.27 million tC. The state produces about 1.5 million $\mathrm{t}$ of logging residues which are currently unused. These residues continuously emit 0.784 million $\mathrm{tC}$ in the atmosphere through decomposition and decay. This unused biomass has the potential to produce approximately of 27,061 billion $\mathrm{kJ}$ of energy, and can offset 0.58 million tC emitted from coal burning. Thus, the net emission benefits of 1.3 million $\mathrm{tC}$ can be achieved by utilizing all the unused biomass for energy production. When such a situation is applied, the carbon stored in wood would shrink to 42.88 million tC (Fig. 4.6), which is about $9 \%$ less than which would have been achieved under the current use pattern. When the emission saving from current fuel wood and potential use of unused residues are combined, biomass energy utilization would have a net benefit of 1.54 million $\mathrm{tC}$ which is approximately 1.8 percent of the state's total emission. A comparison of current and potential emission saving is shown in Fig. 4.7. 


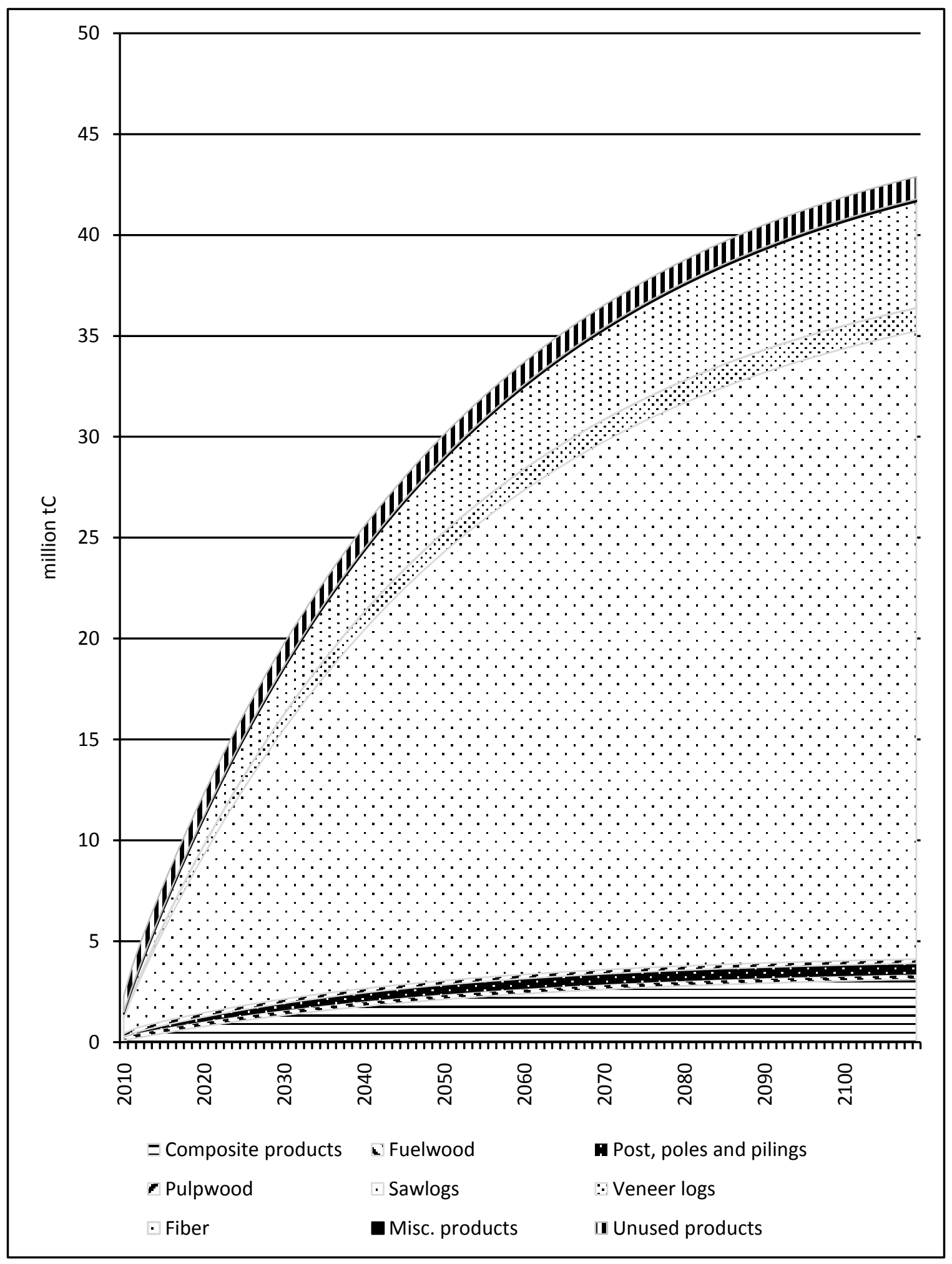

Figure 4.6 Carbon stored in wood products when all unused biomass are used to substitute fossil fuel to produce energy. 


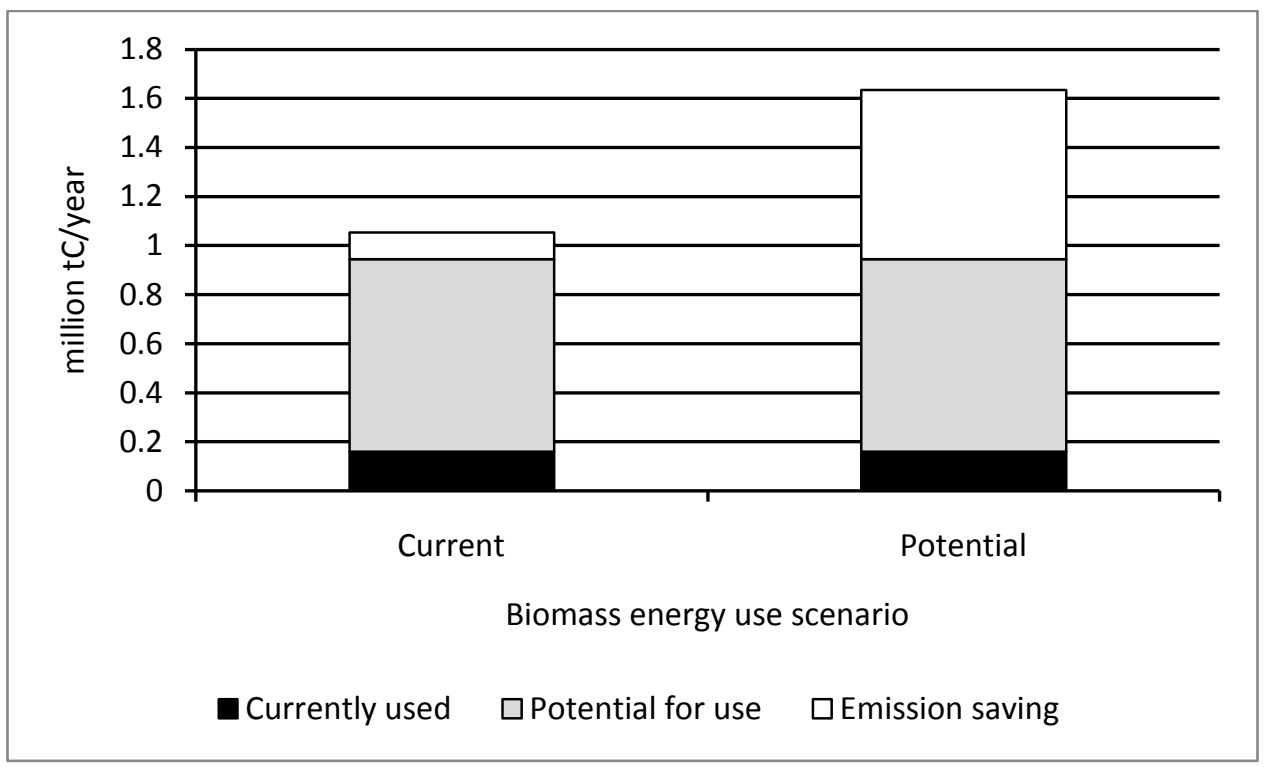

Figure 4.7 Annual estimate of current and potential emissions saving through biomass energy use.

\subsubsection{Carbon sequestration enhancement potential}

Approximately 5.5 million tons of $\mathrm{C}$ is annually sequestered in the state in terrestrial components. Forest growth alone provides over 70 percent of the total annual terrestrial sequestration followed by sequestration in harvested wood products. The forest-based $\mathrm{C}$ stock can be increased by bringing back the harvested stands to forest use and managing them sustainably. Historically, growth to removal ratios have varied in range from 3.78 to 1.3 (The Charleston Gazette Online 2009, Widmann et al. 1998). Although a growth to removal ratio of 1 is theoretically possible, there are practical risks associated with it. For example, when forests are managed with this ratio, there is no margin for detrimental effects of insects, diseases, and climate. Thus, a ratio of 1.25 was assumed as optimally sustainable in this analysis. Such a ratio would bring additional growing space in forests to allow for additional $\mathrm{C}$ sequestration. This would also extend storage capacity by putting more $\mathrm{C}$ in harvested wood products, and supply more fuel wood to replace emission from fossil fuel. The growth-removal ratio has been above 1 in past, but in a declining trend over the past few decades, implying that the state is harvesting more over time. Afforestation of 
marginal agricultural lands has potential for annual sequestration up to 1.45 million $\mathrm{t} C$ per year. If this activity is employed, the total land available for agriculture will be reduced by 60 percent and $\mathrm{C}$ sequestration from agricultural land would equal 0.12 million tons annually with a combined $\mathrm{C}$ sequestration of 1.58 million tons. Reclamation of abandoned mine lands with forests can be achieved by appropriately managing the afforestation projects which would result in an increase in forest area and annual accrual of 0.50 million $\mathrm{t} C$ based on projection of 100 years. Besides sequestration, preventing the stock in harvested pools from decay can help achieve higher $\mathrm{C}$ stock level. For example, the unused residues that accounts for approximately $1 / 3^{\text {rd }}$ of the total harvested carbon from the forest are left in the forest to decay. If such decay is prevented, either through utilization such as in wood-plastic composite (WPC) or using land-fill options to extend the life of these residues, then state's carbon stock in harvested wood products would increase significantly, (about 50\%) as shown in Fig. 4.8. Even if 40 percent of the mine land could be converted to forestry land use, it would contribute to enhancing $\mathrm{C}$ sequestration by 0.11 million tons in the state. Carbon sequestration under different management scenarios are shown in Fig. 4.9 and corresponding $\mathrm{C}$ budget in different pools is shown in Fig. 4.10. These scenarios represent the carbon budget in the state for a 100 -year time period. 


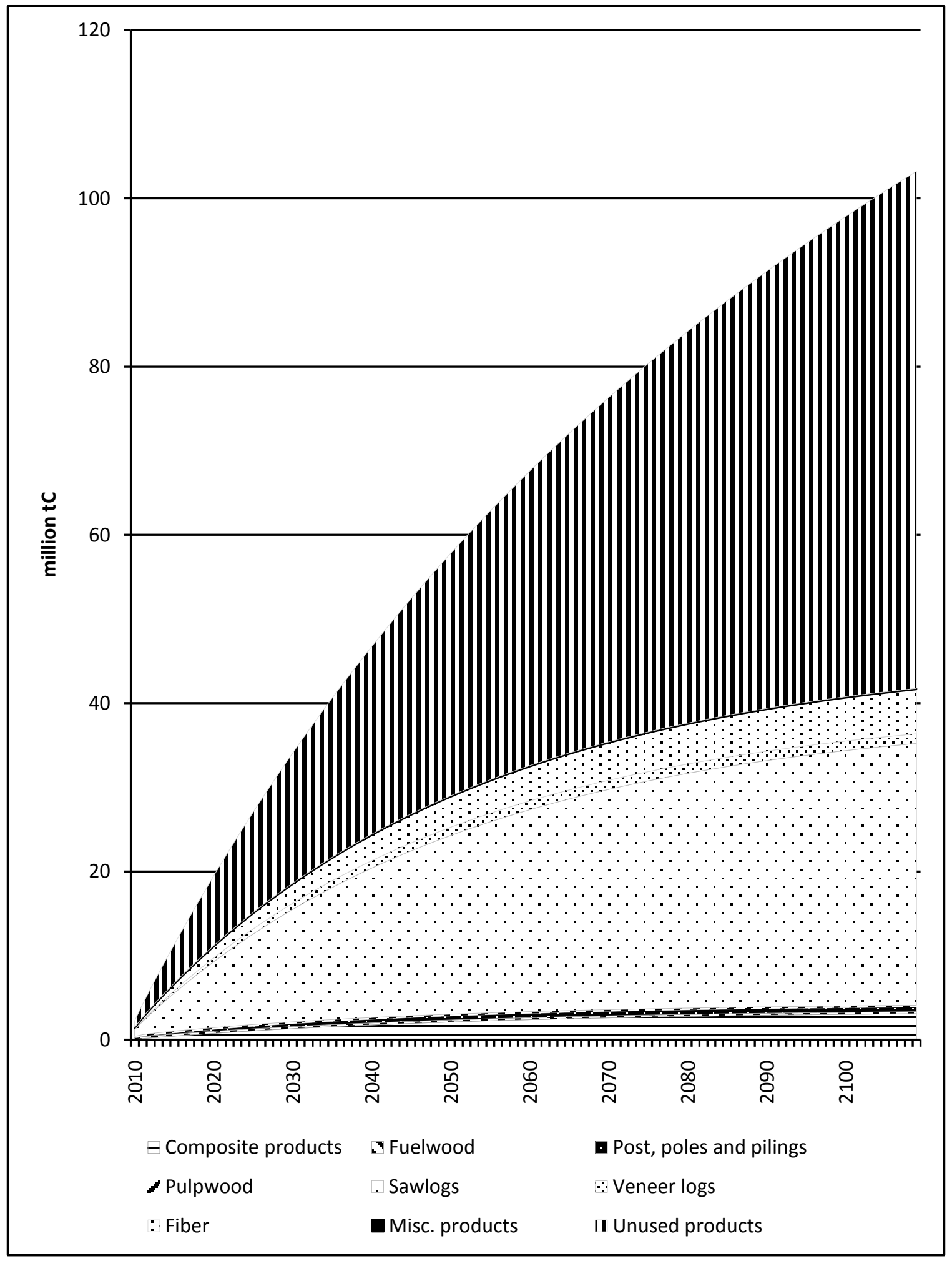

Figure 4.8 Carbon stored in wood products when all unused biomass managed in land fill to prevent quick decay. 


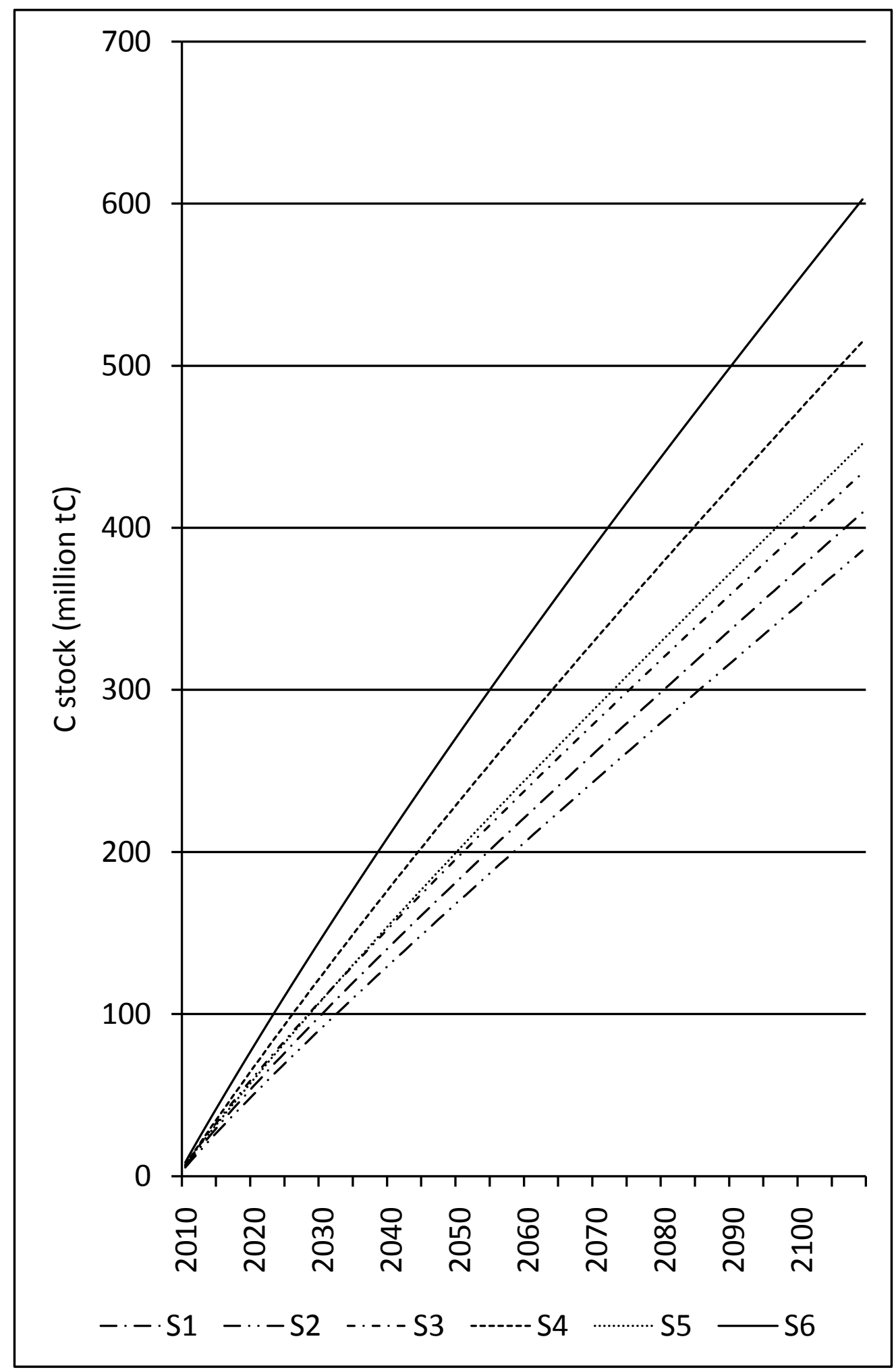

Figure 4.9 Terrestrial carbon stock under different management scenarios. 


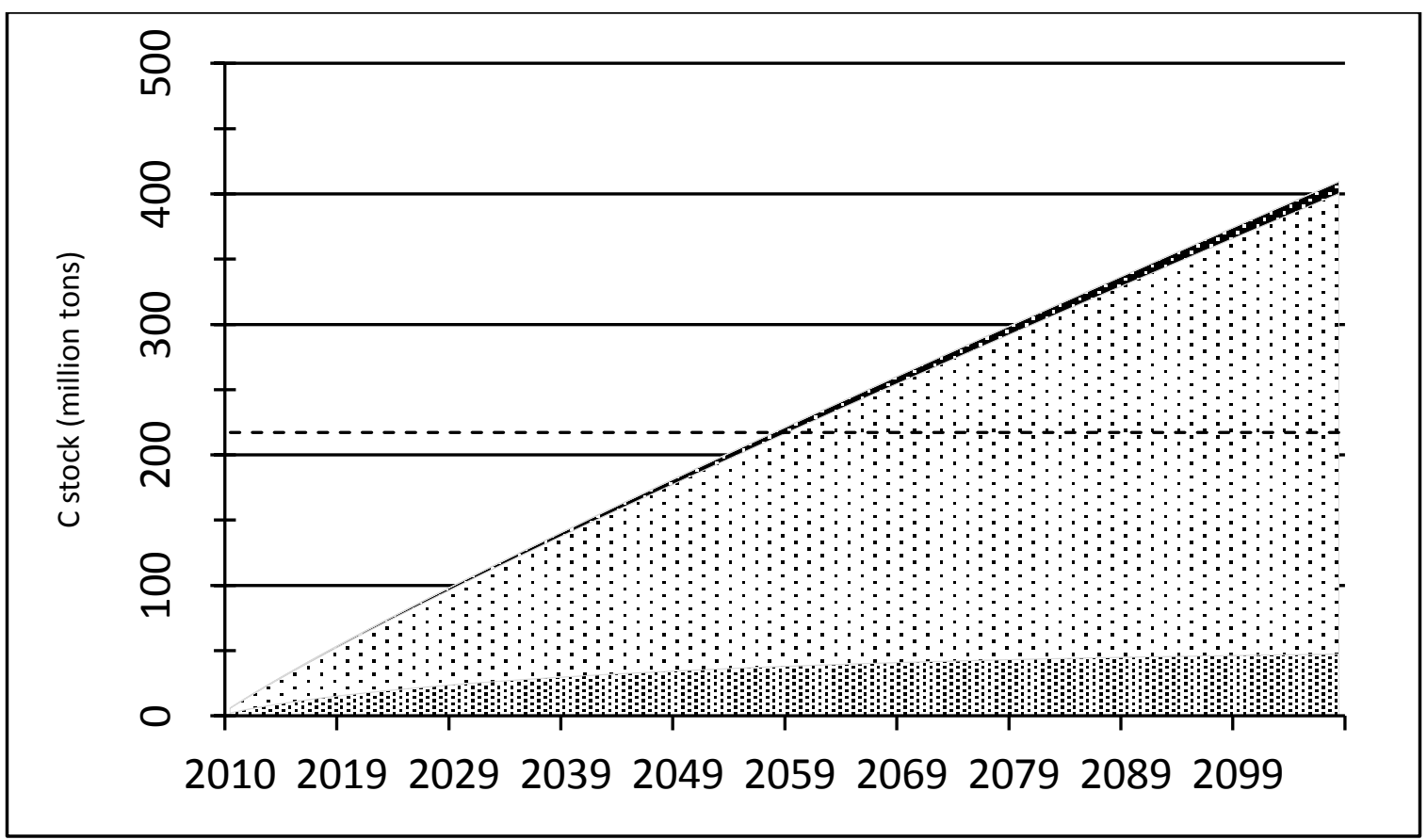

(a)

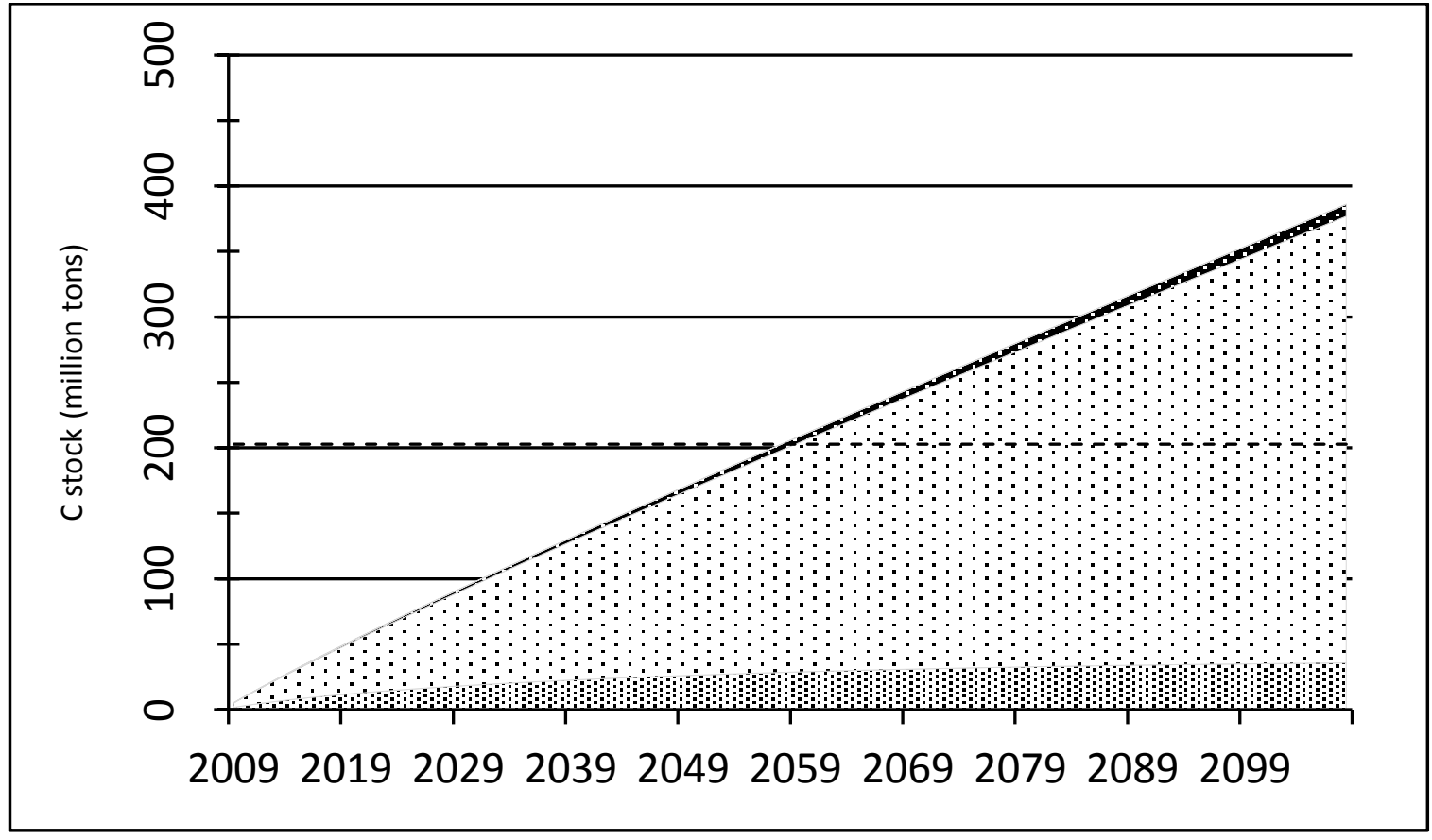

(b) 


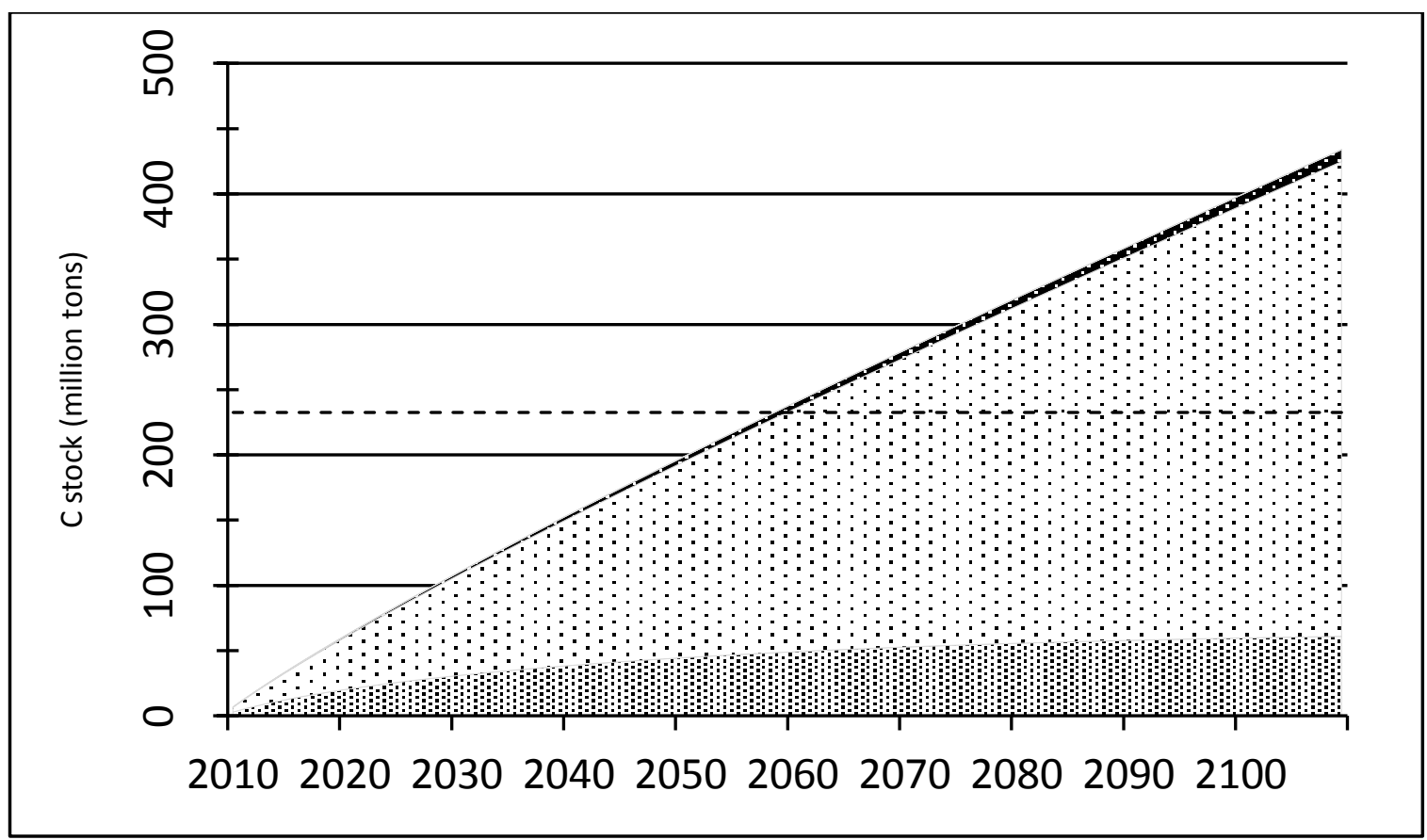

(c)

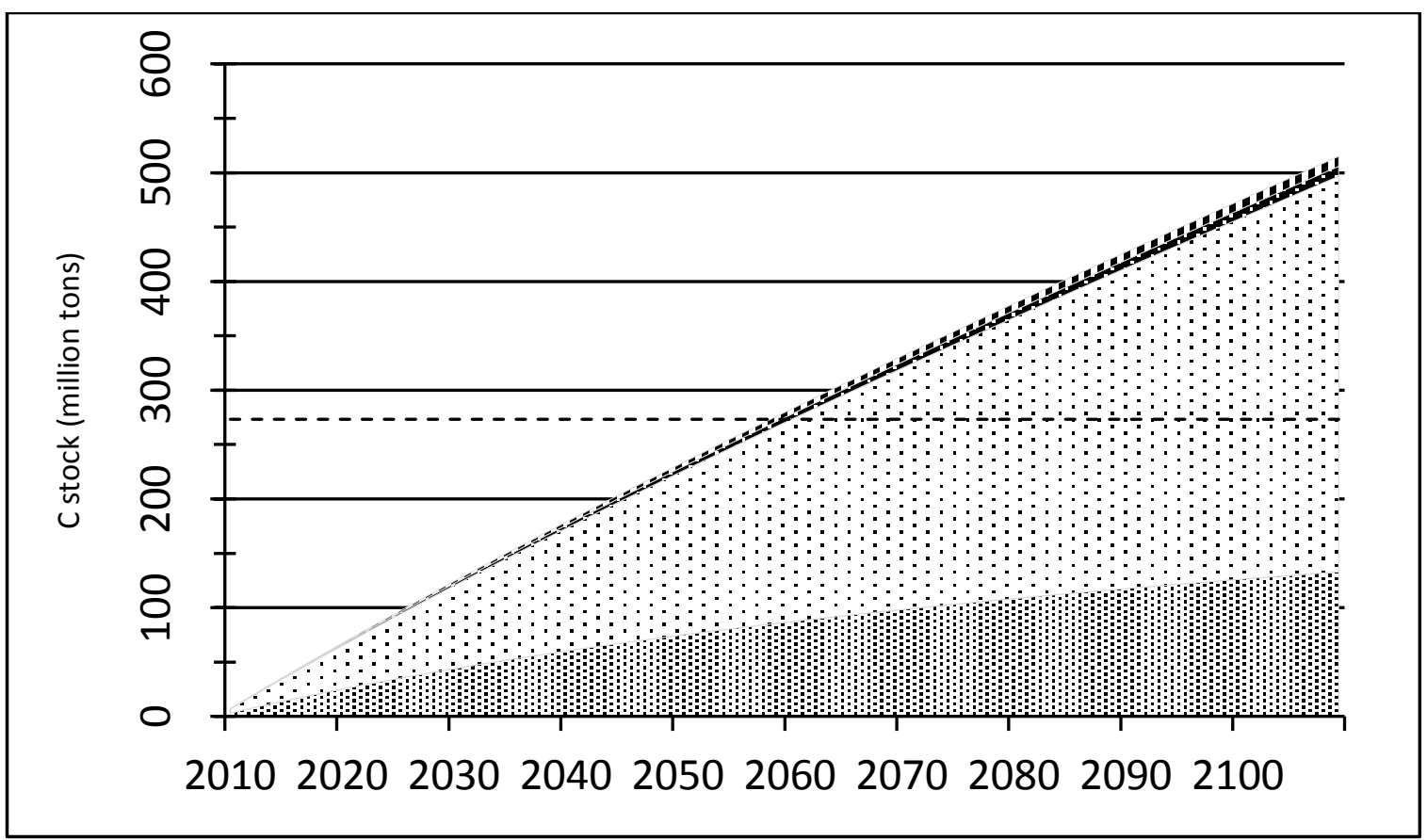

(d) 


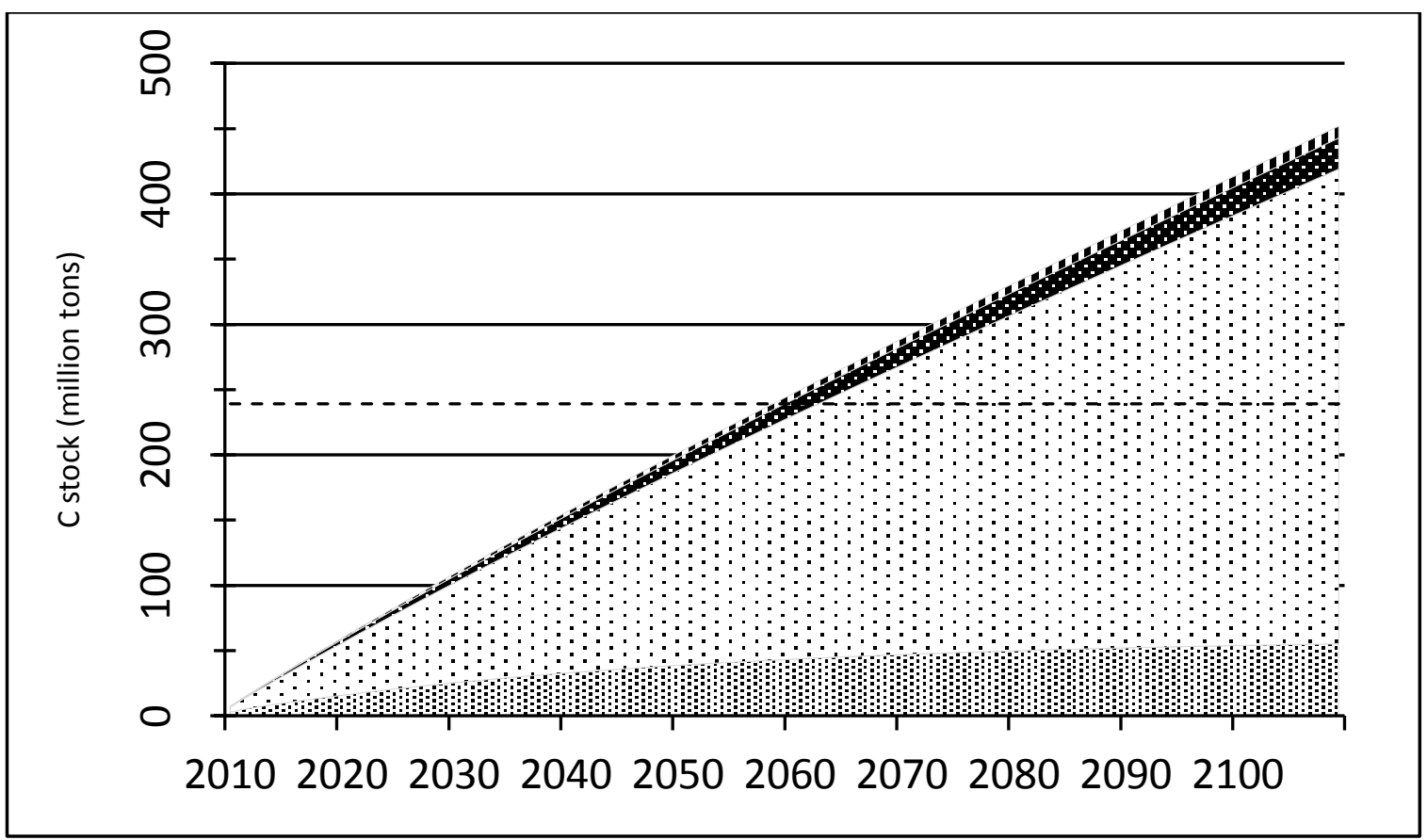

(e)

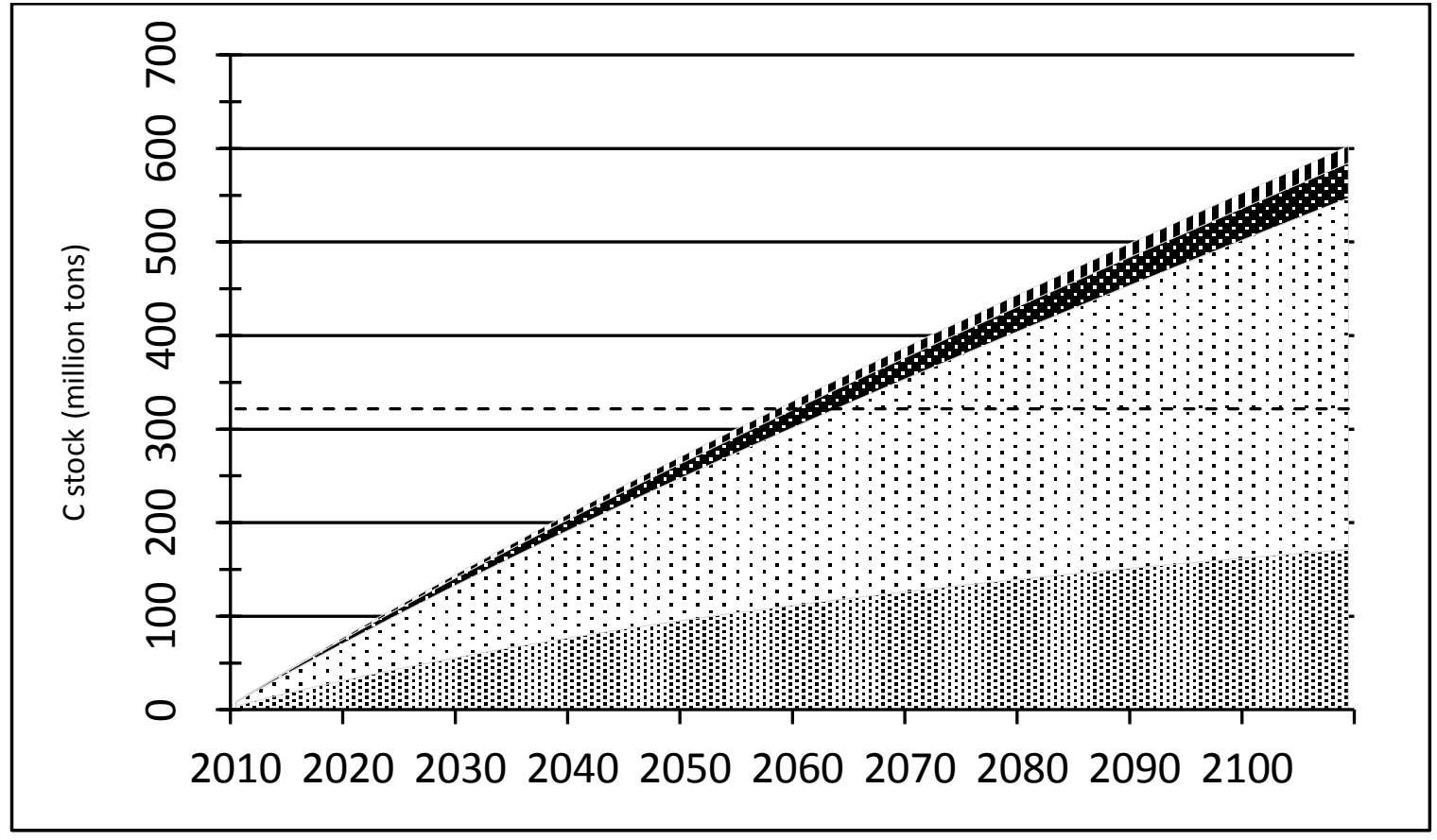

(f)

\section{HWP FS AGS IIIIIIIIAML -..-- Mean}

Figure 4.10 Carbon stock in different terrestrial ecosystem components under different scenarios. Fig. a, b, c, d, e and $f$ respectively represent scenario 1, 2, 3, 4, 5 and 6 described in Table (4.3). HWP, FS, AGS, AML respectively refers to carbon stock in harvested wood products, forests, agricultural lands and mine lands. 


\subsubsection{Alternative $C$ sequestration and terrestrial $C$ sequestration}

Carbon dioxide capture and storage (CCS) provides a range of options to store carbon in the earth's surface, which includes storage in both geologic as well as oceanic earth surface. CCS involves the use of technology to collect and concentrate the C produced in industrial and energy related sources, transport it to a suitable storage location, and then store it away from the atmosphere for an extended period of time. CCS has been a potentially viable solution to reducing GHG. Currently, the estimated cost of managing carbon ranges from $\$ 60$ to $\$ 300$ per ton (IPCC 2005, Friedmann et al. 2006). On the other hand, the cost of carbon sequestration from forest activities ranges from $\$ 10$ to $\$ 150$ per ton, with the median range lying between $\$ 14$ - \$41/t C for the US (Richards and Stokes 2004). Although less expensive, forestry based $\mathrm{C}$ sequestration activities have a maximum upper limit on total sequestration potential. At present, up to 27 percent more $\mathrm{C}$ can be sequestered at a significantly lower cost by modifying current landuse in marginal areas to forest land use. The avoided GHG emissions associated with forest-based fossil fuel alternatives, i.e., fuel wood systems, represent a significant amount of carbon emission savings. These wood resources would eventually decay and emit $\mathrm{C}$ to the atmosphere but if used as fuel, they can help reduce emissions and produce additional energy. The economic savings of wood use in power generation would be further increased when the amount required to dispose off the produced carbon during power generation via geologic sequestration is taken into account. In the absence of fuel wood, 85,451 t of $\mathrm{C}$ which would be produced by burning fossil fuel, would require a total cost in the range of 1.7- 8.5 billion dollars as compared to zero cost for disposal of $\mathrm{C}$ produced from a sustainably grown C neutral biomass fuel source.

\subsection{Discussions and conclusions}

Forest ecosystems of the terrestrial ecosystem component in the state are not only sequestering C from the atmosphere, they are also contributing to reduce the $\mathrm{C}$ emission to the atmosphere. At present, 
this emission reduction is lowering atmospheric $\mathrm{C}$ by 0.27 million $\mathrm{tC}$. This reduction can be further enhanced to contribute a total of 1.57 million $\mathrm{tC}$, equivalent to about 5 percent of the net $\mathrm{C}$ emission in the state. Given the sequestration status and the potential from several activities in the terrestrial ecosystem, one or more of the terrestrial sequestration strategies can be combined to enhance $\mathrm{C}$ sequestration in WV. Sustainably managed forests allow removal of portions of the growing stock accrued over a time period. Thus, there is the possibility of increasing the harvest level of forests up to a point when growth to removal ratio is 1.25 which will put more C in HWP pool. Since the products from these hardwood forests last for a long time period, it provides additional growing space in forests without losing the sequestered $\mathrm{C}$ from the terrestrial component.

Forest area can be increased by converting land use under abandoned mine sites to a forested landscape. Similarly, conversion of marginal agricultural lands to a forested landscape would have a significant impact on increasing forest carbon sequestration. This option is likely to be lucrative, if benefits of emerging carbon markets can be made available to farmers who wish to convert their land to forestry. Reducing emission level at their source is another option to which forestry based activities can contribute by providing an alternative fossil fuel. Increasing bio-based fuels in power plants can have simultaneous and symbiotic effects on the levels of emission and sequestration. This fuel wood use will also create an opportunity for growing more timber, resulting in more sequestration. Over the long run, the carbon neutrality or positivity of using biofuel would help achieve the emission reduction objectives. The use of biomass for fuel will also reduce cost by avoiding the need to reduce the forest fuel loads for fire related implications. The unused woody residue which normally would be a source of $\mathrm{C}$ through natural decay, can be used to substitute 1.04 times the carbon equivalent from coal by avoiding the burning of fossilfuel. Since the order of magnitude of estimate for the amount of biomass required for reduction in $\mathrm{C}$ emissions was within the range of coal-biomass feed systems, it is reasonable to assume that existing technology is adequate (NETL 2007) for the option. When such a strategy can be combined with CCS techniques, future negative $\mathrm{C}$ emissions can be achieved that could permanently reduce the $\mathrm{C}$ in the atmosphere by substituting carbon neutral sustainably grown biomass for carbon emitting fossil fuels. 
The analysis and results presented in this paper are based on the notion that the land use condition does not deteriorate significantly over time. Historically, forest areas had remained consistent around 5.54 million ha in West Virginia and it was assumed that this consistency remains in place in future. This consistency is likely in view of emerging carbon markets where individual landowners can receive supplemental payments for $\mathrm{C}$ sequestration in emerging carbon markets (Brooke 2009). The carbon sequestration in agricultural lands is sensitive to the use of the land for the agricultural production each year. Leaving agricultural lands fallow would result in emissions rather than sequestration. The mine lands are supposed to be vegetated as part of restoration obligation and thus afforestation activities are likely in these lands. The forest growth rate and consequently carbon sequestration by these forest resources under active management, is based on the simulation results. The afforestation activities carried out in the abandoned mine lands and marginal agricultural lands are assumed to have no effect in the total budget of harvested wood products because of the current rotation age applicable in the region which is in the range of 80 to 140 years in the hardwood region. Thus, the benefits in terms of harvesting would only start to accrue after newly regenerated forests surpass the age of standard harvesting. This implementation would slightly underestimate the $\mathrm{C}$ sequestration potential in the state if afforestation activities use short rotation woody crops. Instead of leaving unused residues to decay, if they are properly land filled or buried to extend their lives, the carbon remains stored for a longer period of time. This would reduce emissions from harvested products by up to 50 percent.

Forest products that are removed have different end uses and thus different emission levels. Preventing decay of these wood products would have a significant impact in offsetting $\mathrm{C}$ emissions to the atmosphere. For example, wood products used in pulp and paper would generally last for one year or less. On the other hand, long lasting wood products such as structural timber and furniture retain stored carbon for an extended period of time and go through multiple instances of recycling. Although it is estimated that more than 500 wood processing facilities exist and are growing across the country (EPA 1998) primarily in recovering and recycling wood waste, no quantified information is available on the size and distribution of wood recycling markets at the national level (Falk and McKeever 2004). Recycling, 
avoiding combustion to dispose the wood, and utilizing available residues to replace fossil fuel for power generation would reduce $\mathrm{C}$ emission in the state. Similarly, proper landfills and wood burials can be helpful in enhancing $\mathrm{C}$ sequestration options for the state, rather than merely leaving wood residues on site to decay (Zeng 2008). Thus, West Virginia has the potential to increase the existing C sequestration rate by up to 52 percent to achieve a net annual sequestration rate of 7.62 million tons. These potentials can be achieved by carrying out land use change activities in the marginal agricultural lands and abandoned mine sites, enhancing forest growth and increasing sustainable wood products utilization - a representative of aggressive scenario described earlier (Table 4.3). When unused biomass residues are managed properly to extend the decomposition period, it can delay the return of sequestered $\mathrm{C}$ to the atmosphere and thus enhance the $\mathrm{C}$ stock in the terrestrial component.

The model is sensitive to several of parameters used. The growth-to-removal parameter is likely to have a significant effect in determining $\mathrm{C}$ sequestration, as this ratio controls the amount of wood harvested. This ratio also determines the amount of $\mathrm{C}$ sequestered in forest by proportionally allocating two different $\mathrm{C}$ sequestration rates. The utilization proportions of wood in different categories are next most important parameters. The model is also sensitive to expected half-life and longevity of different wood products, which determines the remaining amount of $\mathrm{C}$ stored in these products over time. The scenarios generated for enhancement options (Fig. 4.9), and various use of unused products (Fig. 4.5, 4.6, and 4.8) provide some insights into model sensitivity. The model described here can be generalized for any geographic location based on the availability of input parameters and data. Key input parameters in this model are information on land use conditions, carbon sequestration rates in existing land uses, forest harvest information, forest products utilization information and management methods. These input parameters are generally available from the literature and with some modification of the default parameters, the model can be used for any area where forestry is a major land use component. 


\section{References}

Brooke, R. 2009. Payments for forest carbon. Opportunities \& challenges for small forest owners. Northern Forests Center. NH.

The Charleston Gazette Online. 2009. Timber committee formed: Panel will examine direction of industry. Available online at http://www.wvgazette.com/static/series/timber/COMMITTEE.html (Assessed on 02/19/2010).

Cole, V., Cerri, C., Minami, K., Mosier, A., Rosenberg, N., Sauerbeck, D. 1996. Agricultural options for mitigation of greenhouse gas emissions. In R.T. Watson, M.C. Zinyowera and R.H. Moss (eds.), Climate Change 1995: Impacts, Adaptations and Mitigation of Climate Change: ScientificTechnical Analyses, New York, Cambridge University Press.

Dixon, R.K., Brown, S., Houghton, R.A., Solomon, A.M., Trexler, M.C., Wisniewski, J. 1994. Carbon pools and flux of global forest ecosystems. Science 263:185-190.

Eggers, T. 2002.The impacts of manufacturing and utilization of wood products on the European carbon budget. European Forest Institute. Joensu, Finland.

EPA [US Environmental Protection Agency]. 1998. Characterization of building related construction and demolition debris in the United States. Report No. EPA 530-R-98-010. Washington DC.

Falk, R.H., McKeever, D.B. 2004. Recovering and wood for reuse and recycling: a United Stated perspective. In proc. European COST E31 Conference: Management of Recovered Wood Recycling Bioenergy and Other Options. Thessaloniki, University Studio Press: 29-40.

Friedmann, S.J., Dooley, J.J., Held, H., Edenhofer, O. 2006. The low cost of geological assessment for underground $\mathrm{CO} 2$ storage: Policy and economic implications. Energy Conversion and Management 47:13-14.

Galang, J.S., Zipper, C.E., Prisley, S.P., Galbraith, J.M., Donovan, P.F. 2007. Evaluating terrestrial carbon sequestration options for Virginia. Environ Manage 39:139-150. 
Grantham, J.B., Ellis, T.H. 1974. Potentials of wood for producing energy. Journal of Forestry 72:552556

Hamilton, K. Shapiro, A., Marcello, T. 2009. Fortifying the foundation - state of the voluntary carbon markets 2009. Ecosystem Marketplace and New Carbon Finance.

Homer, C., Huang, C., Yang, L., Wylie, B., Coan, M. 2004. Development of a 2001 National Landcover Database for the United States. Photogrammetric Engineering and Remote Sensing, Vol. 70, No. 7, July 2004, pp. 829-840.

IEA [International Energy Agency]. 2004. The prospects for CO2 capture and storage. Organization for Economic Cooperation and Development. Paris, France.

IPCC [Intergovernmental Panel on Climate Change]. 2003. Good Practice Guidance for Land Use, LandUse Change and Forestry. In: Penman J, Gytarsky M, Hiraishi T, Krug T, Kruger D, Pipatti R, Buendia L, Miwa K, Ngara T, Tanabe K, Wagner F, editors. Intergovernmental Panel on Climate Change (IPCC), IPCC/IGES, Hayama, Japan

IPCC [Intergovernmental Panel on Climate Change]. 2005. Carbon dioxide capture and storage. Cambridge University Press.

Karjalainen, T., Pussinen, A., Liski, J., Nabuurs, G.J., Erhard, M., Eggers, T., Sonntag, M., Mohren, F. 2002. An approach towards an estimate of the impact of forest management and climate change on the European forest sector budget: Germany as a case study. Forest Ecology and Management $162: 87-103$

Marland, G., Schlamadinger, B. 1995. Biomass fuels and forest management strategies: How do we calculate the greenhouse emissions benefits? Energy 20:1131-1140.

Moulton, R.J., Richards, K.R. 1990. Costs of Sequestering Carbon Through Tree Planting and Forest Management in the United States, GTR-WO-58, U.S. Department of Agriculture, Forest Services, Washington, DC. 
NETL [National Energy Technology Laboratory]. 2007. Increasing security and reducing carbon emissions of the U.S. Transportation sector: A transformational role for Coal with biomass. DOEl/NETL-2007/1298.

Niu, X., Duiker, S.W. 2006. Carbon sequestration by afforestation of marginal agricultural land in Midwestern US. Forest Ecology and Management 223: 415-427.

Piessens, K., Dusar, M. 2004. Feasibility of CO2 sequestration in abandoned coal mines in Belgium. Geologica Belgica 7:165-180.

Richards, K.R., Stokes, C. 2004. A review of forest carbon sequestration cost studies: a dozen of research. Climate Change 63:1-48.

Schelhaas, M.J., van Esch, P.W., Groen, T.A., de Jong, M.K., Kannienen, M., Liski, J., Masera, O., Moheren, G.M.J., Nabuurs, G.J., Palosuo, T., Pedroni, L., Vallejo, A., Vilen, T. 2004. CO2FIX V 3.1 - A modeling framework for quantifying carbon sequestration in forest ecosystems. Wageningen, NL.

Sharma, B.D., Wang, J., Brooks, J.R., Miller, G. 2010 Evaluating forest harvest strategies to enhance timber production and carbon sequestration. Manuscript prepared for successive submission to Forest Science.

Smith, W.B. 1991. Assessing removals for North Central Forest Inventories. Res. Pap. NC-299. U.S. Department of Agriculture. Forest Service. North Central Forest Experiment Stations, St. Paul, MN.

Sperow, M. 2006. Carbon sequestration potential in reclaimed mine sites in seven East-Central states. Journal of Environment Quality 35:1428-1438.

Sperow, M., Eve, M., Paustian, K. 2003. Potential soil C Sequestration on US agricultural soils. Climate Change 57:319-339.

The Charleston Gazette Online. Not Dated. Is W. Va. running out of trees? Forest study shows alarming trends. Available online at http://www.wvgazette.com/static/series/timber/GROWTH.html (accessed on February 10, 2010). 
USDA FS 2009. Forest Inventory Data Online Vers. 1.30r0. US Department of Agriculture. Forest Service. Available online at http://fiatools.fs.fed.us/fido/index.html (accessed on February 10, 2010)

USDA. 2010. COLE 1605(b) Report for West Virginia. COLE Development Group, February 19, 2010. USDA Forest Sertive and RWU-4104, Durham, NH. Available online at http://ncasi.uml.edu/COLE/cole.html (accessed on February 10, 2010)

USDA-FPL [United States Department of Agriculture-Forest Product Laboratory]. 1953. Density, fiber length, and yields of pulp from various species of wood. Technical note 191.

USDA-FPL. 2004. Fuel Value Calculator. TechLine, WOE 3. USDA Forest Producet Laboratory. State \& Private Forestry Technology Marketing Unit. Madison, WI.

USEPA [U.S. Environmental Protection Agency]. 2005. Greenhouse gas mitigation potential in U.S. forestry and agriculture. EPA 430-R-05-006. Office of Atmospheric Programs, Washington, DC.

USEPA [United States Environmental Protection Agency] 2009. Inventory of U.S. Greenhouse Gas Emissions and Sinks: 1990 - 2007. USEPA Washington DC.

Wang, J., Grushecky, S., McNeel, J. 2007.Biomass resources, uses and opportunities in West Virginia. Biomaterials and Wood Utilization Research Center. West Virginia University, Morgantown, WV.

West Virginia Plant Fossils (WVPF). 2009. The APPALACHIAN "MOUNTAINS". Available online at http://www.geocraft.com/WVFossils/coal_rank.html (last accessed on January 31, 2009).

Widmann, R.H., Wharton, E.H., Murriner, E.C. 1998. West Virginia timber products output: 1994. Resource Bulletin NE-143. U.S. Department of Agriculture, Forest Service, Northeastern Research Station, PA.

WVDEP [West Virginia Department of Environmental Protection] -Division of Mining and Reclamation] 2008. West Virginia Mining Permit Boundary Data. Available online http://gis.wvdep.org/data/omr.html (Accessed on April, 6, 2009).

Zeng N. 2008. Carbon sequestration via wood burial. Carbon Balance and Management 3:1-12. 


\section{Appendix 4.1}

$G R R$ used in the model is net growth to removal ratio which can be mathematically stated as in Eq. (4.13).

$$
G R R=\frac{G-R}{R}
$$

where $G$ is gross growth from the forest, and $G R R$, growth to removal ratio is known, which is based on management requirement, $R$ can be estimated as in Eq. (4.14-4.16).

$$
\begin{gathered}
R * G R R=G-R \\
\text { or }(1+G R R) * R=G \\
\text { or } R=\frac{G}{1+G R R}
\end{gathered}
$$

Net growth $(N)$ is the gross growth minus the removed products upon harvesting, i.e., $\mathrm{N}=\mathrm{G}-\mathrm{R}$. When the information on net growth is available, then $R$ can be estimated as in Eq. $(4.17-4.18)$

$$
\begin{aligned}
& R=\frac{G-R}{G R R} \\
& \text { or } R=\frac{N}{G R R}
\end{aligned}
$$

When forest products are removed with certain $G R R$, then average forest growth rate can be estimated using proportionally allocated forest growth rates as used in Eq. (4.4). This is because some trees in the forest would not be harvested if GRR is over 1 whose long term growth rate would be smaller than the areas where harvesting takes place and they will progressively become over- mature lowering the average sequestration of the forest. 
The above derivation is explained with an example. Lets assume that there is a forest of 100 ha in area. Growth to removal ratio implies that for one unit of removal in forest, a corresponding unit of forest is not removed. Thus, when the growth and removal ration of this forest is 1.5 at one particular year total area with harvesting activities becomes 40 using Eq. 4.1.1 with $\mathrm{G}=100$, GRR $=1.5$ and $\mathrm{R}$ is estimated. The total area where harvesting did not occur becomes 60 (Eq. D.6). Now lets assume that a forest is harvested where harvesting takes place at a particular year and the forest is allowed to grow until the end of the rotation period. The newly regenerated forest will grow at higher growth rate than the forest where harvesting does not occur. For example, lets say, mean $\mathrm{C}$ sequestration per ha is 0.25 for stands without harvest and $0.40 \mathrm{tC} / \mathrm{ha}$ for stands with harvest. By applying these values, the $\mathrm{C}$ sequestration for the forest comes out to be:

$0.25 \mathrm{tC} / \mathrm{ha} \mathrm{X} 60 \mathrm{ha}+0.40 \mathrm{tC} / \mathrm{ha} \mathrm{X} 40 \mathrm{ha}=31$ ha for the forest in the given year.

Now, if we plug the values in Eq. 4.4, sequestration in the forest comes out to be $31 \mathrm{tC}$ which is equal to value derived above.

$$
\begin{gathered}
C_{f}=A \frac{1}{G R R+1}\left(G R R * r_{1}+r_{2}\right) \\
C_{f}=100 \frac{1}{1.5+1}(1.5 * 0.25+0.40) \\
C_{f}=100 * \frac{1}{1.5+1}(1.5 * 0.25+0.40) \\
C_{f}=100 * \frac{0.775}{2.5}
\end{gathered}
$$


Therefore, Eq. 4.4 can be used to estimate the mean sequestration of forest when the growth of forest and targeted growth to removal ratio is supplied which are easier to estimate than identifying the amount of area of harvested wood for a region. The management implication of these methods is important in the face of difficulties in monitoring the harvest by amount of woods or by acreage of harvest. A target growth to removal can be supplied instead. 


\section{CON CLUS I O N S}

The "Forest Harvest Planning System" was developed to generate the spatio-temporal harvest scheduling activities which are useful in simplifying spatio-temporal forest harvest problems which involves a large number of stand-time period combinations and multiple constraints. The MILP problem formulation would otherwise have been challenging. The tested algorithms successfully generated optimization models based on simple users input that could be included through graphical user's interfaces. The generated model can be solved with the built-in solver (lp_solve) in the system. The system also allowed exporting the problem in common commercial solver (CPLEX) for large problems that take a long time to solve using the prototype software developed.

The new modeling approach (incorporation of recovery time period in objective function formulation and successive forest harvest scheduling implementation) allowed stands to retain a high proportion of carbon for the planning duration than alternative forest harvest schedules. This gain was highest in harvesting of clearcuts with spatial constraints but the gains were also higher in selection cuts. The forest carbon sequestration can thus be optimized using this approach. Some of the common harvest practices such as non declining flow of harvest volumes have negative consequences in forests' roles in enhancing $\mathrm{C}$ sequestration. Instead of ensuring the even flow of volume, a more aggressive approach of harvesting the stands as soon as its long term potential of $\mathrm{C}$ sequestration potential peaks would provide long-term $\mathrm{C}$ sequestration benefits. This will also allow optimal utilization of scarce growing space for new regeneration which otherwise would be occupied by mature trees. Currently, this approach has industrial significance since hardwood lumber imports in the US are increasing and it can be anticipated that the harvested products do not entail additional storage costs.

The terrestrial carbon balance of West Virginia was studied by developing a system model using stock and flow of carbon in different pools in forests, agricultural lands and abandoned mine lands. If managed, these land-uses could provide over 50\% additional carbon per year than that of the current level. Harvested forest products in the state account for approximately one-half of the total carbon stored 
in the state and this is an important component which cycles over the time period. Biomass resources such as wood residues have important implications in reducing emissions by substituting fossil fuels. Therefore it is concluded that West Virginia, which has abundant forest resources, can achieve emission reductions which is desirable in light of global concerns over greenhouse gas (GHG) emissions through sustainable management of these forest resources. These activities not only provide products for society but also provide emission reduction, energy savings as well as other ecosystem benefits. The forestry-based activities in other marginal lands or lands otherwise barren can play a significant role in the state's carbon balance in the future.

Based on the three topical research papers described in Chapters 2, 3 and 4, this dissertation concludes that efficient harvesting using optimally sustainable forest management practices can be seen as a viable alternative to commercially less economic alternatives to carbon emission reductions which are still at an incipient stage. The dissertation research also foresaw few topical future research ideas that can increase our understanding of forest-based carbon sequestration. Adding regeneration components in the harvest scheduling system is likely to enhance the applicability of the system developed for this research. The system model developed to study the carbon budget in WV can be further improved by including stochasticity in parameters to observe the risks and variations. A life cycle analysis of the cost of different processes of terrestrial carbon sequestrations would help understand the true cost of sequestration process. The model developed and presented in this dissertation utilized data from TPO for harvested wood products and in the future more accurate data from first hand surveys could provide better estimates of the flows of carbon from forest to harvested wood products pools to accurately account for the contribution of harvested wood products in reducing emissions. As in any models, continuous review of the parameter accuracy and their sensitivity should be a part of future research work for enhancing the accuracy of model output. This will consequently make the decisions based on these outputs more applicable and appropriate. 


\section{B I B L I O G R A P H Y}

Backeus, S., Wikstrom, P., Lamas, T. 2005. A model for regional analysis of carbon sequestration and timber production. Forest Ecology and Management 216:28-40.

Brooke, R. 2009. Payments for forest carbon. Opportunities \& challenges for small forest owners. Northern Forests Center. NH.

Buongiorno, J., Gilless, J.L. 2003. Decision Methods for Forest Resource Management, Academic Press, San Diego, CA.

Cole, V., Cerri, C., Minami, K., Mosier, A., Rosenberg, N., Sauerbeck, D. 1996. Agricultural options for mitigation of greenhouse gas emissions. In R.T. Watson, M.C. Zinyowera and R.H. Moss (eds.), Climate Change 1995: Impacts, Adaptations and Mitigation of Climate Change: ScientificTechnical Analyses, New York, Cambridge University Press.

Crookston, N.L, Dixon, G.E. 2005. The forest vegetation simulator: A review of its structure, content, and applications. Computer and Electronics in Agriculture 49:60-80.

Diaz-Balteiro, L., Romero, C. 2003. Forest management optimization models when carbon captured is considered: a goal programming approach. Forest Ecology and Management 174:447-457.

Dixon, R.K., Brown, S., Houghton, R.A., Solomon, A.M., Trexler, M.C., Wisniewski, J. 1994. Carbon pools and flux of global forest ecosystems. Science 263:185-190.

Dixon, G. E. 1986. Prognosis mortality modeling. Internal Rep. Fort Collins, CO: U. S. Department of Agriculture, Forest Service, Forest Management Service Center.

Dixon, G.E. (comp.). 2002. Essential FVS: A user's guide to the Forest Vegetation Simulator. Internal Report. U.S. Department of Agriculture, Forest Service, Forest Management Service Center, Fort Collins, CO.

Eggers, T. 2002.The impacts of manufacturing and utilization of wood products on the European carbon budget. European Forest Institute. Joensu, Finland. 
EPA [US Environmental Protection Agency]. 1998. Characterization of building related construction and demolition debris in the United States. Report No. EPA 530-R-98-010. Washington DC.

Falk, R.H., McKeever, D.B. 2004. Recovering and wood for reuse and recycling: a United Stated perspective. In proc. European COST E31 Conference: Management of Recovered Wood Recycling Bioenergy and Other Options. Thessaloniki, University Studio Press: 29-40.

Frakes, I., Bugg, A.L. 2001. Optimizing algorithms for forest planning and decision-making. New Zeland Journal of Forestry 45:5-9.

Friedmann, S.J., Dooley, J.J., Held, H., Edenhofer, O. 2006. The low cost of geological assessment for underground $\mathrm{CO} 2$ storage: Policy and economic implications. Energy Conversion and Management 47:13-14.

Galang, J.S., Zipper, C.E., Prisley, S.P., Galbraith, J.M., Donovan, P.F. 2007. Evaluating terrestrial carbon sequestration options for Virginia. Environ Manage 39:139-150.

Goycoolea, M., Murray, A., Vielma, J.P., Weintraub, A. 2009. Evaluating alternative approaches for solving the area restriction model in harvest scheduling. Forest Science 55: 149-165.

Grantham, J.B., Ellis, T.H. 1974. Potentials of wood for producing energy. Journal of Forestry 72:552556

Guldin, J.M. 1991. Uneven-aged BDq regulation of Sierra Nevada mixed conifers. West. J. Appl. For. $6: 27-32$.

Gustafson, E.J., Crow, T.R. 1994. Modeling the effects of forest harvesting on landscape structure and the spatial distribution of cowbird brood parasitism. Landscape Ecology 9:237-248.

Hamilton, D. A., Jr. 1986. A logistic model of mortality in thinned and unthinned mixed conifer stands of northern Idaho. Forest Science 32: 989-1000.

Hamilton, D. A., Jr. 1991. Implications of random variation in the Stand Prognosis Model. Res. Note INT-394. Ogden, UT: U. S. Department of Agriculture, Forest Service, Intermountain Research Station. 
Hamilton, K. Shapiro, A., Marcello, T. 2009. Fortifying the foundation - state of the voluntary carbon markets 2009. Ecosystem Marketplace and New Carbon Finance.

Hoen, H.F., Solberg, B. 1994. Potential and economic efficiency of carbon sequestration in forest biomass through silvicultural management. Forest Science 40:429-451

Hokans, R.H. 1983. Evaluating spatial feasibility of harvest schedules with simulated stand selection decisions. Journal of Forestry 81:603-613.

Homer, C., Huang, C., Yang, L., Wylie, B., Coan, M. 2004. Development of a 2001 National Landcover Database for the United States. Photogrammetric Engineering and Remote Sensing, Vol. 70, No. 7, July 2004, pp. 829-840.

Hyams, D.G. 1997. CurveExpert Version 1.3 - A comprehensive curve fitting system for Windows. available at http://curveexpert.webhop.biz/.

IEA [International Energy Agency]. 2004. The prospects for CO2 capture and storage. Organization for Economic Cooperation and Development. Paris, France.

ILOG CPLEX. 2008. Division, ILOG CPLEX 11.0 Reference Manual. Available at http://www.cplex.com.

IPCC [Intergovernmental Panel on Climate Change]. 2003. Good Practice Guidance for Land Use, LandUse Change and Forestry. In: Penman J, Gytarsky M, Hiraishi T, Krug T, Kruger D, Pipatti R, Buendia L, Miwa K, Ngara T, Tanabe K, Wagner F, editors. Intergovernmental Panel on Climate Change (IPCC), IPCC/IGES, Hayama, Japan

IPCC [Intergovernmental Panel on Climate Change]. 2005. Carbon dioxide capture and storage. Cambridge University Press.

Johnson, R. A.; Dixon, G. E. 1986. Adapting models: problems and benefits from incorporating stand density index into the Prognosis Model. Internal Rep. Fort Collins, CO: U. S. Department of Agriculture, Forest Service, Forest Management Service Center.

Karjalainen, T., Pussinen, A., Liski, J., Nabuurs, G.J., Erhard, M., Eggers, T., Sonntag, M., Mohren, F. 2002. An approach towards an estimate of the impact of forest management and climate change 
on the European forest sector budget: Germany as a case study. Forest Ecology and Management $162: 87-103$

Kurz, W. A., Apps, M.J. 1999. A 70-year retrospective analysis of carbon fluxes in the Canadian forest sector. Ecological Applications 9:526-547.

Liu, G., Han, S. 2009. Long-term forest management and timely transfer of carbon into wood products help reduce atmospheric carbon. Ecological Modelling 220:1719-1723.

Lockwood C., Moore, T. 1993. Harvest scheduling with spatial constraints: a simulated annealing approach. Canadian Journal of Forest Research 23:468-478.

Luppold, W. 1996. Structural changes in the Central Appalachian hardwood sawmilling industry. Wood and Fiber Science 23:346-355.

Luppold, W., Baumgras, J. 2000. The changing structure of the hardwood lumber industry with implications on technology adaptation. P. 89-94 in Proc. of. the twenty-eighth annual hardwood symposium, West Virginia now--the future for the hardwood industry? Meyer, D. A.(ed). National Hardwood Lumber Association, Memphis, TN.

Maness, T., Farrell, R. 2004. A multi-objective scenario evaluation model for sustainable forest management using criteria and indicators. Canadian Journal of Forest Research 34:2004-2017.

Marland, G., Schlamadinger, B. 1995. Biomass fuels and forest management strategies: How do we calculate the greenhouse emissions benefits? Energy 20:1131-1140.

Marquis, D.A. 1978. Application of uneven-aged silviculture and management on public and private lands. P. 25-61 in proceeding of uneven-aged silviculture and management in the United States. USDA Forest Service Gen. Tech. Rep. WO-24.

McGill, D.E., Rebain, S., Braze, J. 2002. Harvest scheduling with area based adjacency constraints. Forest Science 48:631-642.

McGill, D.E., Rebain, S., Braze, J. 2002. Harvest scheduling with area based adjacency constraints. Forest Science 48:631-642. 
Mehta, J. S. 1972. On utilizing information from a second sample in estimating the scale parameter for a family of symmetric distributions. J. Am. Statist. Assoc. 67: 448-452.

Meng, F., Bourque, C.P.A, Oldford, S.P., Swift, D.E., Smith, H.C. 2003 Combining carbon sequestration objectives with timber management planning. Mitigation and Adaptation Strategies for Global Change 8:371-403

Moulton, R.J., Richards, K.R. 1990. Costs of Sequestering Carbon Through Tree Planting and Forest Management in the United States, GTR-WO-58, U.S. Department of Agriculture, Forest Services, Washington, DC.

Murray, A.T., Church, R.L. 1996. Analyzing cliques for imposing adjacency restrictions in forest models. Forest Science 42:166-175.

NETL [National Energy Technology Laboratory]. 2007. Increasing security and reducing carbon emissions of the U.S. Transportation sector: A transformational role for Coal with biomass. DOEl/NETL-2007/1298.

Ney, R.A., Schnoor, J.L., Mancuso, M.A. 2002. A methodology to estimate carbon storage and flux in forestland using existing forest and soil databases. Environmental Monitoring and Assessment 783:291-307.

Ney, R.A., Schnoor, J.L., Mancuso, M.A. 2002. A methodology to estimate carbon storage and flux in forestland using existing forest and soil databases. Environmental Monitoring and Assessment 78: 291-307.

Niu, X., Duiker, S.W. 2006. Carbon sequestration by afforestation of marginal agricultural land in Midwestern US. Forest Ecology and Management 223:415-427.

Noble, I., Apps, M., Houghton R., Lashof, D., Makundi, W., Murdiyarso, D., Murray, B., Sombroek, W., Valentini, R. 2000. Implications of different definitions and generic issues. P. 53-126 in IPCC Special Report Land Use, Land-Use Change and Forestry. Watson, R.T., I. Noble, B. Bolin, N.H. Ravindranath, D.J. Verardo, and D. J. Dokken (eds). Cambridge University Press, New York. 
Papadopol, C.S. 2000. Impacts of climate warming on forests in Ontario: options for adaptation and mitigation. For. Chron. 76:139-149.

Piessens, K., Dusar, M. 2004. Feasibility of CO2 sequestration in abandoned coal mines in Belgium. Geologica Belgica 7:165-180.

Plantinga, A.J., Birdsey, R.A. 1993. Carbon fluxes resulting from U.S. private timberland management. Climate Change 23:37-53.

Richards, K.R., Stokes, C. 2004. A review of forest carbon sequestration cost studies: a dozen of research. Climate Change 63:1-48.

Routledge, R.D. 1980. The effect of potential catastrophic mortality and other unpredictable events on optimal forest rotation policy. Forest Science 26:389-399.

Schelhaas, M.J., van Esch, P.W., Groen, T.A., de Jong, M.K., Kannienen, M., Liski, J., Masera, O., Moheren, G.M.J., Nabuurs, G.J., Palosuo, T., Pedroni, L., Vallejo, A., Vilen, T. 2004. CO2FIX V 3.1 - A modeling framework for quantifying carbon sequestration in forest ecosystems. Wageningen, NL.

Sharma, B.D., Wang, J., Brooks, J.R. and Miller, G. 2009. Optimizing forest harvest strategies for timber production and carbon sequestration. Paper presented at 2009 Society of American Forester's Annual Convention, in Orlando, FL.

Sharma, B.D., Wang, J., Brooks, J.R., Miller, G. 2010 Evaluating forest harvest strategies to enhance timber production and carbon sequestration. Manuscript prepared for successive submission to Forest Science.

Smith, W.B. 1991. Assessing removals for North Central Forest Inventories. Res. Pap. NC-299. U.S. Department of Agriculture. Forest Service. North Central Forest Experiment Stations, St. Paul, MN.

Sperow, M. 2006. Carbon sequestration potential in reclaimed mine sites in seven East-Central states. Journal of Environment Quality 35:1428-1438. 
Sperow, M., Eve, M., Paustian, K. 2003. Potential soil C Sequestration on US agricultural soils. Climate Change 57:319-339.

Stage, A. R. 1973. Prognosis Model for stand development. Res. Paper INT-137. Ogden, UT: U. S. Department of Agriculture, Forest Service, Intermountain Forest and Range Experiment Station.

The Charleston Gazette Online. 2009. Timber committee formed: Panel will examine direction of industry. Available online at http://www.wvgazette.com/static/series/timber/COMMITTEE.html (Assessed on 02/19/2010).

USDA FS 2009. Forest Inventory Data Online Vers. 1.30r0. US Department of Agriculture. Forest Service. Available online at http://fiatools.fs.fed.us/fido/index.html (accessed on February 10, 2010)

USDA. 2010. COLE 1605(b) Report for West Virginia. COLE Development Group, February 19, 2010. USDA Forest Sertive and RWU-4104, Durham, NH. Available online at http://ncasi.uml.edu/COLE/cole.html (accessed on February 10, 2010)

USDA-FPL [United States Department of Agriculture-Forest Product Laboratory]. 1953. Density, fiber length, and yields of pulp from various species of wood. Technical note 191.

USDA-FPL. 2004. Fuel Value Calculator. TechLine, WOE 3. USDA Forest Producet Laboratory. State \& Private Forestry Technology Marketing Unit. Madison, WI.

USEPA [U.S. Environmental Protection Agency]. 2005. Greenhouse gas mitigation potential in U.S. forestry and agriculture. EPA 430-R-05-006. Office of Atmospheric Programs, Washington, DC.

USEPA [United States Environmental Protection Agency] 2009. Inventory of U.S. Greenhouse Gas Emissions and Sinks: 1990 - 2007. USEPA Washington DC.

Van Deusen, P.C. 1999. Multiple solution harvest scheduling. Silva Fennica 33: 207-216.

Vielma, J.P., Murray, A.T., Ryan, D.M., Weintraub, A. 2007. Improving computational capabilities for addressing volume constraints in forest harvest scheduling problems. European Journal of Operational Research 176:1246-1264. 
Wang, J., Grushecky, S., McNeel, J. 2007.Biomass resources, uses and opportunities in West Virginia. Biomaterials and Wood Utilization Research Center. West Virginia University, Morgantown, WV.

Wang, J., Ledoux, C.B. 2003. Estimating and validating ground-based timber harvesting production through computer simulation. Forest Science 49:64-76.

Wang, J., Sharma, B.D., Li, Y., Miller, G. 2009. Modeling and validating spatial patterns of a 3D stand generator for central Appalachian hardwood forests. Computer and Electronics in Agriculture 68: 141-149.

Ware, G.O., Clutter, J.L. 1971. A mathematical programming system for the management of industrial forests. Forest Science 17:428-445.

Wellner, C.A. 1940. Relationships between three measures of stocking in natural reproduction of the western white pine type. Journal of Forestry 38:636-638.

West Virginia Plant Fossils (WVPF). 2009. The APPALACHIAN "MOUNTAINS". Available online at http://www.geocraft.com/WVFossils/coal_rank.html (last accessed on January 31, 2009).

Widmann, R.H., Wharton, E.H., Murriner, E.C. 1998. West Virginia timber products output: 1994. Resource Bulletin NE-143. U.S. Department of Agriculture, Forest Service, Northeastern Research Station, PA.

WVDEP [West Virginia Department of Environmental Protection] -Division of Mining and Reclamation] 2008. West Virginia Mining Permit Boundary Data. Available online http://gis.wvdep.org/data/omr.html (Accessed on April, 6, 2009).

Zeng N. 2008. Carbon sequestration via wood burial. Carbon Balance and Management 3:1-12. 


\section{A P PENDIX A: INTRODUCTION TO FOREST VEGETATION}

\section{$\underline{\text { S I M U L A T O R ( F V S ) }}$}

This appendix is provided as a brief review on some of the important aspects of Forest Vegetation Simulation application that was used to generate data that was used during the course of dissertation writing. The appendix is mostly based on Dixon (2008) and which is available from http://www.fs.fed.us/fmsc/ftp/fvs/docs/gtr/EssentialFVS.pdf.

\section{A.1 Background}

The Forest Vegetation Simulator (FVS) is a model used for predicting forest stand dynamics that is used extensively in the United States. FVS is the standard model used by various government agencies including the USDA Forest Service, USDI Bureau of Land Management, and USDI Bureau of Indian Affairs. It is also used by state agencies such as the Washington Department of Natural Resources and Custer State Park, industry, educational institutions, and private landowners. Forest managers have used FVS extensively to summarize current stand conditions, predict future stand conditions under various management alternatives, and update inventory statistics. Output from the model is used as input to forest planning models and many other analysis tools. In addition, FVS has been linked to other Forest Service corporate software such as databases and geographic information systems.

Uses of FVS are not restricted to timber management applications. Other uses of FVS include considering how management practices affect stand structure and composition, determining suitability of stands for wildlife habitat, estimating hazard ratings for insect outbreaks or wildfires, and predicting losses from fire and insect outbreaks. Forest managers are under ever increasing pressure to design and implement stand management alternatives that are biologically and economically sound and meet a wide variety of objectives. Costs associated with timber harvesting are continually increasing and any stand entry must generate enough revenue to justify the treatment. The generated revenue must cover the direct 
cost of the harvest and also the interest that could have been generated by using those monies in other investment alternatives. Generated revenue can be in the form of direct return on the timber harvested, or in delayed return from increased future revenue as a result of increased tree growth resulting from an intermediate treatment. Meanwhile, forest managers must maintain or improve the health, condition, and scenic value of the landscape, reduce the risk of catastrophic fires, and maintain canopy structure and diversity to satisfy various forest practices legislation. Traditional forest management practices such as clear cutting are often not acceptable.

Forest Managers are faced with implementing innovative management alternatives of which the long-term effects on the resource are unknown. However, forest managers have available to them an ever increasing array of tools which can aid resource management decisions. Computer technology has revolutionized land management decision analyses. Geographic information systems, relational databases, mapping technologies, visualization software, and growth and yield simulators are among the many tools currently available, and other software products are being rapidly developed. The Forest Vegetation Simulator is one of the products currently available to aid forest managers in making sound biological and economical management decisions.

\section{A.2 FVS process}

The general flow of operations within FVS is shown in Fig. A.1. A projection begins by reading the inventory records and the descriptions of selected management options. The inventory is then compiled to produce tables that describe initial stand conditions. When this summary is complete, the first projection cycle begins. Each projection cycle starts with a check of the Event Monitor to see if any custom variables need to be computed or management activities scheduled based on pre-thinning stand conditions. Next, any silvicultural actions that have been scheduled for the cycle are attempted. This is followed by another check of the event monitor to see if any custom variables need to be computed or management activities scheduled based on post-thinning stand conditions. Next, periodic diameter 
increment, periodic height increment, and periodic mortality rate are computed. These estimates are then adjusted for effects of insects and pathogens. Tree records resulting from regeneration within the cycle are created next, and change in crown ratios are computed for each tree record in the projection. Many growth prediction equations in the Forest Vegetation Simulator use stand variables such as habitat type, slope, aspect, elevation, site index, and stand location. Stands should be delineated so that these variables are reasonably constant. Stretching this assumption when defining stands, and using some sort of "average value" for these variables, will increase the likelihood that projections will not be accurate.

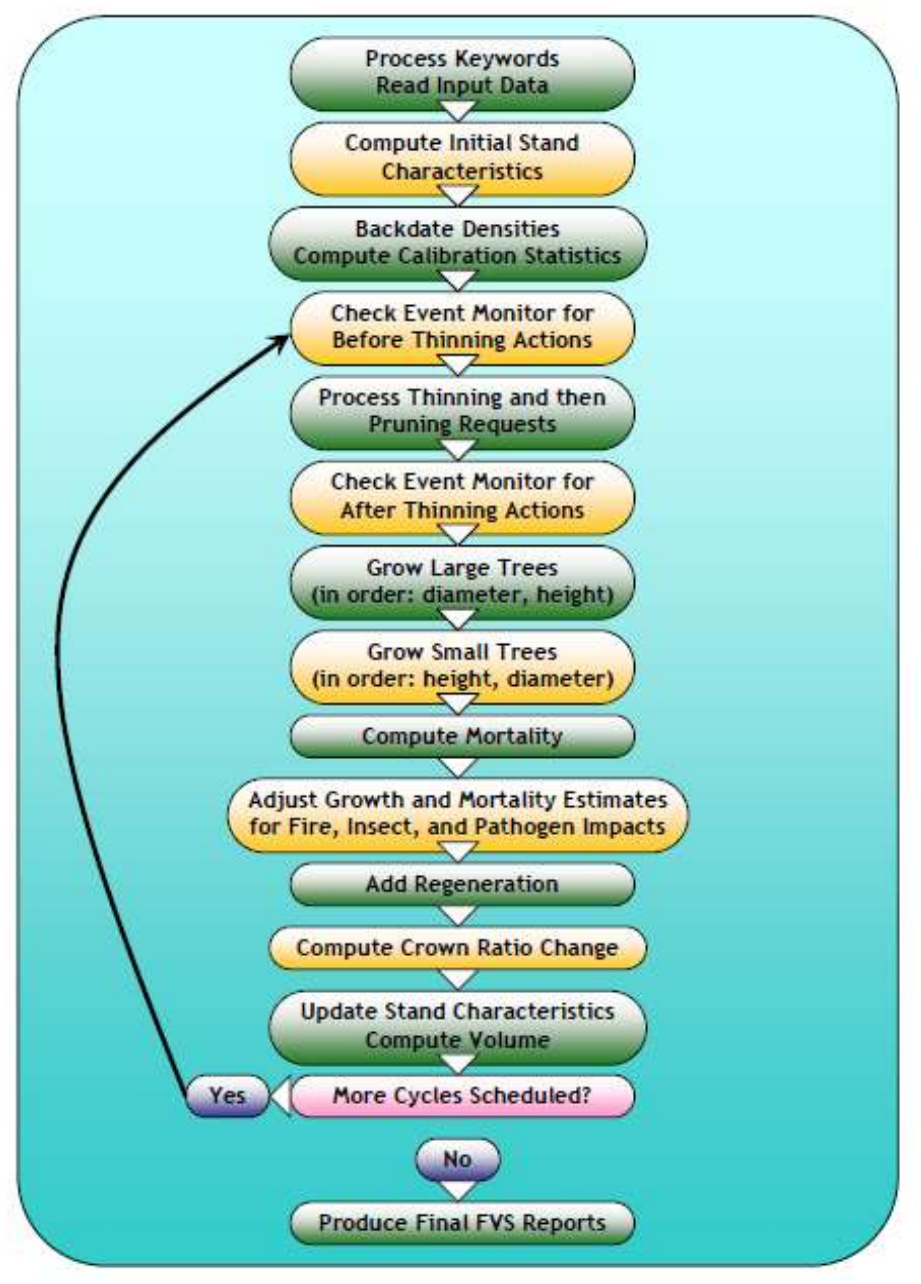

Figure A.1 Overview of the general FVS processing sequence

(Originally published in Dixon 2008) 
Inventory data can be read from any database using Object Database Connectivity (ODBC) on Microsoft Windows platforms. Stand information is entered with applicable information mentioned in Table A.2.

Table A.1 Stand level data in stored in database.

\begin{tabular}{|c|c|c|c|}
\hline Column Name & $\begin{array}{l}\text { SQL } \\
\text { format }\end{array}$ & $\begin{array}{l}\text { DB-FVS } \\
\text { data type }\end{array}$ & Notes \\
\hline Stand_CN & Char(40) & Char(40) & Stand control number \\
\hline Stand_ID & Char(26) & & Stand identification code \\
\hline Inv_Year & num(4) & Integer & Inventory year \\
\hline GIS_Link & Char(26) & & Not read by FVS \\
\hline Project_Name & Char(25) & & Not read by FVS \\
\hline Latitude & $\operatorname{num}(6,4)$ & Float & Latitude in degrees \\
\hline Longitude & $\operatorname{num}(7,4)$ & Float & Longitude in degrees \\
\hline Region & Char(2) & Integer & Region (2 char code ) \\
\hline Forest & Char(2) & Integer & National Forest ( 2 char code) \\
\hline District & Char(2) & Integer & District code within National Forest (2 char) \\
\hline Compartment & Char(10) & Integer & Compartment code within National Forest or District \\
\hline Ecoregion & Char(6) & & Bailey's Ecoregion code, not read by FVS. \\
\hline PV_Code & Char(10) & Char(10) & $\begin{array}{l}\text { PV_Code identifies the potential vegetation. It is } \\
\text { often the Habitat type or Plant association code. In } \\
\text { the SN variant this field is populated with Bailey's } \\
\text { Ecoregion code. }\end{array}$ \\
\hline PV_Ref_Code & Char(10) & & Reference code for PV_Code variable. \\
\hline Age & $\operatorname{num}(4)$ & Integer & Stand age in years \\
\hline
\end{tabular}




\begin{tabular}{|c|c|c|c|}
\hline Aspect & $\operatorname{num}(3)$ & Float & Aspect in degrees \\
\hline Slope & $\operatorname{num}(3)$ & Float & The slope in percent \\
\hline ElevFt & $\operatorname{num}(6,1)$ & Float & Elevation in feet. \\
\hline Basal_Area_Factor & $\operatorname{num}(5,1)$ & Float & $\begin{array}{l}\text { If positive, it is the basal area factor used in the large } \\
\text { tree inventory. If negative, it is the inverse of the } \\
\text { fixed area plot size used in the large tree inventory. } \\
\text { Always NULL when data is extracted from FSVEG. }\end{array}$ \\
\hline Inv_Plot_Size & $\operatorname{num}(9,4)$ & Float & $\begin{array}{l}\text { The inverse of the fixed area plot size used in the } \\
\text { small tree inventory. Always } 1 \text { when data is } \\
\text { extracted from FSVEG. }\end{array}$ \\
\hline Brk_DBH & $\operatorname{num}(5,1)$ & Float & $\begin{array}{l}\text { Breakpoint dbh between small and large tree } \\
\text { inventory design. Always } 999 \text { when data is } \\
\text { extracted from FSVEG. }\end{array}$ \\
\hline Num_Plots & $\operatorname{num}(4)$ & Integer & Number of plots \\
\hline NonStk_Plots & $\operatorname{num}(4)$ & Integer & Number of non-stockable plots \\
\hline Sam_Wt & $\operatorname{num}(13,4)$ & Float & $\begin{array}{l}\text { Sampling Weight used to compute the average yield } \\
\text { tables and other weighted averages. Usually stand } \\
\text { size (acres). }\end{array}$ \\
\hline Stk_Pcnt & $\operatorname{num}(5,2)$ & Float & $\begin{array}{l}\text { Proportion of stand considered stockable from a } \\
\text { surface area perspective. }\end{array}$ \\
\hline DG_Trans & $\operatorname{num}(2)$ & Integer & $\begin{array}{l}\text { Diameter growth translation code. Code } 0 \text { for } \\
\text { increment cores and } 1 \text { for permanent plot re- } \\
\text { measurement. (see Growth keyword) }\end{array}$ \\
\hline DG_Measure & $\operatorname{num}(2)$ & Integer & Diameter growth measurement period in years \\
\hline HTG_Trans & num(1) & Integer & Height growth translation code. Code 0 for height \\
\hline
\end{tabular}




\begin{tabular}{|c|c|c|c|}
\hline & & & growth and 1 for permanent plot re-measurement. \\
\hline HTG_Measure & $\operatorname{num}(2)$ & Integer & Height growth measurement period in years \\
\hline Mort_Measure & $\operatorname{num}(2)$ & Integer & Mortality measurement period in years \\
\hline Max_BA & $\operatorname{num}(3)$ & Float & $\begin{array}{l}\text { Maximum Basal Area; Modifies stocking and } \\
\text { mortality distribution pattern. }\end{array}$ \\
\hline Max_SDI & $\operatorname{num}(4)$ & Float & $\begin{array}{l}\text { Maximum Stand Density Index ; Modifies stocking } \\
\text { and mortality distribution pattern. }\end{array}$ \\
\hline Site_Species & Char(8) & Char(8) & Site Index Species Code. \\
\hline Site_Index & $\operatorname{num}(3)$ & Float & Site index \\
\hline Model_Type & $\operatorname{num}(1)$ & Integer & $\begin{array}{l}\text { Sub-Model Type Code. Applies to CR and SE } \\
\text { variant only. }\end{array}$ \\
\hline Physio_Region & Char(3) & Integer & Physiographic Region Code. (SE variant only) \\
\hline Forest_Type & Char(10) & Integer & Forest Type Code. Applies to SN variant only. \\
\hline State & $\operatorname{num}(2)$ & Integer & 2-digit FIA State Code* \\
\hline County & $\operatorname{num}(3)$ & Integer & 3-digit FIA County Code* \\
\hline Fuel_0_1 & $\operatorname{num}(6,2)$ & Float & Initial tons per acre of 0 to 1 inch fuel \\
\hline Fuel_1_3 & $\operatorname{num}(6,2)$ & Float & Initial tons per acre of 1 to 3 inch fuel \\
\hline Fuel_3_6 & $\operatorname{num}(6,2)$ & Float & Initial tons per acre of 3 to 6 inch fuel \\
\hline Fuel_6_12 & $\operatorname{num}(6,2)$ & Float & Initial tons per acre of 6 to 12 inch fuel \\
\hline Fuel_gt_12 & $\operatorname{num}(6,2)$ & Float & Initial tons per acre of greater than 12 inch fuel. \\
\hline Fuel_Litter & $\operatorname{num}(6,2)$ & Float & $\begin{array}{l}\text { Initial tons per acre of litter. Always NULL when } \\
\text { data is extracted from FSVEG. }\end{array}$ \\
\hline Fuel_Duff & $\operatorname{num}(6,2)$ & Float & $\begin{array}{l}\text { Initial tons per acre of duff. Always NULL when } \\
\text { data is extracted from FSVEG. }\end{array}$ \\
\hline
\end{tabular}


Table A.2 Individual tree data stored in database.

\begin{tabular}{|c|c|c|c|}
\hline Column Name & SQL Format & $\begin{array}{l}\text { DB-FVS } \\
\text { data type }\end{array}$ & Notes \\
\hline Tree_CN & Char(40) & & Not read by FVS. \\
\hline Stand_CN & Char(40) & Char(40) & $\begin{array}{l}\text { Same as Stand_CN from the StandInit table. Not read } \\
\text { by FVS, but may be used for querying purposes. }\end{array}$ \\
\hline Stand_ID & Char(26) & Char(26) & Stand identification code; Not read by FVS \\
\hline Tree_ID & num(5) & Integer & Tree Identification Code \\
\hline Plot_ID & $\operatorname{num}(4)$ & Integer & Plot Identification \\
\hline Tree_Count & $\operatorname{num}(10,5)$ & Float & Tree Count \\
\hline History & $\operatorname{num}(1)$ & Integer & $\begin{array}{l}\text { History Code } 0-5 \text { are live trees, } 6 \text { and } 7 \text { are trees that } \\
\text { died recently (during mortality observation period), } 8 \\
\text { and } 9 \text { are older, dead trees (died before mortality } \\
\text { observation period) }\end{array}$ \\
\hline Species & Char(8) & Char(8) & Tree Species Code idendified in variant overviews. \\
\hline Diameter & $\operatorname{num}(6,3)$ & Float & Usually diameter at breast height (DBH) \\
\hline $\begin{array}{l}\text { Diameter_Heig } \\
\text { ht }\end{array}$ & $\operatorname{num}(6,3)$ & Float & Not read by FVS. \\
\hline DG & $\operatorname{num}(4,1)$ & Float & DBH Growth \\
\hline $\mathrm{Ht}$ & $\operatorname{num}(7,4)$ & Float & Height in feet \\
\hline $\mathrm{HtG}$ & $\operatorname{num}(7,4)$ & Float & Height Growth in feet \\
\hline HtTopK & $\operatorname{num}(7,4)$ & Float & $\begin{array}{l}\text { Height to top kill is the height to the point of the tree of } \\
\text { top kill in feet }\end{array}$ \\
\hline CrRatio & $\operatorname{num}(3)$ & Integer & If the number is $0-9$ then it is considered a crown ratio \\
\hline
\end{tabular}




\begin{tabular}{|c|c|c|c|}
\hline & & & $\begin{array}{l}\text { code, according to the FVS documentation. If the } \\
\text { number is } 10-99 \text { the value is considered a percent live } \\
\text { crown. }\end{array}$ \\
\hline Damage1 & $\operatorname{num}(2)$ & Integer & Damage Code 1, see the EFVS guide for details \\
\hline Severity1 & $\operatorname{num}(2)$ & Integer & Severity Code corresponding to damage code 1 \\
\hline Damage2 & $\operatorname{num}(2)$ & Integer & Second damage code. \\
\hline Severity 2 & $\operatorname{num}(2)$ & Integer & Second severity code. \\
\hline Damage3 & $\operatorname{num}(2)$ & Integer & Third damage code. \\
\hline Severity3 & $\operatorname{num}(2)$ & Integer & Third severity code. \\
\hline TreeValue & num(1) & Integer & $\begin{array}{l}\text { Tree Value Class Code } 1 \text { for desirable, } 2 \text { for acceptable, } \\
8 \text { for non-stockable and any other number represents a } \\
\text { live cull }\end{array}$ \\
\hline Prescription & $\operatorname{num}(1)$ & Integer & $\begin{array}{l}\text { Prescription code (0-9) where anything other than a } 1 \text { or } \\
0 \text { marks the tree for removal }\end{array}$ \\
\hline Slope & $\operatorname{num}(3)$ & Integer & Slope Percentage on the plot where the tree was located \\
\hline Aspect & $\operatorname{num}(3)$ & Integer & Aspect in degrees on the plot where the tree was located \\
\hline PV_Code & Char(10) & Integer & $\begin{array}{l}\text { The potential vegetation code on the plot where the tree } \\
\text { was located }\end{array}$ \\
\hline TopoCode & $\operatorname{num}(1)$ & Integer & $\begin{array}{l}\text { Topography Code } 1=\text { bottom, } 2=\text { lower, } 3=\text { mid slope, } \\
4=\text { upper slope, and } 5=\text { ridge top, on the plot where the } \\
\text { tree was located }{ }^{2}\end{array}$ \\
\hline SitePrep & num(1) & Integer & $\begin{array}{l}\text { Site Preparation code } 1=\text { none, } 2=\text { mechanical, } 3=\text { burn, } \\
\text { and } 4=\text { road cuts/road fills/stockable road beds, on the } \\
\text { plot where the tree was located }\end{array}$ \\
\hline
\end{tabular}

\footnotetext{
* Not directly used by FVS
} 


\section{A.3 Description of the site on which stand is located}

Growth prediction equations in the Forest Vegetation Simulator use stand variables such as habitat type, slope, aspect, elevation, site index, and stand location. Stands should be delineated so that these variables are reasonably constant. A keyword record, STDINFO, is used to supply data on stand variables. This record has seven parameter fields specifying information on stand location, habitat type/plant association/ecological class code, stand age, aspect, slope, elevation, and a reference code for indicating the source of the habitat type/plant association/ecological class code. The reference code is used to indicate a habitat type/plant association/ecological class from a literature source other than the one used to fit the variant. The FSVEG database recognizes habitat type/plant association/ecological class codes from many sources. By knowing the literature source, FVS can translate the habitat type/plant association/ecological class code to one recognized by the variant.

Site index is an important predictor variable in many of the FVS variants. Site index and site species is provided to the model with the SITECODE keyword record. A site index can be entered for a particular site species, or site index values can be entered for each individual species. If site index is entered for a particular site species, the model translates that site index to a corresponding site index for each species in the variant for which an individual site index was not entered. If site index is not entered, then variant-specific default values are used. A site index table is printed in the main output file. Users should check this table to see if the site values are reflective of the stand they are projecting. When entering a site index value, users need to base the value on site curves that were used to build the variant relationships. These site index curves will be listed in the variant overview document.

Stand location, in terms of latitude, longitude, state, and county can be entered in the database. Latitude is used for growth prediction in the Western Sierras variant, and in some insect and pathogen applications in the eastern United States. County is used in determining forest type in California. Otherwise, these values are only for informational purposes. Another keyword relates to stand location and affects growth rates in some variants. Some variants include geographic sub-divisions that contain 
different growth equations. The MODTYPE keyword is used to indicate which model sub-division that the stand should be run with. This keyword is used to input model type, physiographic region, or forest type, depending on the variant. Whether the stand is a managed stand, or a natural stand, affects growth rates in some variants. The MANAGED keyword is used to signify that a stand should be grown under a managed condition. If this keyword is not present, the stand will be grown as if it is a naturally occurring stand (applicable in data used in this dissertation).

\section{A.4 Stand composition and species group}

Some FVS applications apply to more than one species in a stand, but not all species. Rather than repeating a set of keyword records for each species, it is possible to define a species group and use one set of keyword records that applies to all species in the group. Species groups are defined using the SPGROUP keyword record, which specifies the group name, followed by a supplemental record containing the FVS alpha code or sequence number for each species contained in the group. Species codes are entered in free-form format on the supplemental record and are separated by one or more blank characters.

The Stand Composition portrays stand development over time, and displays the distributions of important stand attributes relative to DBH and species. Per acre values are calculated for the stackable area of the stand only. One line in the stand composition table is allotted to the description of each reported stand attribute at each cycle endpoint. The description consists of a terse label, per acre total for the attribute, the distribution of the attribute by DBH class, and the distribution of the attribute by species and tree value class. The attributes summarized in the stand composition table include trees per acre, volume per acre for three merchantability standards, and annual per acre accretion and mortality (total stem cubic feet). Accretion is growth on trees surviving to the end of the cycle. The merchantability standards used in eastern variants to compute volumes include: 
- Merchantable stem cubic feet pulpwood if the entire tree were to be used for pulp

- Merchantable stem cubic feet sawtimber

- Merchantable stem board feet

The trees per acre and the volume per acre are reported at the beginning of the projection. These are repeated, along with accretion and mortality statistics, at the completion of each projection cycle. If there are any thinning requests in a cycle, the number of trees per acre and the volume per acre removed as well as the number of trees per acre in the residual stand are reported.

\section{A.5 Regeneration simulation}

The regeneration model can simulate the effects of site preparation treatments. Individual plots may be mechanically scarified, burned, or left untreated. Site preparation treatments can occur at years other than the year of disturbance, but they should be scheduled sometime during the first tally. The Regeneration Establishment Model is called at the end of each projection cycle. Regeneration, however, can be scheduled for any year during a projection cycle and the trees are then grown to the end of the cycle by the regeneration model. The regeneration model creates a list of tree records describing new trees on $1 / 300$-acre plots. A regeneration summary printed in the main output file reports the average probability of stocking for 1/300-acre plots, total trees per acre by species, identification of best trees from the list of total trees, and average estimated heights of best trees. New trees are added to plots that correspond to the inventory plots contained in the input data. Predictions are made for each plot, and then averaged to produce stand statistics.

The regeneration period is the number of years during which regeneration becomes established as a result of a disturbance. The length of the regeneration period varies depending on many factors, but for the purposes of FVS this period is set at 20 years. Regeneration that occurs after the regeneration period is 
called ingrowth. Ingrowth is both the result of succession by shade tolerant species and the continued regeneration of trees into gaps in the tree canopy.

The Regeneration Establishment Model is invoked following harvesting, growth, and mortality that occurs in the base model, thus the updated inventory is used to predict new regeneration.

Regeneration is scheduled through the use of keywords (and by automatic calls in variants using the full establishment model). In variants having the full establishment model (which includes north-east variant), the regeneration model is automatically called when trees have been removed or when in-growth is to be added to the stand.

Regeneration is added to the FVS tree list at the end of the cycle in a regeneration tally. A tally is similar to results of a regeneration survey for a stand. At each tally, new regeneration may be added to the FVS tree list and a regeneration summary output table is printed. Regeneration is assumed to occur in the spring of the year in which it is scheduled. Because regeneration is added at the end of the cycle, which corresponds to the fall of the year, the number of years of regeneration appears to be 1 year less than the cycle length. For example, if FVS were using 10-year cycles beginning in the year 2000, regeneration would be added in the "fall" of 2009. A total of 10 growing seasons have elapsed from 2000 to the fall of 2009. The new trees would appear in FVS summary tables beginning in 2010.

Best trees play a key role in the FVS regeneration establishment model. This role is especially important in the full establishment model. The idea of best trees follows from the fact that many more trees reproduce than will exist in the mature forest (Wellner 1940). By selecting a few trees on each stocked plot, attention is focused on the growing stock that will contribute to yield. Best trees are chosen by the following rules:

- Select the two tallest trees on each 1/300-acre plot regardless of species.

- Select the one tallest tree of each additional species represented on the plot.

- If the first two rules do not total four trees, select in order of descending height from any remaining trees, if present, until four are chosen. 
All best trees are passed to the FVS tree list for simulation of future stand development and are coded as being "desirable" trees (tree value class code 1, Table A.2). From the trees not chosen as best trees, up to five additional trees of each species per plot are passed to FVS but are coded as being “acceptable" trees (tree value class code 2, Table A.2). Additional acceptable trees may be passed to FVS using the PASSALL keyword record.

Some variants of FVS represent species that produce sprouts from stumps or roots of harvested trees. For these variants, the Regeneration Establishment Model automatically adds regeneration sprouts to the tree list following harvests. The species that sprout are different in the different variants of the Forest Vegetation Simulator, but all variants contain this feature. Both the number of sprouts and the sprout height can be adjusted using the SPROUT keyword. Information regarding sprouting trees is contained in a separate regeneration summary table in the main output file.

\section{A.6 Calibration and randomization}

A variant does a reasonably good job of projecting yields for managed and unmanaged stands in the geographic area for which it was fit. However, situations exist where the model may perform poorly. The FVS model includes several features that facilitate improvement of performance in these situations:

- FVS includes a built-in scaling procedure that adjusts the small-tree height increment model and the large-tree diameter increment model so that predicted growth matches observed growth for the median trees. Scale factor calculations can be modified or bypassed.

- Random effects have been represented in FVS in various ways (Stage 1973). There are options that alter or entirely suppress the application of these random effects. 
- Options to input multipliers for all the increment functions have been provided.

Additional options that affect the behavior of the mortality models can be targeted to specific species or species groups, and to specific cycles.

The first two of these are discussed in this section, and the third one is discussed in the next section.

\section{A.6.1 Calculation of scale factors}

The increment models contained in FVS are based on the best available data. For the most part, the data are representative of growing conditions in the geographic area for which the variant was fit, and the models produce relatively unbiased estimates of growth. However, it is reasonable to expect considerable variation about the expected value of the predictions for any set of values of the predictor variables. Many sites perceived to be the same, in terms of the variables used to predict growth, are in fact different, and the differences are reflected in growth rates. The tree is a good integrator of site factors, and tree growth is a good indicator of site capability.

The scaling procedure (Stage 1973), when stripped of statistical condiments, is really quite simple. Both the large-tree diameter growth model and the small-tree height growth model are linear with logarithmically scaled dependent variables. Therefore, the model intercepts are, in effect, growth multipliers. An increment is predicted to match each observed increment for a species, and differences are sorted. The median difference is then added to the model for that species, on the logarithmic scale, as an additional intercept term. The diameter increment scale factors are attenuated over time. On long-term projections, the base model is assumed to be a more stable estimate of growth potential than is the scale factor. The attenuation is asymptotic to one-half the difference between the initial scale factor value and one. The rate of attenuation is dependent only on time, and has a half-life of 25 years. Figure A.3 shows this attenuation for two examples: (1) an initial scale factor of 2.0, and (2) an initial scale factor of 0.5. In the first case, the attenuation goal is 1.5 (half the difference between the initial scale factor of 2.0 and 
one). At 25 years, the value is 1.75 (halfway between 2.0 and 1.5); at 50 years the value is 1.62 (halfway between 1.75 and 1.5); at 75 years the value is 1.56 (halfway between 1.62 and 1.5; and at 100 years the value is 1.53 (halfway between 1.56 and 1.5. Similarly, the attenuation goal in the second example is 0.75 (half the difference between the initial scale factor of 0.5 and one).

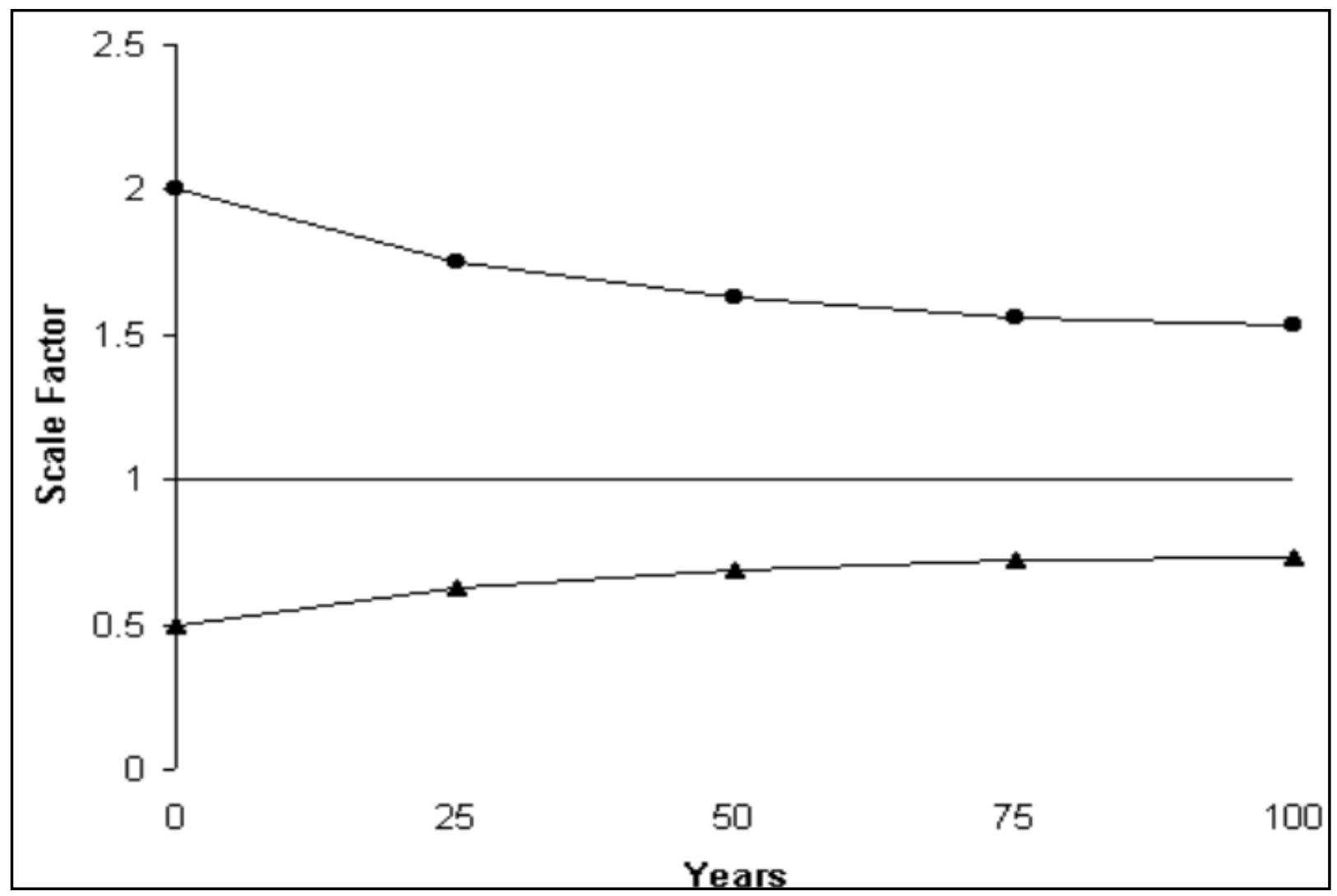

Figure A.2 Scale factor example

(Originally published in Dixon 2008.)

The calibration procedure described above changes the increment prediction in a proportional manner. It does not influence the relative effects of the predictor variables and there is no change in the shape of the response surface. FVS models are high-level abstractions. The connections between the selected set of predictor variables and physiological processes that actually control tree growth are, at 
best, tenuous. Therefore, it is unreasonable to assume that growth responses in locations with substantially different environmental limitations will be the same. It is more likely the shape of the response surface in these locations, relative to the selected set of predictor variables, will be different. When this is the case, the models should be refit

\section{A6.2 Randomization}

Random effects are incorporated in the Forest Vegetation Simulator in the manner originally described by Stage (1973), and subsequently updated to reflect changes in program control variables. The program assigns all random effects to the distribution of errors associated with the prediction of the logarithm of basal area increment. Basal area increment was selected to reflect the stochastic variation because the effects of differing diameter growth rates extend in highly nonlinear ways through most of the remaining components of the model. This distribution of errors is assumed to be Normal, with a mean of zero. The variance of this Normal distribution is computed as a weighted average of two estimates; the first estimate is derived from the regression analysis that developed the prediction function, and the second estimate is the standard deviation of the differences between the recorded growth for the sample trees in the population (transformed to the logarithm of basal area increment) and their corresponding regression estimates. The weights assigned to these two estimates are (1) the number of observations by species and/or habitat type in the database for the model for the prior component of error, and (2) the number of growth-sample trees in the stand for the second component of error (Mehta 1972).

The random component of change in tree diameter is treated in two ways, depending on how many tree records make up the stand being projected. When there are many tree records, the effects of any one random deviation on the growth rate of one tree would be blended with many other trees, and the stand totals should be quite stable estimates. Accordingly, a random deviate from the specified distribution is added to the logarithm of basal area increment. 
When relatively few sample trees represent the stand, however, a different strategy is used. In order to increase the number of replications of the random effects, two additional records augment each tree record. These new records duplicate all characteristics of the tree except the predicted change in diameter and the number of trees per acre represented by the source tree record. The trees per acre value of the original tree record are reduced to 60 percent of its current value. The two new records are given 15 and 25 percent of the original value; thus, the three records together still represent the same number of trees per acre. This process is known as tripling.

Each of these three records is associated with one of the three portions of the error distribution characterizing the deviations about prediction (Fig. A.3). The first record, representing 60 percent of the population (approximately the center of the distribution), is given a prediction corresponding to the average value of the deviations in that portion of the Normal distribution. This "biased" point is indicated by point A in Fig. A.3. The second record, representing the upper 25 percent of the error distribution, is given a prediction corresponding to point B; and likewise, the record for the lower 15 percent is given a prediction corresponding to point $\mathrm{C}$. With this method, the weighted average prediction for the three records is equal to the estimate associated with the original record. 


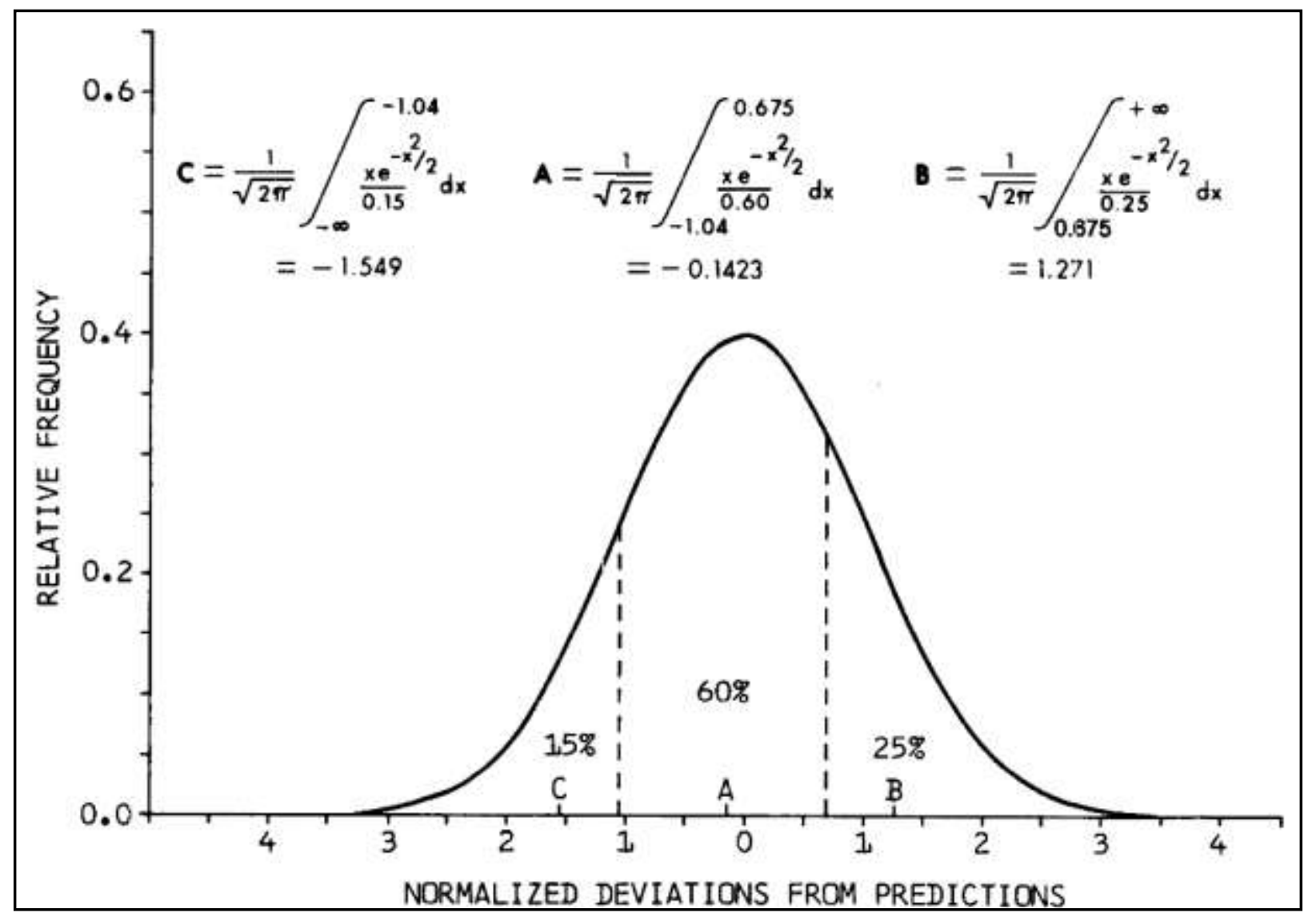

Figure A.3 Location of prediction points for three fractions of the normal distribution

(Orginally published in Dixon 2008.)

Unless otherwise specified, records will be tripled twice or until additional tripling would exceed the program storage capacity for tree records (currently set to 3000). The maximum number of triples can be increased or decreased. The region of the Normal distribution from which random increments are drawn is bounded by $+/-2$ standard deviations. These bounds can be changed with the DGSTDEV record. The uniform random number generator is automatically reset prior to each FVS run so that a given set of tree records and control variables will always produce the same projection output in a specific computing environment. 
It is possible to manually reseed the random number generator and thus produce variation in projection results. There are three seeds involved and they can be replaced with the RANNSEED record. Seeds can be replaced individually or as a group. The new seeds should be odd integer values. If they are otherwise, they will automatically be converted to odd integers by truncating fractions and/or adding 1 . Hamilton (1991) recommends that in almost all applications of the model, it would be wise to make at least two or three projections (using different random seeds for each projection) rather than to rely on the results of a single simulation. Further, some research applications of the model requiring high precision levels may need substantially more replications to stabilize variance estimates of projected values.

\section{A.7 Mortality simulation}

The Forest Vegetation Simulator base model mortality predictions are intended to reflect background or normal mortality rates. Increases in mortality from insects, pathogens, and fire are accounted for in the various FVS extensions. Mortality from other causes, such as logging damage, animal damage, or wind events, needs to be simulated with FVS keywords. The Stand Density Index (SDI) based mortality model (Dixon 1986, Johnson and Dixon 1986) is used in NE variant. The model has two steps. In the first step, the number of mortality trees is determined; in the second step, this mortality is dispersed to the individual tree records in FVS.

\section{A.7.1 Determining the number of mortality trees}

Three types of mortality are estimated: (1) background mortality, (2) density related mortality and (3) breakup of over mature stands. Density related mortality accounts for mortality in stands that are dense enough for competition to be the causal agent. Mortality associated with the breakup of over mature stands is mainly age related. All other mortality is attributable to background mortality. Background

mortality gives way to density related mortality based on the relationship between current and maximum 
Stand Density Index. By default, density related mortality begins when the stand SDI is above 55 percent of maximum SDI, and stand density peaks at 85 percent of maximum SDI. These percentages can be adjusted using the SDIMAX keyword. Background mortality is used when current stand SDI is below 55 percent of maximum SDI. The 55 percent value is referred to as the lower limit of density related mortality, and the 85 percent value is the upper limit. The stand SDI maximum is a weighted average of the individual species SDI maximums. The weights are based on the basal area each individual species represents in the stand. The weighted maximum SDI is calculated each growth cycle, and mortality is determined based on the stands' position relative to the maximum SDI. Over time, maximum SDI changes as the species mix in the stand changes.

If the stand SDI at the time of inventory is above the upper limit of density related mortality plus 5 percent (e.g. $90 \%$ if using the default value of $85 \%$ for the upper limit), then the maximum SDI is automatically reset. The new maximum is set so the stand SDI at the time of inventory corresponds to the upper limit of density related mortality. If the stand SDI at the time of inventory is greater than the upper limit of density related mortality, but within 5 percent, then the stand stocking will be reduced to the upper limit the first projection cycle. The relationship between stand SDI at the time of inventory and the maximum SDI determines the trajectory a stand will take throughout the projection. Certain management actions, such as a thinning, may change this trajectory. This trajectory can be thought of as a relationship between trees per acre on the y-axis and quadratic mean diameter on the x-axis. For density related mortality, this trajectory determines how many trees will die in the projection cycle. This density related mortality is then dispersed to individual tree records.

For background mortality, a mortality rate formula determines the number of trees dying. The background mortality rate is an annual rate that is adjusted to the projection cycle length using a compound interest formula. This is patterned after Hamilton (1986). This total number of mortality trees is then dispersed to individual tree records. 


\section{A.7.2 Dispersing mortality to individual tree records}

Once the number of mortality trees has been determined, the mortality needs to be dispersed across the individual tree records. Mortality in FVS is achieved by adjusting the number of trees per acre a record represents. Tree records are processed, each receiving a calculated mortality, until the total number of mortality trees has been achieved. All tree records will receive some mortality in a projection.

Mortality rates for individual tree records are determined by an equation that is variant dependent. The more intolerant species have higher mortality rates than the tolerant species. The rate is also dependent on a tree's social position as measured by its' rank in the basal area distribution. Trees with a lower rank (e.g. understory tree) receive heavier mortality than those with a higher rank (e.g. overstory tree). And finally, the rate is dependent on a tree's vigor as measured by crown ratio. Trees with a lower crown ratio receive higher mortality than trees with a higher crown ratio. The mortality model makes multiple passes through the tree records multiplying a record's trees per acre value times the mortality rate, accumulating the results, and reducing the trees per acre representation until the desired mortality level has been reached.

\section{A.8 Harvest simulation}

The process of harvesting involves removal of trees. Each tree record within FVS has a tree count attribute that indicates the number of trees per acre the tree record represents. If the other tree attributes (diameter, height, etc.) fall within the harvest parameters, then the tree count attribute is simply reduced to reflect how many of the trees per acre represented by this tree record are removed. It is possible to remove the entire trees per acre representation, or only a portion of the trees per acre representation, for a tree record during a harvest. FVS may process multiple thinning keywords in the same cycle. The tree count for each tree is reduced appropriately for each thinning scheduled for the same cycle. For clear cut harvest, thinning of stands in particular year was achieved by allowing FVS 
to remove all the trees present in the stand. Similarly, for partial cut harvest situation, target residual basal area needs to be species.

\section{A.9 Carbon estimation}

The Fire and Fuelwood extension of the FVS base program has a function that returns amount of carbon stored in various carbon pools which include: live tree biomass (above-and belowground), dead tree biomass (above-and belowground), down dead wood, forest floor, and herbs and shrubs. Calculation methods are consistent with US carbon accounting rules and guidelines. These pools correspond to those in stand composition and volume estimation. Carbon in following pools can be obtained through this function.

- Total above ground live tree carbon

- Merchantable above ground live tree carbon

- Below ground live carbon (roots)

- Below ground dead carbon (roots of dead or cut trees)

- Standing dead carbon

- Down dead wood carbon

- Forest floor carbon

- Shrub and herb carbon

- Total stand carbon

- Total removed carbon

- Carbon released from fire

- Merchantable removed carbon in wood products

- Merchantable removed carbon in landfills 
- Merchantable removed carbon emitted with energy capture

- Merchantable removed carbon emitted without energy capture

- Merchantable removed stored carbon (products + landfills)

- Merchantable removed carbon (all categories) 


\section{References}

Dixon G.E. Essential FVS: A user's Guide to the Forest Vegetation Simulator. Internal Rep. Fort Collins, CO: U.S. Department of Agriculture, Forest Service, Forest Management Service Center.

Dixon, G. E. 1986. Prognosis mortality modeling. Internal Rep. Fort Collins, CO: U. S. Department of Agriculture, Forest Service, Forest Management Service Center.

Dixon, Gary E. comp. 2003. Essential FVS: A User's Guide to the Forest Vegetation Simulator. Internal Rep. Fort Collins, CO: U. S. Department of Agriculture, Forest Service, Forest Management Service Center.

Hamilton, D. A., Jr. 1986. A logistic model of mortality in thinned and unthinned mixed conifer stands of northern Idaho. Forest Science 32: 989-1000.

Hamilton, D. A., Jr. 1991. Implications of random variation in the Stand Prognosis Model. Res. Note INT-394. Ogden, UT: U. S. Department of Agriculture, Forest Service, Intermountain Research Station.

Johnson, R. A.; Dixon, G. E. 1986. Adapting models: problems and benefits from incorporating stand density index into the Prognosis Model. Internal Rep. Fort Collins, CO: U. S. Department of Agriculture, Forest Service, Forest Management Service Center.

Mehta, J. S. 1972. On utilizing information from a second sample in estimating the scale parameter for a family of symmetric distributions. J. Am. Statist. Assoc. 67: 448-452.

Stage, A. R. 1973. Prognosis Model for stand development. Res. Paper INT-137. Ogden, UT: U. S. Department of Agriculture, Forest Service, Intermountain Forest and Range Experiment Station.

Wellner, C.A. 1940. Relationships between three measures of stocking in natural reproduction of the western white pine type. Journal of Forestry 38:636-638. 


\title{
$\begin{array}{llllll}\text { A P P E N D IX B : I N T RODUCTION T O US ING } & \text { FOR ES T }\end{array}$
}

\section{HA R V E S T P LA N N I N G S Y S T E M}

The forest management planning system is Spatio-temporal optimization model for scheduling harvest activities in different spatial locations and temporal points. The system relies on data from external sources. This study used FVS-NE Fire and Fuel extension to generate such data. A brief overview of FVS process was provided in Appendix A. This chapter is devoted on the following topics:

\author{
What data and inputs are needed? \\ How to obtain such data? \\ How to use the system ? \\ How to get the results? \\ What are the post processing needs ?
}

When the inventory data in required form is loaded in FVS and a "no-harvest" situation can be obtained by simply projecting the growth on to future time period. In this analysis, the projection was made at 5-year long time interval.

For harvested scenario, a data in the following form is needed. Lets assume that we have 11 stands (or harvest tracts or simply tract) to which harvest scheduling activities are to be implemented (Fig. B.1). 


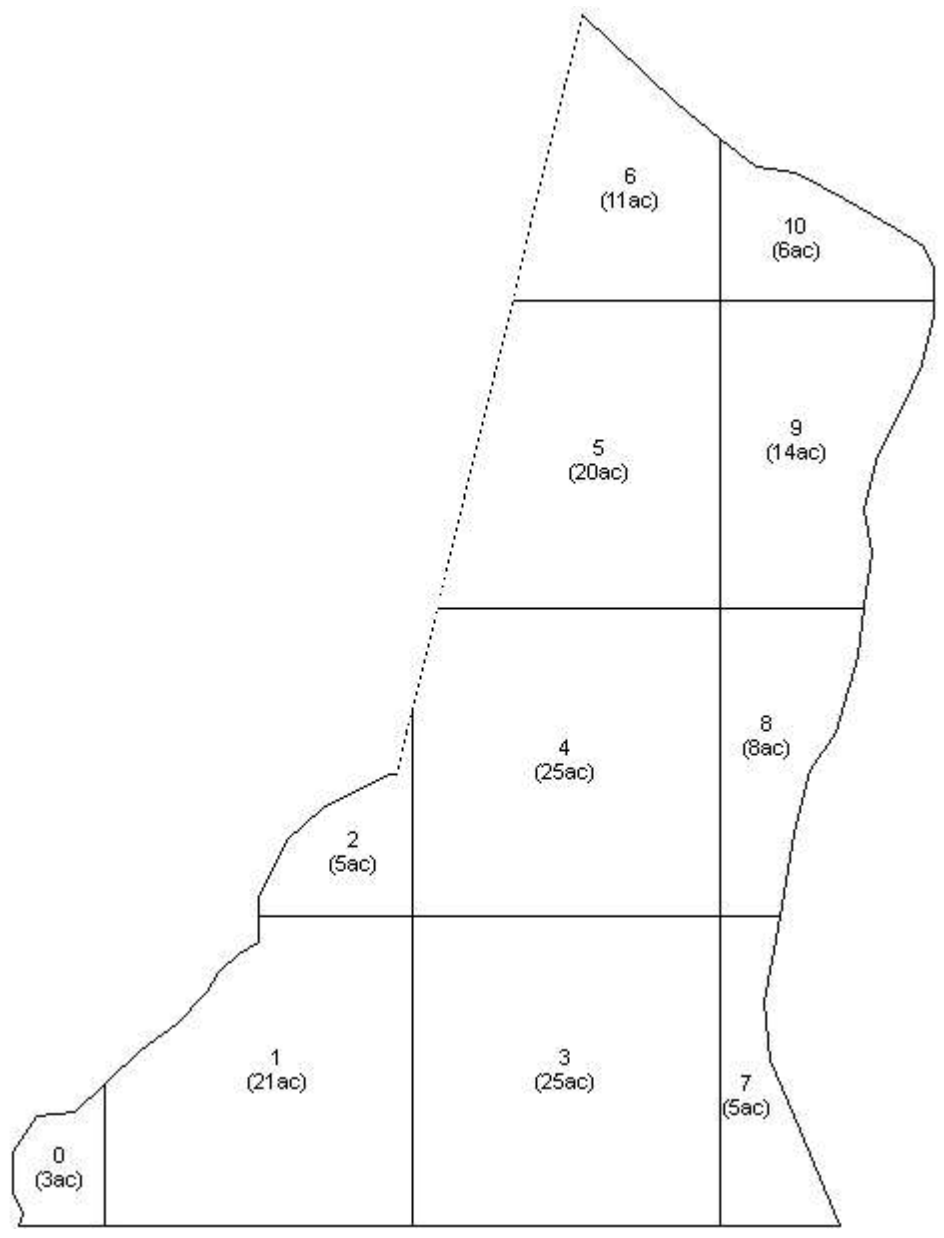

Figure B.1 A forest comprised of 11 individual stands.

(The stands are identified with numbers from 0 to 10 with their area in acre shown in parenthesis)

Each stand is identified as stand ID - an integer number. We would need information presented in Table B.1 to generate enforce spatial information in the model. This information can be obtained by using GIS. An arc-script was run in GIS to obtain this neighborhood information. 
Table B. 1 : Stand neighborhood relationship of forest map shown in Fig B.1.

\begin{tabular}{lll}
\hline Stand ID & Stand Area (acre) & Neighboring stands (ids) \\
\hline 0 & 3 & 1 \\
\hline 1 & 21 & $0,2,3,4$ \\
\hline 2 & 5 & $1,3,4$ \\
\hline 3 & 25 & $1,2,4,7,8$ \\
\hline 4 & 25 & $1,2,3,5,7,8,9$ \\
\hline 5 & 20 & $4,6,8,9,10$ \\
\hline 6 & 11 & $5,9,10$ \\
\hline 7 & 5 & $3,4,8$ \\
\hline 8 & 8 & $3,4,5,7,9$ \\
\hline 9 & 14 & $4,5,6,8,10$ \\
\hline 10 & 6 & $5,6,9$ \\
\hline
\end{tabular}

Given that the maximum opening size is 25 acre, 17 feasible blocks are identified for the stand in Fig. B.1 and shown in Table B.2. These blocks are comprised of one or more of the connected stand for which spatial adjacency is to me maintained while harvesting the stand. All of these blocks are feasible as none of the block has area exceeding the maximum opening size specified. 
Table B. 2 Feasible blocks with their total area for forest map.

\begin{tabular}{|c|c|c|}
\hline Block ID & Constituent stand & Block Area (acre) \\
\hline 0 & 0 & 3 \\
\hline 1 & 1 & 21 \\
\hline 2 & 2 & 5 \\
\hline 3 & 3 & 25 \\
\hline 84 & 4 & 25 \\
\hline 5 & 5 & 20 \\
\hline 6 & 6 & 11 \\
\hline 7 & 7 & 5 \\
\hline 8 & 8 & 8 \\
\hline 9 & 9 & 14 \\
\hline 10 & 10 & 6 \\
\hline 11 & 0,1 & 24 \\
\hline 12 & 6,9 & 25 \\
\hline 13 & 6,10 & 17 \\
\hline 14 & 7,8 & 13 \\
\hline 15 & 8,9 & 22 \\
\hline 16 & 9,10 & 20 \\
\hline
\end{tabular}

These feasible blocks will be the part of objective functions. One or more of these feasible blocks can be harvested by maintaining the adjacency relationship. In this block, the connectivity can be obtained by using the stand neighborhood relationships constituting the blocks. Block 0 and Block 11 are connected because they have common stand. Similarly, Block0 and Block 1 are connected as they are neighbor to each other. These two relationships can be generalized for all the feasible blocks to formulate 
appropriate constraints. For example, if Block 0 is harvested, Block 1, Block11 cannot be harvested because this will lead to harvesting Block 0 twice which is not desirable. To formulate appropriate constraints for this, scheme of identifying connected feasible blocks is developed which yields equation for implementing adjacency restrictions.

In order to restrict the harvesting of adjacent blocks and limit harvesting of one block once in one planning period, we will need five of the following constraints.

$$
\begin{aligned}
& \mathrm{B} 0+\mathrm{B} 1+\mathrm{B} 11<=1 \\
& \mathrm{~B} 1+\mathrm{B} 2+\mathrm{B} 3+\mathrm{B} 4+\mathrm{B} 11<=1 \\
& \mathrm{~B} 3+\mathrm{B} 4+\mathrm{B} 7+\mathrm{B} 8+\mathrm{B} 14+\mathrm{B} 15<=1 \\
& \mathrm{~B} 4+\mathrm{B} 5+\mathrm{B} 8+\mathrm{B} 9+\mathrm{B} 12+\mathrm{B} 14+\mathrm{B} 15+\mathrm{B} 16<=1 \\
& \mathrm{~B} 5+\mathrm{B} 6+\mathrm{B} 9+\mathrm{B} 10+\mathrm{B} 12+\mathrm{B} 13+\mathrm{B} 15+\mathrm{B} 16<=1
\end{aligned}
$$

Where $B_{i}$ are feasible blocks for $i=0,1, \ldots \ldots .16$

These equations make sure that adjacency restrictions are maintained. For example, equation (1) restricts harvesting to one of the block 0,1 and 11 . Block 0 has only one element, stand 1; block 1 has element stand 2 and block 11 has element stand 1 and stand 0 and block 0 and block 1 are neighbors. Therefore, block 1, block 0 and block 11 cannot be harvested simultaneously. Similar arguments hold true for rest of the equations. In the problem solving process, stand restriction for harvesting of stand 1 and 2 needs not to be considered because they will form infeasible blocks which are not in our space of feasible blocks. Thus five constraints are sufficient in this problem.

This simplifies the planning process which otherwise would take several number of equations. For example,

$$
\begin{aligned}
& \mathrm{S} 1+\mathrm{S} 2<=1 \\
& \mathrm{~S} 2+\mathrm{S} 3+\mathrm{S} 4<=1
\end{aligned}
$$


..... and so on.

where $S_{i}$ are stands and $i=1 \ldots . . n$ ( $n$ being number of stands).

The software developed takes care of feasible block generation based on the spatial map or the neighborhood relationship. Spatial maps are to be entered as text file of certain cell size. These equations were then applied for each time period to impose the spatial restriction in temporal horizon. The model has following components as in any integer program.

$$
\text { Max: } C_{i j} * B_{i j}
$$

where, $C_{i j}$ is the amount of benefits (in net present terms after discounting) by harvesting stand $i$ in $j$ time period, and $B_{i j}$ is 1 if block $B i$ is harvested in time $j$

This follows a series of variables until all the blocks (and corresponding stands) values are summed in the objective function. The $C_{i j}$ component can be obtained by running FVS for each of the 11 stands shown above. Following routines must be implemented for conducting simulations:

For each stands (i.e. 0 to 11 )

For defined planning horizon (i.e. 80 years or 50 years) at each interval of plan periods (i.e. 5)

Simulate harvest

Store results in terms of harvested carbon, carbon in merchantable timber

Next plan period

Next stands

This routine can be implemented for multiple cutting types and for multiple rotations. Once this routine is completed, recovery periods for each harvest should be estimated. This recovery period would be rounded to the nearest plan period. And carbon in the mean recovery period for each stand needs to be identified. The objective function would then be simply be summation of carbon in harvested timber, 
carbon in stands and carbon in recovery period for each block. Values for the block would simply be summation of individual values from constituting stands in each feasible block.

For example, if there are 11 stands in the forest shown in Fig. B.1 and the 5-year long plan period is desired for a planning horizon of 80 years, then 176 (i.e. $16 \times 11$ ) simulation is desired in minimum. On the top of this, if additional simulation to account for projection variability is desired, it should be at least 528 (i.e. 176 x 3) simulation must be run to obtain the results. These results are stored in MS access table described in chapter 2 of this document.

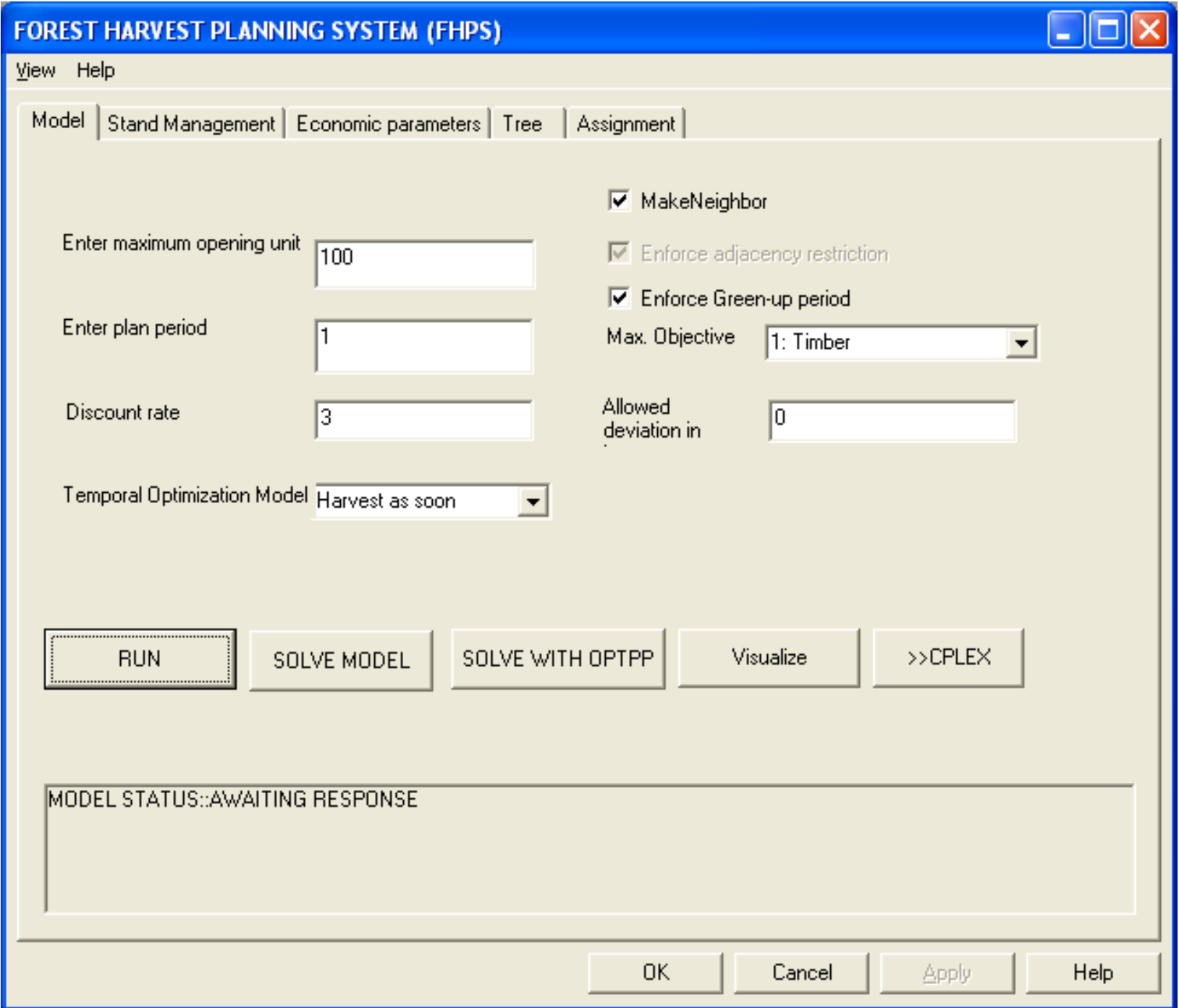

Figure B.2 Application interface of Forest Harvest Planning System. 
Once data required to generate models are setup and put to the same directory where executable of FHPS resides, running the fhps.exe opens the screen mentioned in Fig. B.2. User needs to provide maximum opening area in (desired unit), typically in the same unit provided in the database (i.e, ha or acre). The required number planning period is the length of planning horizon divided by period length (or interval), usually 5 years. The discount rate is the rate at which future $\mathrm{C}$ value will be discounted to obtain the net present value (NPV). Checking "MakeNeighbor" will generate blocks. If the same forest needs to be modeled, un-checking the "MakeNeighbor" function would result in faster processing. Max objective functions need to be selected to generate different objective functions i.e. timber, timber and carbon, or only carbon. Allowed deviation is required for harvesting with uniform flow of benefits. If a negative value is specified, this constraint will not be enforced. The green-up period check mark will enforce the corresponding restrictions.

Hitting RUN button prepares the model and waits for users action. Solve will solve the model. >>CPLEX button allows to export the model file into CPLEX readable format which later be used to commercially available CPLEX package. An overview of working with CPLEX is provided in Appendix C. Sometimes, the defined time periods and adjacency relationship won't allow harvesting all the stands in user's provided time frame. In such cases SOLVEOPTP will help users to obtain the minimum number of planning periods required to carry out harvesting of the all the stands under the given restrictions. Solving with this option will make sure all the stands are harvested once at a given planning period. This essentially nullifies the users supplied planning periods and generates the optimal time by itself. 


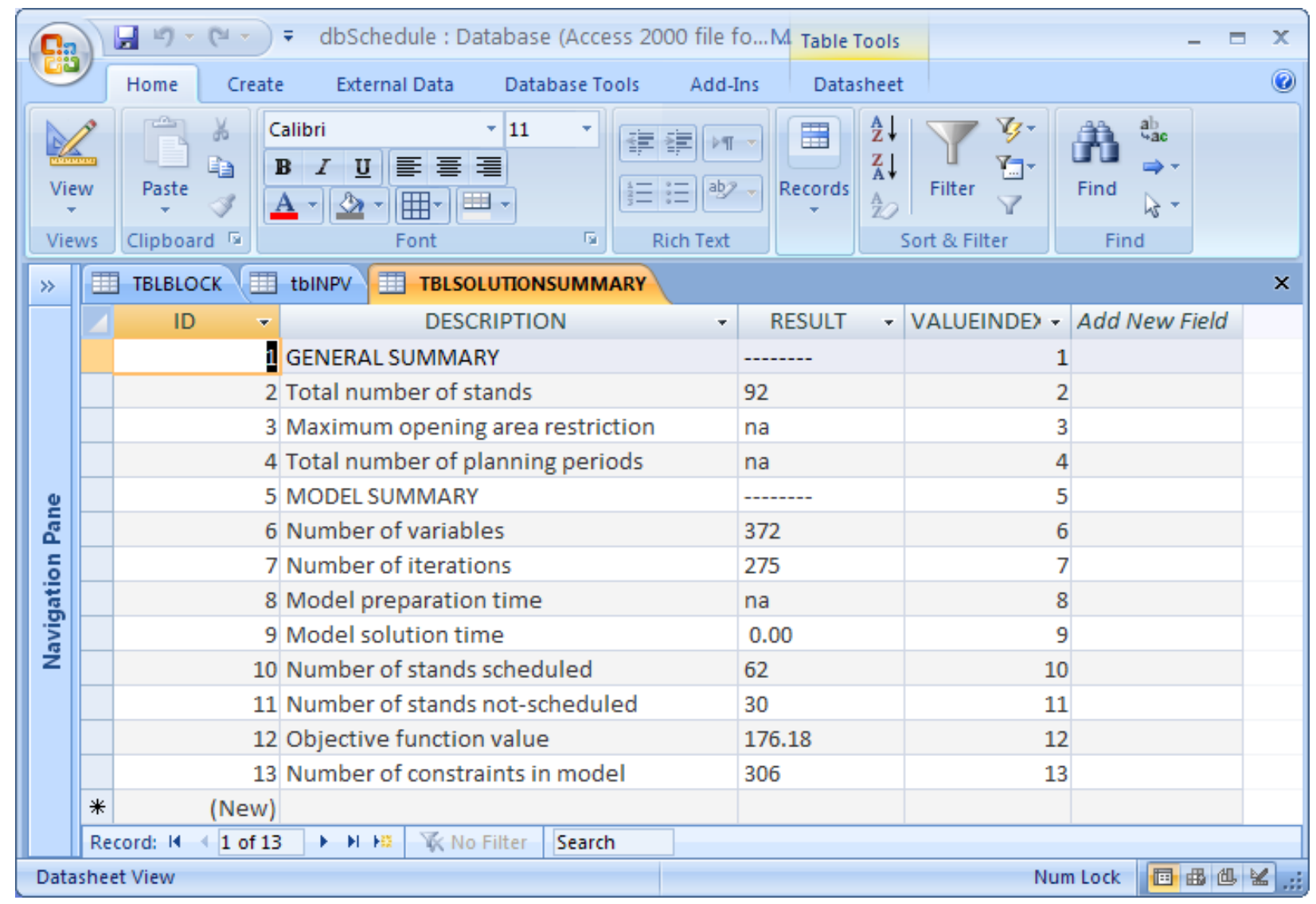

Figure B.3 Solution summary.

The detailed model output of the model specifies time and space of harvesting units in different years to meet the desired objective of management. The output has the following format.

$\begin{array}{ll}\text { Stand } & \text { Pl } \\ 0 & 1 \\ 1 & 1 \\ 2 & 1 \\ 3 & 1 \\ 4 & 1 \\ 5 & 1 \\ 6 & 1\end{array}$




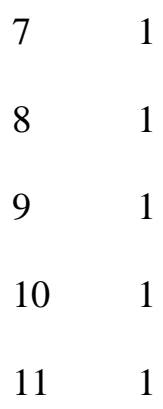

This solution generated is presented in terms of stands after disaggregating from feasible blocks users do not have to take care of the stand-block relationship. Simply put, this is the schedule generated that is optimal for the given management objective and imposed restrictions. This output is stored in a text file in the root directory. Summary of result is resides in a table in the database with table name “TBLSOLUTIONSUMMARY” (Fig. B.3).

Once the schedule is generated, it can be linked to Access database table and queries can be formulated to obtain the carbon value in different pools at each time period based on unique stand and harvest time relationships. Some post processing techniques that can be implemented includes:

- Stand time combination of harvest

- Actual harvested volume at each harvest event

- Actual remaining volume in stands throughout the planning horizon

- Annual sequestration (that can be obtained by $\mathrm{C}$ stock at time $2-\mathrm{C}$ stock at time 1 divided by difference in 2 time periods)

Visualization of harvest schedule can be made but the system requires the base map in text file format. This can be obtained from GIS in which raster images are exported in ASCII text file. The number in the text file should represent the area covered by one particular stand. 


\section{A P P E N DIX C: INTRODUCTION TO CPLEX}

When the forest harvest planning system takes longer than expected time, it is possible that the defined problem could have been very complex to solve for the used LP_SOLVE solver. In such case, using CPLEX - a commercial optimization solver is viable alternative, if available. This document provides some general information on using CPLEX for the problem developed in the forest harvest planning system. This process involves following five steps:

- Define and develop problem in forest harvest planning system

- Export the problem in CPLEX LP format

- Open CPLEX package

- $\quad$ Load the problem in LP format developed in step $b$ into CPLEX

- Solve the problem and interpret the results.

Defining problem in forest harvest planning system is already explained in Chapter 2 of this dissertation. Once it was found out that the software is taking longer than expected to solve the problem, then the problem can be exported to CPLEX format using command "Export" available in menu bar in FHPS system described in Appendix B.

The successive paragraphs assume that the CPLEX solver is installed in the computer and the computer has valid licenses to run CPLEX. The details of installing and obtaining license can be obtained from developer's website at http://www.ilog.com. The CPLEX can be run using command prompt in Windows operating machine by typing "CPLEX" in the command prompt which will enact the CPLEX program (Fig. C.1). The program then shows that the 'help' command can be entered for possible help (Fig. C.2). 


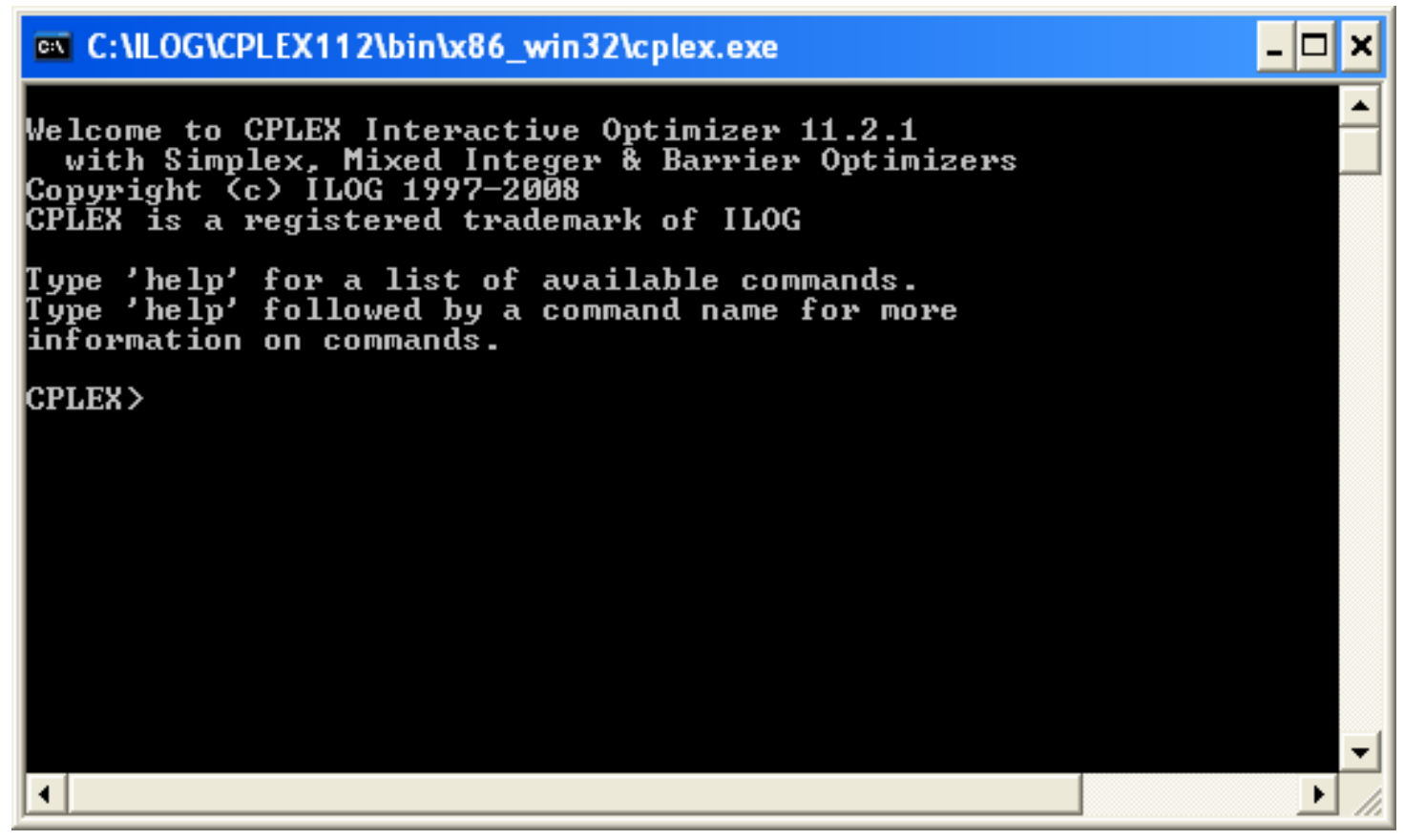

Figure C.1 CPLEX initialization window.

\begin{tabular}{|c|c|c|}
\hline \multicolumn{2}{|c|}{ c: C:MLOGICPLEX1121binlx86_win32lcplex.exe } & $x$ \\
\hline \multicolumn{3}{|c|}{ 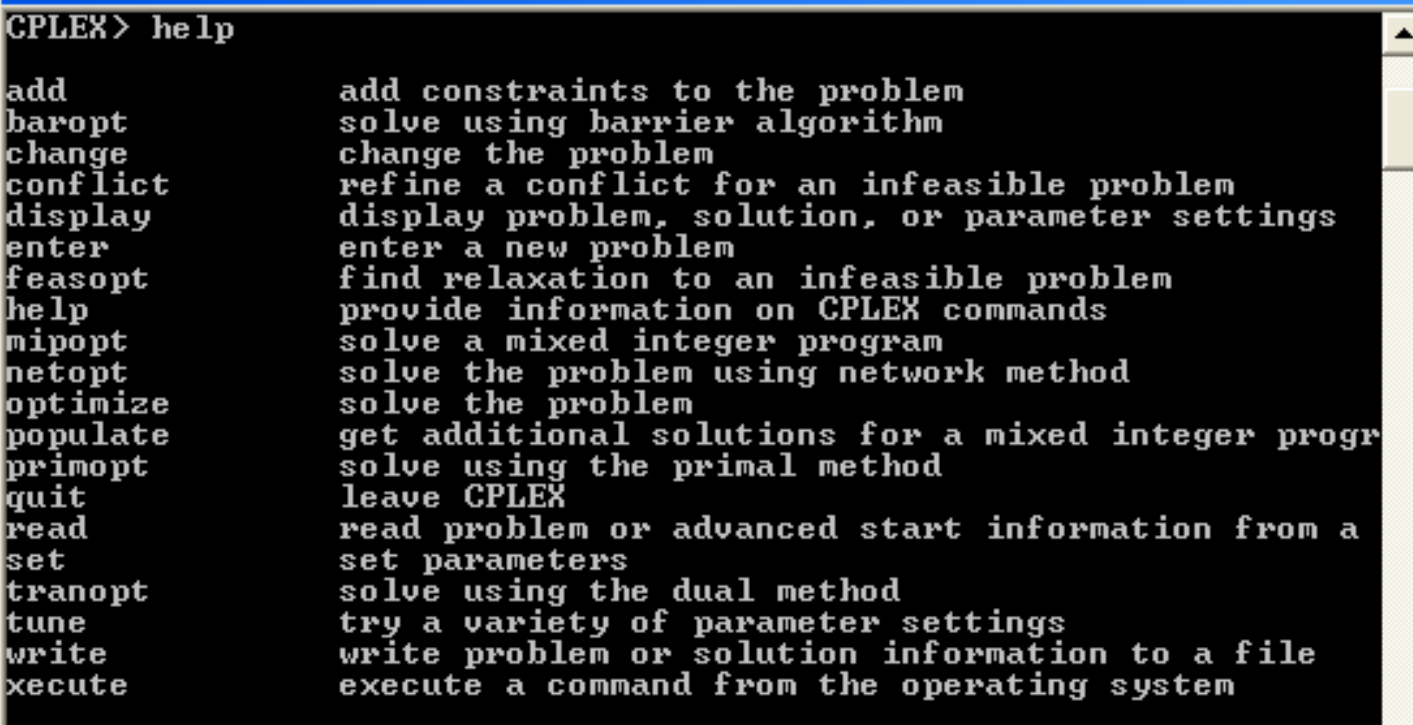 } \\
\hline $\begin{array}{l}\text { Enter eno } \\
\text { entered } \\
\text { CPLEX> - }\end{array}$ & $\begin{array}{l}\text { racters to uniquely identify commands \& options - C } \\
\text { y (CPLEX will prompt you for further information) }\end{array}$ & \\
\hline 1 & $v$ & \\
\hline
\end{tabular}

Figure C.2 CPLEX help window. 
Root directory where the LP program resides can be typed in initial window at CPLEX prompt i.e. "CPLEX>" and the new program can be loaded into CPLEX using common "read FILENAME.LP". FILENAME.LP is the program file that has been generated using model builder described in Chapter I of this document.

Lets say the model developed in FHPS was exported to CPLEX format and saved in the file "CPLEX.lp". First the directory needs to be changed to the place where this model file is located. Lets assume that the model file is located in desktop folder. In the command prompt window, once the root directory i.e. desktop in this case is navigated, typing "CPLEX" would activate the window shown in Fig. C.2. Entering "help" in CPLEX command prompt gives the general idea of applicable commands at that level (Fig. C.2).

Entering "read" command would prompt for file name. In this example, "CPLEX.lp" is entered. If this file is correct, CPLEX will prompt the user with the result. In this example, problem 'CPLEX.lp" read prompt is given. Once the program can is read by CPLEX, it is ready. Command "optimize" would give a solution with a summary of information (Fig. C.3). 


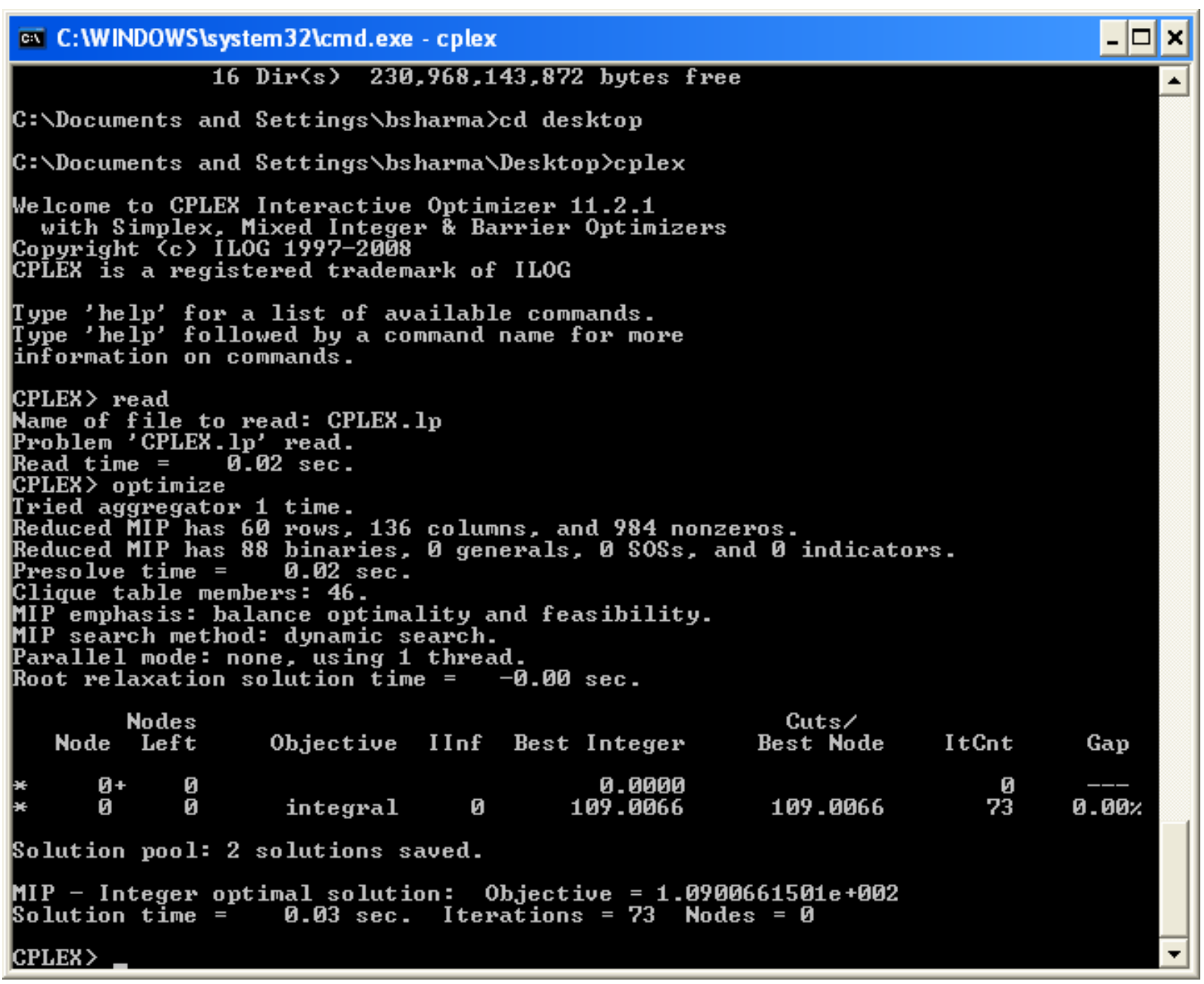

Figure C.3 CPLEX optimization command results.

The brief summary of models, solution time, solution and iterations are shown in as result of "optimize" command. Command "display" would prompt for further input. In this example, "solution" was entered. The CPLEX window will ask for further input. If we want to see the solution with values of variables which is what we need to find out to obtain the schedule, then entering "variables" to CPLEX prompt of "Display which part of the solution" will result in Fig C.4. On prompt for variables, either variable name should be entered to see the value of specific variables. For example, in the model B0_1 is variable block0 if harvested in time 1 . To see all the variables, “-"should be entered. The CPLEX model 
does not have stand information in block. Stand block information is contained in access table used in

FHPS and this information can be obtained from that table.

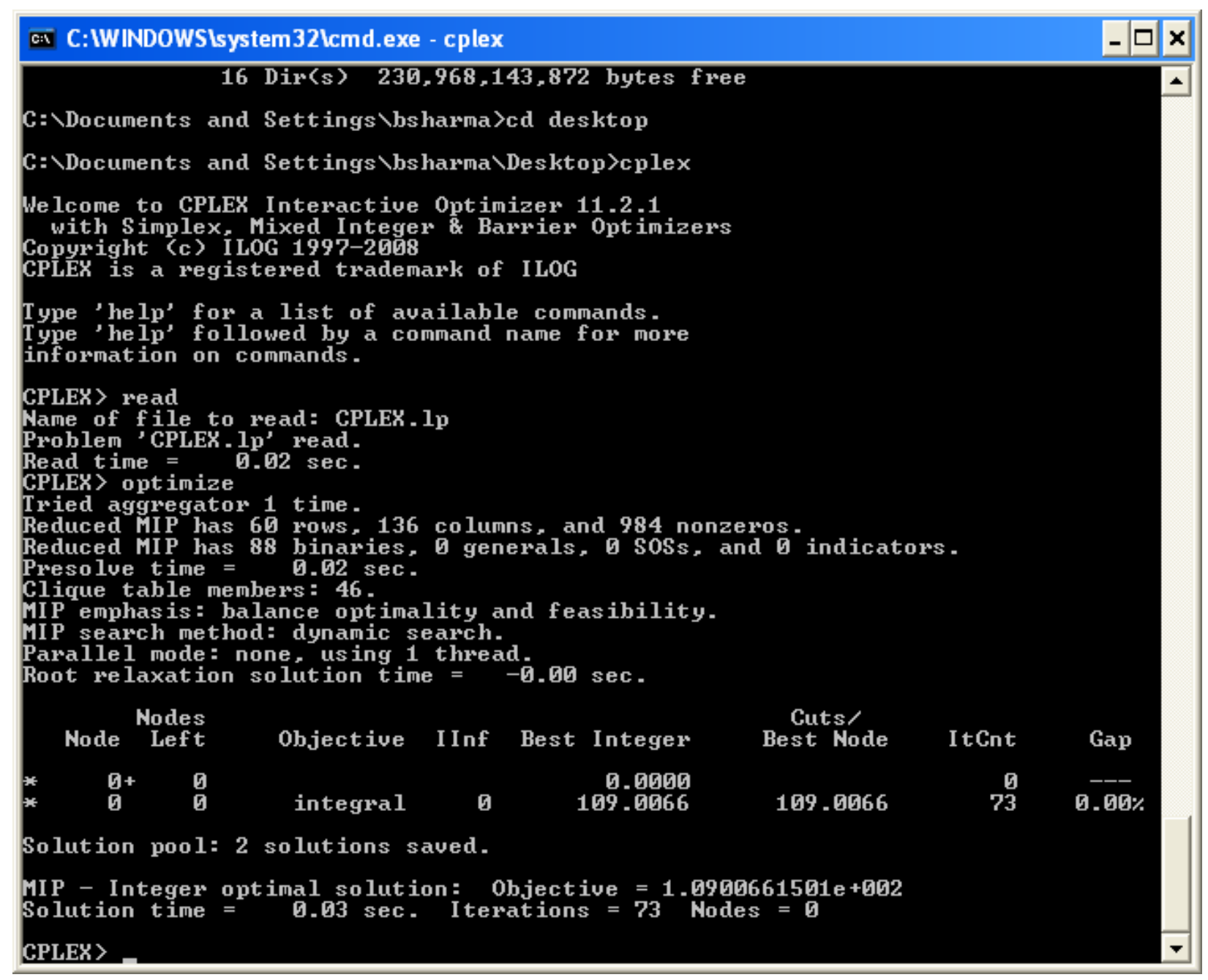

Figure C.4 CPLEX display solution command.

CPLEX comes with several additional command at the beginning. Available commands and their brief descriptions are listed below:

- add - add constraints to the problem

- baropt - solve using barrier algorithm

- change - change the problem 
- display - display problem, solution, or parameter settings

- enter - enter a new problem

- help - provide information on CPLEX commands

- mipopt - solve a mixed integer program

- netopt -solve the problem using network method

- optimize - solve the problem

- $\quad$ primopt - solve using the primal method

- quit - leave CPLEX

- read - read problem or basis information from a file

- $\quad$ set - set parameters

- tranopt - solve using the dual method

- write - write problem or solution info. to a file

- xecute - execute a command from the operating system

Commands can be entered partially (CPLEX will prompt for further information) or as a whole. However, the solution process used in this work used command displayed in bold face as model generation part was already made in developed computer software. 


\section{SE Q E S T RA T I O N M O D E L}

This model is available from either the student or the committee chair person. The terrestrial carbon sequestration enhancement model can be used from any web browser from the client site. This model actually sits in a TomCat server. The illustration assumes that TomCat server is already set up in a computer. The same computer can be used to function both as client and server. A web browser is needed to connect to the server. The index file for this program is usually located at //Carbon/index.html. If the same computer is used for both client and server, then accessing http://localhost:8080/Carbon/index.jsp (assuming the default port of 8080 that TomCat uses in Windows operating machines) would open the initial page.

Land use resources information needs to be entered in the format listed in Fig. (D.1)in the form. Percent column reflects how much is available. For example, if certain percent is restricted, then that should be accounted for in advance.

\begin{tabular}{|l||l||l|}
\hline Type & Percent & Area (mil acre) \\
\hline Forest & 100 & 12 \\
\hline Prime agricultural & 60 & 1.2 \\
\hline Marginal agricultural land & 40 & 0.8 \\
\hline Current mine lands & 100 & 0.45 \\
\hline Abandoned mine lands & 30 & 0.137 \\
\hline
\end{tabular}

Figure D.1 Land use resource information

Following simulation parameters are needed to run this model. 
- Simulation Start Year $\longdiv { 2 0 0 \varsigma }$

Desired Simulation Horizon $\longdiv { 1 0 0 }$

Desired GRR $\longdiv { 1 . 5 6 }$ (Default shown)

- Net Annual C sequestration rate of Forest (old growth without harvest) (ton/acre) $\sqrt{0.25}$ (Default $\mathrm{tC} /$ acre shown)

Net Annual C sequestration rate of Managed Forest (ton/acre) $\sqrt{0.44}$ (Default tC/acre shown)

Agriculture lands can be divided into marginal agricultural lands where productivity is low and which can be considered for possible land use change options. The total area of agricultural lands, proportion of marginal lands and proportion of marginal lands for land use change options are needed. Similarly net $\mathrm{C}$ sequestration rates under each type are also needed. Agriculture land use and potential afforestation activities are to be entered (Fig. D.2).

\begin{tabular}{|c|c|c|c|}
\hline Agricultural landuse & Percent & $\begin{array}{l}\text { Area (mil } \\
\text { acre) }\end{array}$ & $\begin{array}{l}\text { Net annual } \mathrm{C} \text { sequestration rate } \\
\text { (tC/acre) }\end{array}$ \\
\hline Total Available & 100 & 2 & 0.05 \\
\hline Prime agricultural land & 60 & 1.2 & 0.05 \\
\hline Marginal agricultural land & 40 & 0.8 & 0.05 \\
\hline \multicolumn{4}{|c|}{ Management options (land use change options) } \\
\hline $\begin{array}{l}\text { Afforestation activities in marginal } \\
\text { agricultural land }\end{array}$ & 100 & 0.8 & 0.44 \\
\hline
\end{tabular}

Figure D.2 Marginal agricultural land afforestation information 
Mine lands can be left as they are or can be brought under forestry land use. Here parameters needed total available mine land area, and percent of mine lands that are to be brought to forestry land use as management options. Net annual C sequestration rate under current as well as future land use options are also needed. Mine land related parameters are entered in the following form:

\begin{tabular}{|c|c|c|c|}
\hline Abandoned mine lands & Percent & $\begin{array}{l}\text { Area (mil } \\
\text { acre) }\end{array}$ & $\begin{array}{l}\text { Net annual } \mathrm{C} \\
\text { sequestration rate } \\
\text { (tC/acre) }\end{array}$ \\
\hline Total mine lands & 100 & 0.456 & 0.0 \\
\hline Abandoned mine lands & 30 & 0.137 & 0.0 \\
\hline \multicolumn{4}{|l|}{ Management options (land use change options) } \\
\hline Afforestation activities in abandoned mine lands & 100 & 0.137 & 0.44 \\
\hline
\end{tabular}

Figure D.3 Abandoned mine land afforestation information

Distribution of harvested wood products in different categories, their longevity and expected half lives can be entered (Fig. D.4). Here, harvested wood products are categorized in several possible types. For other product types "Misc" can be used. The nature of use i.e. expected life can be selected, and corresponding half life can be entered. The proportion of $\mathrm{C}$ stock and flow under different product categories are to be entered in percentage as shown below: 


\begin{tabular}{|c|c|c|c|}
\hline \multicolumn{4}{|c|}{ Distribtuion of harvested wood products use in different category (percent) } \\
\hline Proportion & Product category & Expected Life & Half Life(years) \\
\hline 3.52 & Composite products & $\odot$ Long Term $\bigcirc$ Medium Term $\bigcirc$ Short Term $\bigcirc$ Dump and Decay $\bigcirc$ Land Fill & 30 \\
\hline 7.39 & Fuelwood & $\bigcirc$ Long Term $\bigcirc$ Medium Term $\odot$ Short Term $\bigcirc$ Dump and Decay $\bigcirc$ Land Fill & 1 \\
\hline 1.13 & Post, poles and pilings & $\bigcirc$ Long Term $\odot$ Medium Term $\bigcirc$ Short Term $\bigcirc$ Dump and Decay $\bigcirc$ Land Fill & 15 \\
\hline 6.50 & Pulpwood & $\bigcirc$ Long Term $\bigcirc$ Medium Term $\odot$ Short Term $\bigcirc$ Dump and Decay $\bigcirc$ Land Fill & 1 \\
\hline 35.17 & Sawlogs & $\odot$ Long Term $\bigcirc$ Medium Term $\bigcirc$ Short Term $\bigcirc$ Dump and Decay $\bigcirc$ Land Fill & 30 \\
\hline 2.35 & Veneer logs & $\bigcirc$ Long Term $\odot$ Medium Term $\bigcirc$ Short Term $\bigcirc$ Dump and Decay $\bigcirc$ Land Fill & 15 \\
\hline 5.96 & Fiber & $\odot$ Long Term $\bigcirc$ Medium Term $\bigcirc$ Short Term $\bigcirc$ Dump and Decay $\bigcirc$ Land Fill & 30 \\
\hline 3.88 & Misc. products & $\bigcirc$ Long Term $\bigcirc$ Medium Term $\odot$ Short Term $\bigcirc$ Dump and Decay $\bigcirc$ Land Fill & 1 \\
\hline 34.10 & Unused products & $\bigcirc$ Long Term $\bigcirc$ Medium Term $\bigcirc$ Short Term $\odot$ Dump and Decay $\bigcirc$ Land Fill & 5 \\
\hline
\end{tabular}

Figure D.4 Harvested wood products related information

The submit button will enact the model and the results will be displayed in the following form (for 8 years):

**********************BEGIN RESULT : Carbon in LANDUSE******************

\begin{tabular}{|l|l|l|l|l|l|l|l|}
\hline Description & Year & HWP & FS & AGS & AML & TOTAL \\
\hline 1 & 2010 & 2.49 & 3.89 & 0.82 & 0.2 & 7.4 \\
\hline 2 & 2011 & 4.53 & 7.78 & 1.23 & 0.4 & 13.94 \\
\hline 3 & 2012 & 6.35 & 11.67 & 1.64 & 0.6 & 20.26 \\
\hline 4 & 2013 & 8.02 & 15.56 & 2.05 & 0.8 & 26.43 \\
\hline 5 & 2014 & 9.57 & 19.45 & 2.46 & 1.0 & 32.49 \\
\hline 6 & 2015 & 11.04 & 23.34 & 2.87 & 1.2 & 38.45 \\
\hline 7 & 2015 & 12.42 & 27.23 & 3.28 & 1.4 & 44.33 \\
\hline 8 & 2016 & 13.73 & 31.12 & 3.69 & 1.6 & 50.14 \\
\hline
\end{tabular}


**********************END OF RESULT $:$ Carbon in LANDUSE************************

************BEGING RESULT : Carbon in Harvested Wood Pool by product*********

\begin{tabular}{|l|l|l|l|l|l|l|l|l|l|l|l|l|l|}
\hline Year & ComWood & Fuelwood & PolePost & Pulpwood & Sawlogs & Veneer & Fiber & Misc & Unused & Total & Actual \\
\hline 2010 & 0.088 & 0.184 & 0.028 & 0.162 & 0.877 & 0.059 & 0.149 & 0.097 & 0.85 & 2.494 & 2.49 \\
\hline 2011 & 0.174 & 0.241 & 0.055 & 0.212 & 1.734 & 0.115 & 0.294 & 0.126 & 1.583 & 4.533 & 4.98 \\
\hline 2012 & 0.257 & 0.258 & 0.081 & 0.227 & 2.571 & 0.168 & 0.436 & 0.136 & 2.214 & 6.348 & 7.47 \\
\hline 2013 & 0.339 & 0.264 & 0.105 & 0.232 & 3.389 & 0.219 & 0.574 & 0.138 & 2.758 & 8.017 & 9.96 \\
\hline 2014 & 0.419 & 0.265 & 0.128 & 0.233 & 4.188 & 0.267 & 0.71 & 0.139 & 3.226 & 9.575 & 12.45 \\
\hline 2015 & 0.497 & 0.266 & 0.151 & 0.234 & 4.968 & 0.313 & 0.842 & 0.139 & 3.629 & 11.039 & 14.94 \\
\hline
\end{tabular}

***********BEGING RESULT : Carbon in Harvested Wood Pool by product********

These two outputs are can used to generate graphs and further analysis in Excel using required procedures. 
A P P E N DIX E: DENSITY OF WOOD B IOMASS

Table E. 1 Density of forest biomass.

\begin{tabular}{|c|c|c|c|c|c|c|c|}
\hline \multirow[b]{2}{*}{ Species } & \multicolumn{2}{|c|}{ Reporting year } & \multicolumn{2}{|c|}{ Mean annual } & \multirow{2}{*}{$\mathrm{lbs} / \mathrm{cft}$} & & \multirow{2}{*}{ Factor } \\
\hline & 1997 & 2002 & 2007 & arvest (cft) & & & \\
\hline Ash & 2037338 & 2034849 & 1126036 & 1732741 & 34 & 29456.598 & 0.017 \\
\hline Basswood & 2245456.9 & 2245854 & 1833366 & 2108225 & 21 & 22136.367 & 0.0105 \\
\hline Beech & 1311975.3 & 1321368 & 1644830 & 1426058 & 34 & 24242.983 & 0.017 \\
\hline Black cherry & 3443940.3 & 3400087 & 2089972 & 2978000 & 30 & 44669.998 & 0.015 \\
\hline Black walnut & 334544.9 & 334553.2 & 174945.3 & 281347.8 & & 5626.956 & 0.02 \\
\hline Elm & 83975 & 83368 & 51411.6 & 72918.2 & & 1093.773 & 0.015 \\
\hline Hard maples & 4300100.5 & 4258056 & 3079820 & 3879326 & 33 & 64008.874 & 0.0165 \\
\hline Hickory & 2119996.2 & 2167979 & 1256075 & 1848017 & 41 & 37884.346 & 0.0205 \\
\hline Other birch & 406357 & 406841.3 & 319659.7 & 377619.3 & & 6419.5287 & 0.017 \\
\hline Other hardwoods & 16109346.7 & 15698443 & 39897609 & 23901800 & & 406330.59 & 0.017 \\
\hline Other red oaks & 9194039.9 & 9375009 & 7325209 & 8631419 & & 172628.38 & 0.02 \\
\hline Other white oaks & 7159152.9 & 7246211 & 4882218 & 6429194 & & 118940.09 & 0.0185 \\
\hline Select red oaks & 19092392.7 & 19161162 & 6606999 & 14953518 & 35 & 261686.56 & 0.0175 \\
\hline Select white oaks & 9338329.5 & 9495183 & 3110232 & 7314581 & & 135319.76 & 0.0185 \\
\hline Soft maples & 3834654.4 & 3834497 & 3694810 & 3787987 & & 56819.808 & 0.015 \\
\hline Spruce & 5411.8 & 2284.7 & & 3848.25 & & 48.103125 & 0.0125 \\
\hline Sweetgum & & & 9091 & 9091 & 28 & 127.274 & 0.014 \\
\hline Sycamore & & & 283301.5 & 283301.5 & & 4107.8718 & 0.0145 \\
\hline Tupelo/black gum & 247935.7 & 255017 & 93349.2 & 198767.3 & & 3180.2768 & 0.016 \\
\hline White pine & 763350.7 & 743530.3 & 157953.4 & 554944.8 & 20 & 5549.448 & 0.01 \\
\hline Yellow birch & 163635.6 & 159732.8 & 117687.3 & 147018.6 & & 2499.3156 & 0.017 \\
\hline Yellow-poplar & 23143180.7 & 23226859 & 21497040 & 22622360 & & 271468.32 & 0.012 \\
\hline Cedars & & & 31.4 & 31.4 & 27 & 0.4239 & 0.0135 \\
\hline Hemlock & 221130.7 & 217903.2 & 189428.9 & 209487.6 & 24 & 2513.8512 & 0.012 \\
\hline Other pines & 1896191.1 & 1948327 & 1052820 & 1632446 & 24 & 19589.354 & 0.012 \\
\hline Red pine & & & 187045.2 & 187045.2 & & 2525.1102 & 0.0135 \\
\hline
\end{tabular}

Source: USDA-FPL 1953, Grantham and Ellis 1970, Smith 1991, TPO data.

Factor: is multiplier to convert from green cubic foot volume to dry ton biomass. 
APPENDIX F: GROWTH TO REMOVAL RATIO OF FOREST

GROWING STOCK (CFT/YEAR) IN DIFFERENT COUNTIES

I N W E S T VIR G I N I A

Table F. 1 Forest growth to removal ratio in West Virgnia.

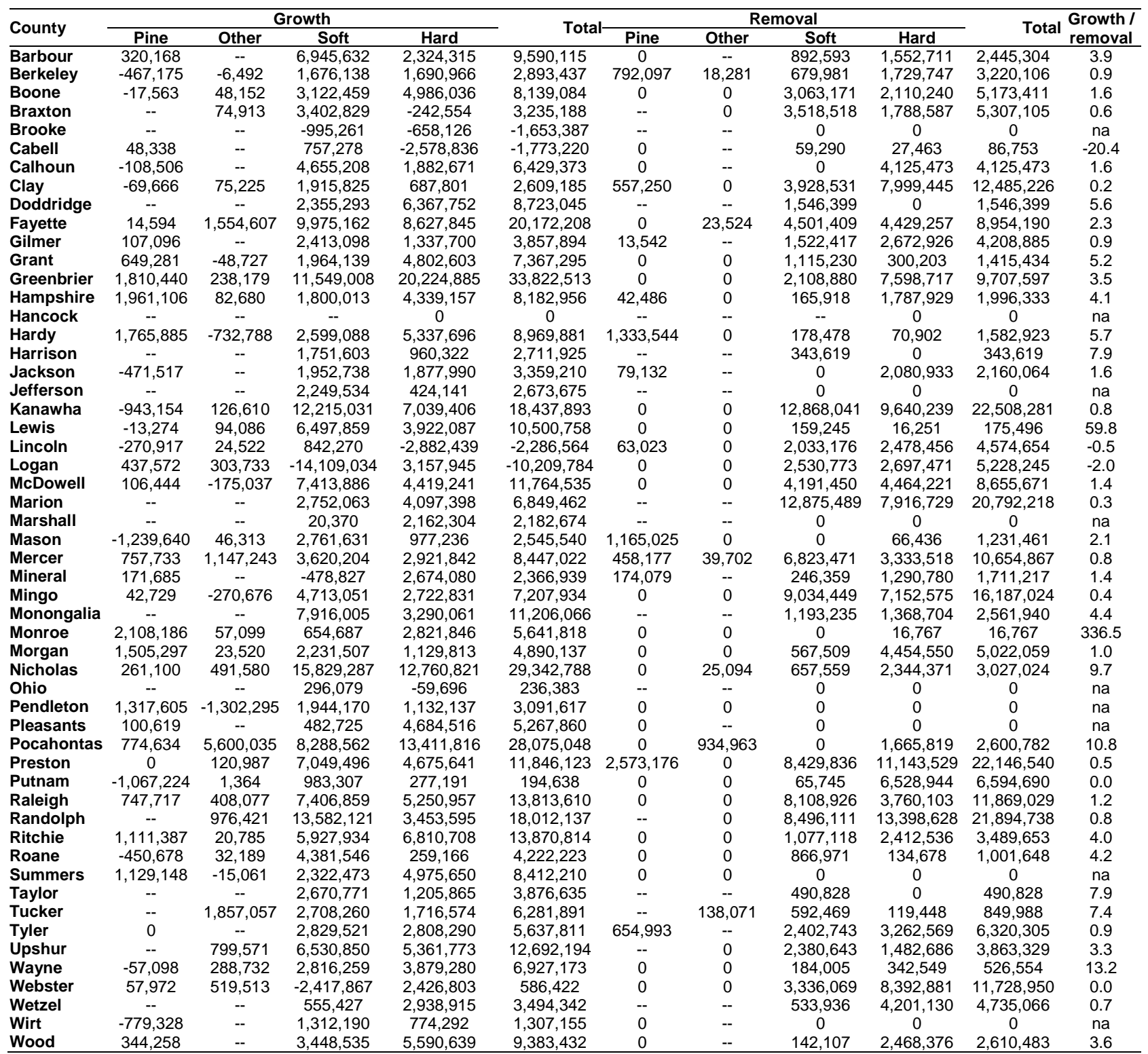

Source: USDA -FS 2010. 


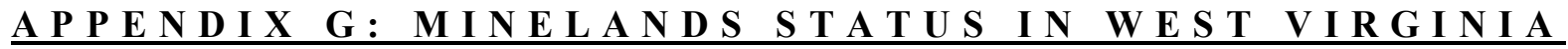

Table G. 1 Reclaimation status of minelands as of 2009.

\begin{tabular}{|c|c|c|c|c|c|c|}
\hline $\begin{array}{l}\text { Status } \\
\text { code }\end{array}$ & $\begin{array}{l}\text { Inspection } \\
\text { Status }\end{array}$ & Nos & $\begin{array}{r}\text { Original } \\
\text { (acres) }\end{array}$ & $\begin{array}{r}\text { Current } \\
\text { (acres) }\end{array}$ & $\begin{array}{r}\text { Disturbed area } \\
\text { (acres) }\end{array}$ & $\begin{array}{r}\text { Reclaimed } \\
\text { (acres) }\end{array}$ \\
\hline A1 & Moving Coal & 7 & 2720.71 & 3038.16 & 897.57 & 0 \\
\hline $\mathrm{A} 2$ & Reclaimed & 412 & 96117.61 & 89208.55 & 35106.62 & 5564.92 \\
\hline A3 & $\begin{array}{l}\text { Reclaimed } \\
\text { No coal }\end{array}$ & 363 & 39820.84 & 43669.91 & 15316.83 & 2609.76 \\
\hline A4 & Removed & $\begin{array}{l}589 \\
135\end{array}$ & 71603.56 & 77363.384 & 40518.28 & 2389.26 \\
\hline AM & Moving Coal & 6 & 258127.46 & 357435.13 & 192521.34 & 636.22 \\
\hline$A Q$ & Quarry & 104 & 11547 & 17315.44 & 9496.73 & 0 \\
\hline $\mathrm{BF}$ & -- & 34 & 6585 & 6468.96 & 2134.37 & 892 \\
\hline IA & inactive & $\begin{array}{l}245 \\
260\end{array}$ & 12572.65 & 16760.47 & 9789.58 & 8.88 \\
\hline NONE & -- & 8 & 180424.41 & 150084.96 & 71624.01 & 58803.53 \\
\hline NS & Not Started & 128 & 19577.19 & 19147.13 & 518.74 & 0 \\
\hline P1 & -- & 60 & 7592 & 9446.7 & 4402.48 & 1434.41 \\
\hline P2 & -- & 262 & 61006.58 & 63185.44 & 44483.62 & 41146.54 \\
\hline P3 & -- & 3 & 81.5 & 96.5 & 32.55 & 32.55 \\
\hline PV & -- & 456 & 50464.67 & 49262.32 & 26424.04 & 22497.45 \\
\hline $\mathrm{RC}$ & Reclaimed & 192 & 23940.78 & 20636.56 & 2297.18 & 467.25 \\
\hline-- & -- & & 12554.92 & 7252.7201 & 0 & 0 \\
\hline Total & & & 854736 & 930372 & 455563 & 136482 \\
\hline
\end{tabular}

These statistics were derived from mining permits issued in WV on and after 1970.

Table G. 2 Recent mining activities in WV.

\begin{tabular}{lrrrr}
\hline Mines & 2004 & 2005 & 2006 & 2007 \\
\hline Underground mines (number) & 315 & 329 & 330 & 304 \\
Surface mines (number) & 229 & 245 & 271 & 244
\end{tabular}

Source: West Virginia Office of Miner's Heath and Safety and Training, 2007. Calendar Year Statistical

Report available online at http://www.wvminesafety.org/2007\%20Annual\%20figures/compare2007.pdf 


\section{CURRICULUM VITAE}

Benktesh Dash Sharma

Division of Forestry and Natural Resources

West Virginia University

322 Percival Hall, Morgantown, WV 26506

Tel: 3042930043 (Office), 3042128826 (Cell), Fax: 3042932991

Email: $\underline{\text { benktesh@yahoo.com or bsharma@mix.wvu.edu }}$

\section{Education}

Ph.D. Forest Resource Science 2010 (in progress) West Virginia University

M.Sc. Tropical Forestry (Silviculture and Forest Ecology) 2003 Wageningen University, the Netherlands

B.Sc. Forestry 2001. Tribhuvan University, Nepal

\section{Professional Experience}

2005 - 2010 Research/Teaching Assistant \& Instructor. West Virginia University

2003 - 2005. Program Officer. Nepal Trust for Nature Conservation, Nepal

2003 - 2005. Lecturer. Tribhuvan University, Institute of Forestry, Nepal

1999 - 2001. Research Assistant. Tribhuvan University, Institute of Forestry, Nepal

\section{Professional Association/Memberships}

Xi Sigma Phi, Honorary Forestry Society

Society of American Foresters

Nepal Foresters' Association 